Portland State University

PDXScholar

\title{
An Exploratory Study of Student Retention in Kindergarten and Grade One and the Associated Decision Making Processes as Perceived by Principals and Teachers
}

Doris Cameron-Minard

Portland State University

Follow this and additional works at: https://pdxscholar.library.pdx.edu/open_access_etds Let us know how access to this document benefits you.

\section{Recommended Citation}

Cameron-Minard, Doris, "An Exploratory Study of Student Retention in Kindergarten and Grade One and the Associated Decision Making Processes as Perceived by Principals and Teachers" (1993).

Dissertations and Theses. Paper 1137.

https://doi.org/10.15760/etd.1136

This Dissertation is brought to you for free and open access. It has been accepted for inclusion in Dissertations and Theses by an authorized administrator of PDXScholar. Please contact us if we can make this document more accessible: pdxscholar@pdx.edu. 
AN EXPLORATORY STUDY OF STUDENT RETENTION IN KINDERGARTEN AND GRADE ONE AND THE ASSOCIATED DECISION MAKING

PROCESSES AS PERCEIVED BY PRINCIPALS

AND TEACHERS

by

DORIS CAMERON-MINARD

A dissertation submitted in partjal fulfillment of the requirements for the degree of

\author{
DOCTOR OF EDUCATION \\ in \\ EDUCATIONAL LEADERSHIP: \\ ADMINISTRATION AND SUPERVISION
}

Portland State University

O1993 
TO THE OFFICE OF GRADUATE STUDIES:

The members of the committee approve the dissertation of Doris Cameron-Minard presented May 20, 1993.

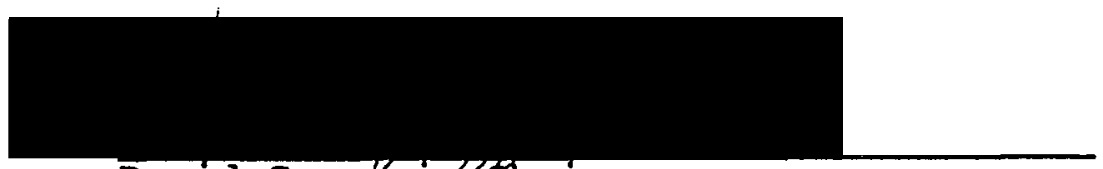
David Capuzzi, Ochair

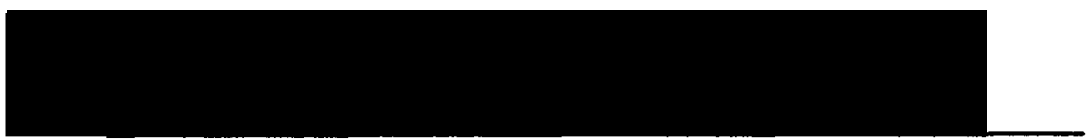

Thomas Chenoweth

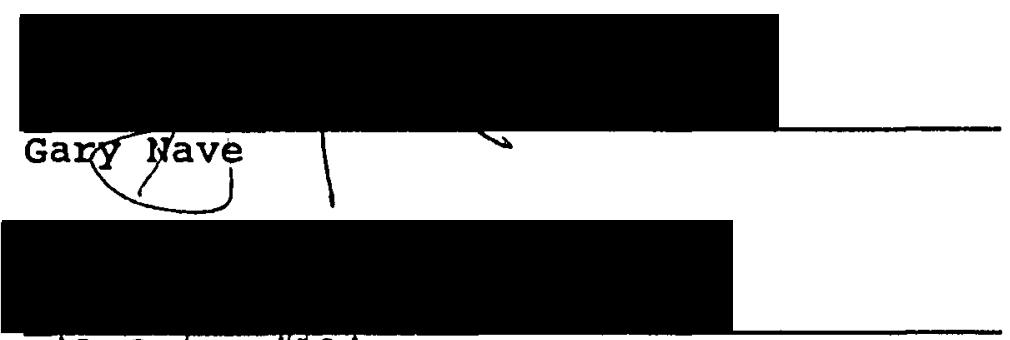

Dilafruz Williams

Martha M. Balshem

APPROVED :

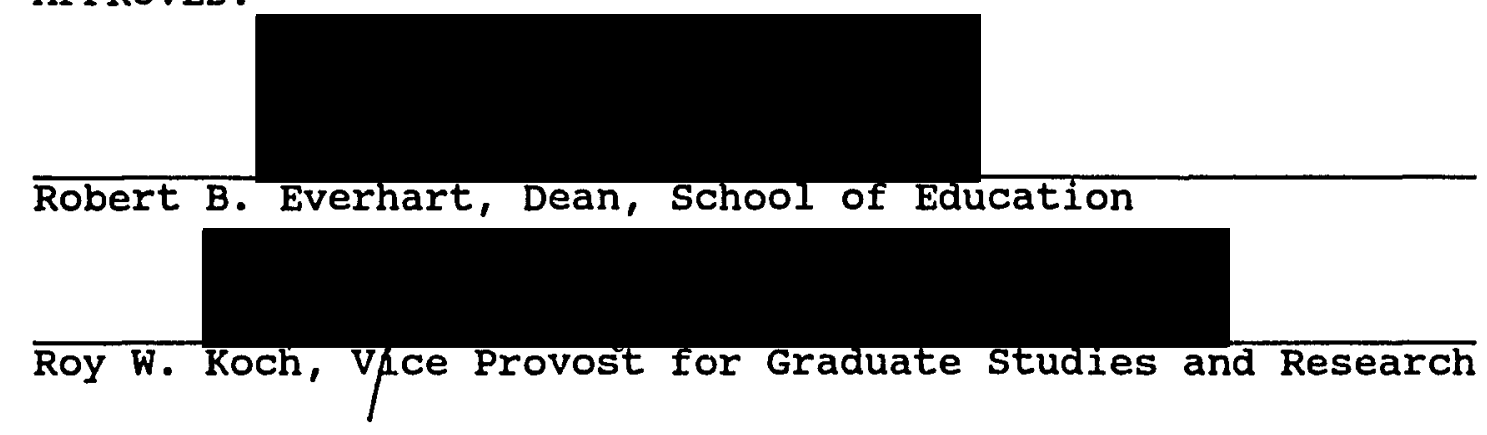


AN ABSTRACT OF THE DISSERTATION OF DOris Cameron-Minard for the Doctor of Education in Educational Leadership: Administration and Supervision presented May 20, 1993.

Title: An Exploratory study of student Retention in Kindergarten and Grade one and the Associated Decision Making Processes as Perceived by Principals and Teachers

APPROVED BY THE MEMBERS OF THE DISSERTATION COMMITTEE:

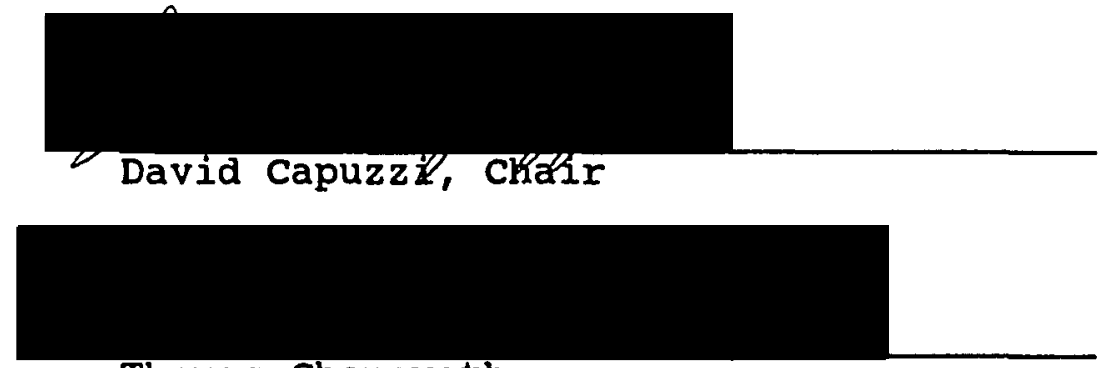
Thomas Chenoweth

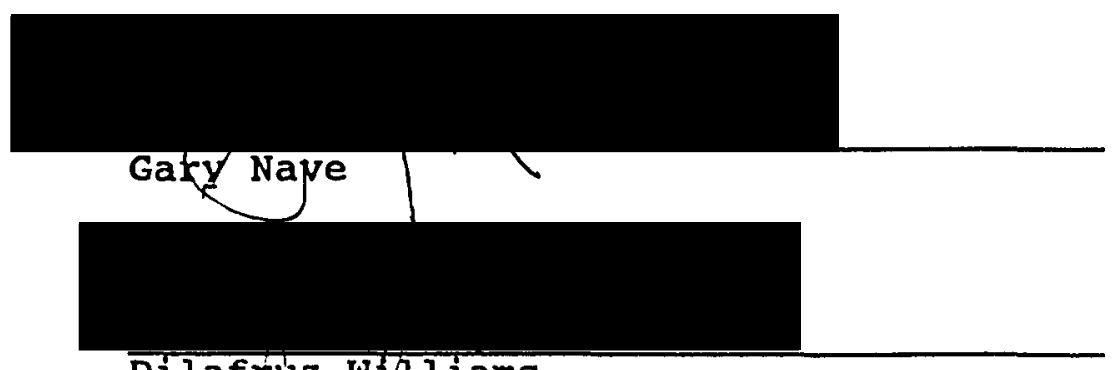
Dilafruz Wiliiams

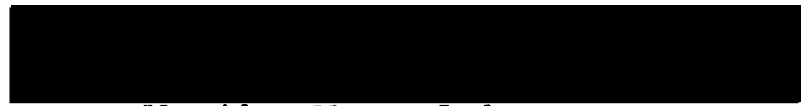

Martha M. Balshem

students who fail to achieve in school are frequently retained in grade to remediate their lack of satisfactory 
progress. In this study, elementary school principals, kindergarten, and first grade teachers were interviewed to explore their perceptions of the decision making processes used in recommending retention. The belief systems which underlie their reliance on retention as a remedial option were also examined.

Three research questions were addressed:

1. What is the relationship between the written retention policy of a selected school district and the actual decision making process used by its schools?

2. What are the influences by district socio-economic level which impact the decision making process used in student retention?

3. What are the perceptions across district socioeconomic level of teachers and principals regarding the use of retention as an intervention for students?

Some additional questions related to the three research questions were also explored in the study.

The primary method of data collection consisted of interviews with nine participants. In addition, principals, kindergarten, and first grade teachers from 12 schools, representing three socio-economic levels, were surveyed. Data were integrated to develop a more complete narrative of retention practice as perceived by these practitioners. The results of this study indicate several factors influence retention decision making and practice: 
1. expectations of other teachers

2. pressure of curriculum standards

3. the evailability of alternatives

4. the perceived needs of students

5. the belief systems of teachers

6. knowledge of retention research

Recommendations are presented for encouraging practice more aligned with current research and to assist district policy makers in developing alternatives for retention. The research suggests that future study be conducted to further explore teacher belief systems underlying retention practice. 


\section{DEDICATION}

This work is dedicated to my colleagues without whose cooperation and help this work would remain undone. May their dedication to doing what is in the best interests of children continue to be pursued. To my husband, for his unflagging support and encouragement; his gift of time and concern for the fulfillment of my goals provided incentive to my pursuit.

Lastly, I dedicate this work to my parents for instilling in me a fierce determination to achieve and to learn, and the persevering spirit needed to making dreams come true.

"A great pleasure in life is doing what people say you cannot do. Never, never, never give up." Winston Churchill 


\section{ACKNOWLEDGEMENTS}

I would like so express my gratitude toward the following people for their support, encouragement, and expert assistance: Dr. David Capuzzi, Program and Dissertation Advisor; Dissertation Committee Members: Dr.

Gary Nave, Dr. Thomas Chenoweth, Dr. Dilafruz Williams, and Dr. Martha Balshem; the principals and teachers who told me about their experiences and beliefs, and to Pati sluys, typist.

Special thanks also to my husband, Dr. Gene Minard, for his tireless encouragement and confidence in me, to Dr. Ron Russell, Assistant Superintendent of David Douglas School District, for his helpful advice and positive reinforcement of my goal, and to Dr. B. J. Nicoletti, for her support, help, and encouragement, my deepest gratitude. 
TABLE OF CONTENTS

PAGE

ACKNOWLEDGEMENTS. . . . . . . . . . . . . . . . iii

LIST OF TABLES. . . . . . . . . . . . . . . . . . ix

LIST OF FIGURES . . . . . . . . . . . . . . . . . . xi

CHAPTER

I STATEMENT OF THE PROBLEM. . . . . . . . . . 1

Introduction. . . . . . . . . . . 1

Statement of the Problem. . . . . . . 4

Purpose of the study. . . . . . . . . 9

Research Goals. . . . . . . . . 10

Primary Goal

Significance of the study . . . . . . 11

Summary . . . . . . . . . . . . 15

II REVIEW OF THE LITERATURE. . . . . . . . . . 17

Introduction. . . . . . . . . . . 17

Historical Background . . . . . . . . 19

Beginnings

The 1900s-1930s

The 1930s-1950s

The 1960s-1990s

The Purpose of Retention. . . . . . 26

Retention as an Intervention

Retention and Teachers'

Justification

Belief \#1: Retention and Higher

Achievement 
Belief it 2: Retention Maintains Higher standards

Belief 3 : Retention and the Integrity of the Diploma

Belief \#4: Retention and Homogeneous Classrooms

Belief \$5: Retention as Punishment for Failure to Achieve

Belief \#6: Retention as a Motivator

The Practice of Retention . . . . . . .

Retention Criteria

Characteristics of Retainees

Retention and Immaturity

Retention and Transition Rooms

The Effects of Retention. . . . . . . .

50

Retention and Academic

Achi.evement

Retention and Social Development

Retention and Equity

Retention and Later Effects

Retention Decision Making

Practices and Policies. . . . . .

Persistence of Retention Practice

Decision Making Models

Retention Policies

Implications for this study . . . . . . 75

Summary . . . . . . . . . . . . 76

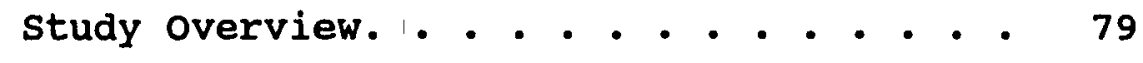

Research Questions. . . . . . . . 80

Sample. • • • • • . • • . . . 82

Instruments - • . . . . . . . . . 88 
Data Collection . . . . . . . . . 90

Pilot study

Primary study

Descriptions of Respondents

Research Framework. . . . . . . . 96

Data Analysis . . . . . . . . . 99

Analysis of the Interviews

Analysis of the surveys

Summary . . . . . . . . . . . . 101

IV PRESENTATION OF THE DATA. . . . . . . . . 103

Introduction . . . . . . . . . . 103

Descriptions of School District

Policies and Processes of

Retention Decision Making . . . . . 104

District one. . . . . . . . . . 105

District Description

Retention Policy

Guidelines for Practitioners

District Two. . . . . . . . . . 106

District Description

Retention Policy

Guidelines for Practitioners

District Three. . . . . . . . . . 107

District Description

Retention Policy

Guidelines for Practitioners

District Four . . . . . . . . . 108

District Description

Retention Policy

Guidelines for Practitioners

Perceptions of District Retention Policy

by Total Population . . . . . . . 109 
Perceptions of Individual School Retention Policies as Reported by the Total Sample. . . . . . . . . 112

Perceptions of Individual School Retention Policies as Reported by Status Groups. . . . . . . . . 113

Summary of District and Building Policies. . . . . . . . . . . . 115

Narratives of Job Group Respondents by District . . . . . . . . . . . 118

Narratives from the High Status Districts . . . . . . . . . . 119

Decision Making Process Influences on Retention

Narratives from the Middle status Districts . . . . . . . . . . 132

Decision Making Process Influences on Retention

Narratives from the Low status Districts . . . . . . . . . . . 143

Decision Making Process Influences on Retention

Retention as an Intervention. . . . . 154

Retention: Successes and Failures

Retention: Effect of Research

Retention: An Intervention Option

Summary of Results. . . . . . . . . 165

Question 1

Question 2

Question 3 
viii

Conclusions and Implications. . . . . 178

Question 1

Question 2

Question 3

Limitations of the study. . . . . . . 198

Recommendations . . . . . . . . . . 199

Toward a Reconsideration of Current Practice

summary . . . . . . . . . . 204

REFERENCES. . . . . . . . . . . . . . . . 206 APPENDICES

A DEFINITION OF TERMS . . . . . . . . . . . 227

B SURVEY LETTERS TO RESPONDENTS AND

FOLLOW-UP LETTER. • . . . . . . . . . . 230

C LIST OF CODE CATEGORIES . . . . . . . . . 233 


\section{LIST OF TABLES}

TABLE

PAGE

I Distribution of Survey Respondents by District Status . . . . . . . . . . . 94

II Distribution of Survey Respondents by Job Position. . . . . . . . . . . 95

III District Retention Policy by Total Population. . . . . . . . . . . . 109

IV Development of District Retention Policy. • . 110

V District Retention Policy by District Status Groups . . . . . . . . . . . 111

VI Development of District Retention Policy by District Status Groups . . . . . . . 112

VII Individual School Retention Policies by Status Groups . . . . . . . . . . . 114

VIII Retention Decision Responsibility by District Status Groups. . . . . . . . 115

IX Retention Beliefs of Principals and Teachers-Question 12 . . . . . . . . . 157

X Retention Beliefs of Principals and Teachers-Question 14 . . . . . . . . 158

XI Retention Beliefs of Principals and Teachers--Question 15 . . . . . . . . 158

XII Retention Beliefs of Principals and Teachers-Question 20. . . . . . . . 159

XIII Summary of District Retention Policies and Decision Making Processes (Research Question 1) . . . . . . . . . . . . . 181

XIV Summary of Influences on Decision Making Process (Research Question 2) . . . . . . . 192 
XV Summary of Responses of High Socio-Economic Groups (Research Question 3). . . . . . . 196

XVI Summary of Responses of Middle SocioEconomic Groups (Research Question 3) . . . 197

XVII Summary of Responses of Low Socio-Economic Groups (Research Question 3). . . . . . 197 


\section{LIS'T OF FIGURES}

FIGURE

PAGE

1. Overview of Participant Selection. . . . . . 87 
CHAPTER I

STATEMENT OF THE PROBLEM

INTRODUCTION

The importance of providing quality education for today's youth is being recognized as perhaps at no other time in the history of this country. Nationally, educational needs are now recognized as deserving top priority. There is considerable debate by legislators, citizens, and educators regarding what is wrong and what is right with the nation's schools. There is no dispute that children need a successful educational experience to become productive, responsible, and self-supporting citizens. With the national concern over lower achievement test scores and the need to compete with other countries world-wide, minimum standards and competencies are being examined as realistic expectations for school performance. How to remedy these problems and fund their solutions are concerns at every level of government.

Parents, members of the teaching profession, and the community expect children, while progressing through school, to successfully master competencies at every grade level. When children fail to do so, a dilemma occurs regarding whether to promote or retain the child. The impact of 
failing to be promoted has importance not only to children and their families but to the schools.

Retention, traditionally, has been used as a method of ensuring that children are ready for the requirements of the next grade. It is expected that retention will ease any frustration the child has experienced in attempting work too difficult at the current grade (Rose, Medway, Cantrell, \& Marus, 1983). With younger children in kindergarten and first grade, other alternatives have also been used. In the case of kindergarten entrants, an additional year at home or an extra year between kindergarten and first grade might be an option (Bossing \& Brien, 1979). Such an additional year may be called a transitional class or junior first grade. Its purpose is to give more time for the young child to achieve the competencies expected in the primary grades. Other approaches, such as ungraded primary classes or blended classrooms, are being attempted (see Appendix A). Such continuous progress models may provide for success at a more individual rate. Such alternatives allow for flexible learning and teaching arrangements to accommodate student needs.

Teachers express concerns that children should come to school "ready" to learn, with appropriate readiness skills already in place for beginning school experiences. Tris not only implies that parental involvement with the child in some form of enrichment activities has occurred, but that 
the child's basic needs for adequate nutrition, rest, and nurturing have been met. Increasingly, educators state the need for their assumption of at least a portion of these parental responsibilities if the child is to have optimum opportunities to learn and make acceptable progress in the classroom.

The educational reform movement with such reports as $\underline{A}$ Nation at Risk (National Commission on Excellence in Education [NCEE], 1983), has intensified the pressure on teachers and administrators regarding their accountability for pupil success (Bossing \& Brien, 1979; Ebel, 1980; Lehr, 1982). Further, current discussions of a national agenda for education which include both a nation-wide curriculum and testing, increase the pressure on public schools to produce high performing students (Elam, Rose, \& Gallup, 1991; Rothman, 1990b). The resulting emphasis on accountability and minimum standards has stimulated a renewed focus on retention as a solution for a failing child (McDill, Natriello, \& Pallas, 1985; Riley, 1986). Educators are faced with the dilemma of balancing the need for at least minimum competencies, against the cost of an additional year to taxpayers and the effects of retention policies on failing children. 
STATEMENT OF THE PROBLEM

There is disagreement among educators regarding the traditional practice of retaining students in light of a growing body of research which does not support the practice (Bocks, 1977; Jackson, 1975; Smith \& Shepard, 1987). The paradox of retaining (or failing) students is that it seems logical to teachers using subjective judgment. Their practical experience leads them to believe that an extra year to review and learn material will help ensure academic success (Byrnes \& Yamamoto, 1986). Research, however, points to the likelihood of only transitory academic gains and the potential for declines in self-concept (Holmes \& Matthews, 1984; Plummer \& Graziano, 1982; Rose et al., 1983). The result of this dilemma is a disparity between best practice and current practice.

The use of retention has varied with shifts in the philosophy of educational thinking. Although analyses of retention research have shown that the practice has heen overvalued and has not been successful with a majority of children, educators continue to act upon their mostly subjective beliefs in its effectiveness as a means of improving achievement (Byrnes, 1989; Grissom \& Shepard, 1989; Shepard \& Smith, 1989).

As an example, a study by Holmes and Matthews (1984) found students who had been retained and then evaluated, had made minimal galins, if any, compared with peers having 
similar achievement levels and who had been passed to the next grade. Although teachers indicate they feel retention is generally successful, and parents tend to support this practice, evidence exists that any academic gains made by retained students are quickly lost and they are soon back on a par with their promoted classmates (Byrnes \& Yamamoto, 1986; May \& Welch, 1984 ; Peterson, DeGracie, \& Ayabe, 1987). Additionally, the impact on the student's self-concept and confidence level needs to be considered as a negative aspect of retention (Cuddy, Frame, \& Devincentis, 1987; Goodlad, 1954; Norton, 1983).

Proponents of retention argue that for a child already frustrated with failing the current grade level work, it would be even more frustrating to be promoted to the next grade with its additional expectations. They contend that maturity, as well as the basic skills necessary to perform satisfactorily, is better gained if an additional year is spent repeating the same material.

Those advocating social promotion, or the practice of keeping the students with peers, assert that the deleterious effects of retention on self-concept and the doubtful gains in achievement negate any short-term benefits of retention (White \& Howard, 1973). They contend that the interests of children are best served if they are kept with their age peers and remediation for specific achievement deficits is provided. 
Cost factors are critical determinants in implementing any intervention program. The additional year of education, which results when retention is implemented, is an expensive remedy for the child, school districts, and taxpayers (Holmes, 1986). The National Education Association reported that an average of $\$ 4,890$ was spent on each public school pupil's education in the 1989-1990 school year ("Across the Nation," 1990). The cost to school districts runs into billions of dollars when students repeat an additional year (Frymier, 1989; Toch, 1984). Shepard and Smith (1990) estimate that 2.4 million students are retained each year resulting in an annual cost of nearly $\$ 10$ billion. If it is not beneficial in terms of improved achievement, retention needs to be re-evaluated in terms of its effectiveness, its financial cost, and its emotional impact on children (Finlayson, 1977; Goodlad \& Anderson, 1987; Holmes \& Matthews, 1984; House, 1989; Shepard \& Smith, 1985). A number of factors are influential in making decisions regarding promotion versus retention. Sandoval and Hughes (1981) found in their study of promoted and retained first graders that teacher beliefs in the efficacy of retention impacted on the success of the retention year. They state, "Another important predictor of academic progress was the confidence the initial first grade teacher had in the decision to retain the child" (p. 97). They caution, however, that the positive benefits resulting from 
the retention decisions were evaluated after one year whereas the full effects can only be determined after a longer period of time. According to Smith (1989), in an examination of teacher beliefs on the benefits of retention, "teachers almost universally endorse retention" (p. 147). In their comments on the Sandoval study, Smith and Shepard (1989) state:

Correlates of successful retention included relatively high achievement and high self-concept, perhaps implying that the most successful retainees are those who need the treatment the least. (p. 235)

School district policies regarding retention or promotion usually preclude students being retained for such inappropriate reasons as disruptive behavior (Caplan, 1973), gender (Chansky, 1964), or socio-economic status or race (Walker, 1973). The existence of a clear and well-defined policy is essential if expectations for its implementation are to be realized (Graham, 1982). Procedures for decision making in promotion/retention policies need to address the question of who is to be part of that process (Pennsylvania state Department of Education, 1985).

The process of maxing the retention/promotion decision typically begins with the classroom teacher initiating the formal decision making design plan. This design is probably not as systematic as the process usually used in determining a student's special education status. Such placements are preceded by rigorous testing and specific criteria before a 
decision is made. In contrast, subjective judgment and practical experience may establish a case for a student's retention. Such critical decisions as retention which affect a child's educational future, career options, and feelings of self-worth are worthy of a more systematic design and thoughtful consideration. As Germain and Merlo (1985) state, "Formal retention policies are important to prevent inconsistent, haphazard or discriminatory retention practices" (p. 176).

Promotion policies, formulated in response to the drive toward national excellence in our schools, need to be based on the needs, achievement potential, and the effects of such standards on the dropout population. Promotion standards also have the potential for challenge through the courts as equity issues are analyzed. Decisions made for an individual student's educational program should be derived from assessment of multiple criteria in order to lessen any disproportionate effect on minority students. Thompson (1980) found that retention decisions made solely by an individual teacher or the building principal are suspect for possible discrimination. Further, Cross (1984) recommends that "standardized, substantive criteria [based on] objective measures of student progress" (p. 14) be increasingly implemented by districts for teachers' use in retention recommendations. This would provide assurances 
for equitable treatment of all children facing non-promotion.

PURPOSE OF THE STUDY

Educational practice in the area of retention has not kept pace with education research (House, 1989). Educators who are knowledgeable regarding retention/promotion research literature and who act upon that knowledge are able to make decisions based upon best practice guidelines. In addition, it appears important to determine if there is a difference between the actual versus stated practice of school policy used by educators making retention decisions.

secondly, by examining the beliefs surrounding the decision making process, a clearer understanding of the significant factors driving the process may occur. This broader knowledge base may result in a subsequent reduction of retention. Increasing the number of staff who participate in the decision making and providing additional educational alternatives to classroom teachers, may result in realigning retention decisions with the majority of research findings. Actual practice would increasingly become best practice. Building principals, by understanding the influence of belief systems on the decision making process, could influence policy shifts toward a more research based design. Best practice could then become best policy. 
To summarize, this study explores and describes the real experiences, beliefs, and practices of educators and uses that information to reveal the actual processes used by them. The connections between interactions on practices and beliefs will allow other factors, in particular rate patterns, to be considered in any future quantitative research. A discussion of the inter-connectedness of these various factors may provide a clearer view of their influences on retention rates. Reporting this influence would assist educational policy makers in the greater alignment of policy with practice. The influence of policy, practice, decision process, and belief system were explored for any effect on educators. Additionally, analyses address components of who makes the final decision for recommending retention, who establishes the decision making process which is used, and how demographic characteristics impact on retention decision making.

\section{RESEARCH GOALS}

\section{Primary Goal}

The primary orientation of this study is to explore and describe the processes used in retention decision making in kindergarten and grade one as reported by practitioners in high, middle, and low achieving school groups.

The research goal is more specifically addressed by focusing on the following areas described more fully in 
Chapter III: (a) district retention policies and the processes used by schools in their implementation, (b) influences upon the decision making process used by schools, and (c) the perceptions of teachers and principals in the use of retention as a viable option for students failing to achieve.

\section{SIGNIFICANCE OF THE STUDY}

The tendency of educators, both teachers and administrators, to be unfamiliar with current research on student retention results in a continuation of a potentially adverse practice affecting hundreds of thousands of students each year. According to Bocks (1977), over one million students were retained in 1971 . Since retention data are not gathered on a national scale, rates of non-promotion are generally derived from the numbers of students who are not at the modal age for their grade placement. Rose et al. (1983), reporting on a 1980 South Carolina national survey of retention rates, note the 13 states reporting had a retention of $4 q$ to $8 \%$ for grade levels 1-12. The authors indicate that the percentages of students who were retained in first grade were generally higher than for other grades. This reflects the common belief in using retention as a remediation early in a child's educational career.

Summing rates across various grade levels would reveal an even higher and more accurate rate as retained students 
move through school. Shepard and Smith (1990) estimate an annual rate of retention between $5 \%$ to $7 \%$. If $6 \%$ of children are annually retained the cumulative rate would be more than $50 \%$.

Escalating curriculum expectations in elementary schools and the more stringent demands placed upon kindergarten programs in particular, compound the problem of student failure. The emphasis, both nationally and locally, of stricter promotion standards overlooks the fundamental needs of individual students (Johnson, 1984; Riley, 1986; Shepard \& Smith, 1988a; Taylor, 1978). That is, an appropriate educational program needs to be developed which will take into account the differing abilities and backgrounds of all students in our schools (Gredler, 1978; Shepard \& Smith, 1988a).

Continuing to follow a policy only because it temporarily solves a problem of what to do with students having difficulty with subject matter is untenable. policies of the past are now questionable in light of the most current research on this subject (Byrnes \& Yamamoto, 1986; Holmes \& Matthews, 1984; Plummer \& Graziano, 1982; Rose et al., 1983, Shepard \& Smith, 1985) . Understanding the effect of teachers' belief systems on retention practices enables educational leaders and policy makers to design remedies which might bring practice and research into closer alignment (House, 1989; Smith \& Shepard, 1988). 
A more collaborative, systematic, and judicious decision making design could be developed to facilitate a restructuring of the decision making process. Teachers need assistance in developing alternatives to retention. By including into the process a building team whose responsibilities also included planning alternatives and developing remediation/acceleration strategies, the likelihood of student success might be improved. The input of various school specialists into the decision making process would also help relieve the anxiety and excessive sense of responsibility which many classroom teachers experience (Riffel \& Switzer, 1986; Rose et al., 1983). Staff development specialists should explore ways to help teachers and administrators to become more familiar with the current research on retention and to question the traditional belief in its efficacy as a remediation technique. Special education processes which are used to cevelop individual education plans need to be examined to help develop similar individual achievement plans for potential retention candidates.

The cost in terms of lost self-esteem, the postponement of more effective remediation strategies, the loss of a year in a student's educational career, and the dollar cost to school districts, is staggering (Frymier, 1989; Toch, 1984; Walker, 1984). School districts already faced with dollar shortfalls, need to consider the impact of 
the number of students being retained each year. These same dollars could be used to develop alternative, less punitive, and far less costly programs for low-achieving students. Issues of equity also need to be carefully examined for their impact on the numbers of minority students currently falling into the retention pool (Baenen, 1988; Murphy, 1986; Ralph, 1989). School districts have been requested by courts to justify their retention/promotion policies when a large proportion of retainees have been minorities (Stroup \& zirkel, 1983). Cross (1984) found that:

In the absence of standardized, substantive criteria for recommending students for retention, the procedural guidelines were weak assurances of similar treatment of similar cases. (p. 14)

Both a carefully designed retention policy as well as specified decision making procedures appear to be minimum essentials for ensuring equity among pupils.

Educators frequently play less of a role in establishing policy than do public officials or members of the lay public. State legislatures, school boards, and other citizens who may be unfamiliar with educational research are often the initiators of policy. The resulting educational practices may serve as constraints on the better judgment of educators (Doyle, 1989). Educators must assume the role of communicators in informing the lay public regarding current educational research and school issues. 
Persuading teachers to be cautious in their use of retention as a strategy and to consider and develop other alternatives in remediating student achievement needs to be pursued. We are doing no service to students by continuing to use such a questionable intervention as retention without carefully reviewing the research. Teachers, especially those in the high retention rate primary grades, need to be familiar with and incorporate research findings into their decision making. Such a knowledge base assists in the development of educational policies. The programs which result will help educators to prescribe appropriate recommendations to ensure student success. As Doyle (1989) states "We urgently need to explore the reasons why educational practice often resists the findings of educational research" (p. 217). Until that time, the deliberate use of a more collaborative decision making model may help to reduce retention rates and the penalties of failure.

SUMMARY

In summary, practitioners may need to re-examine the use of retention as a practice. It has been widely accepted as an appropriate solution for many slow achieving students. since it has such significance in children's lives and appears to impact on their later school success, educators will need to explore alternative options. Viewing learning 
as a continuous process may help to promote student success rather than student failure in mastering and accommodating to the structure of programs we call school. 
CHAPTER II

REVIEW OF THE LITERATURE

INTRODUCTION

In reviewing the literature, this chapter focuses upon the historical background of retention; the purpose and practice of retention as an intervention; current decision making practice and policy trends; research on the effects of retention including significant later effects; and implications for this study.

A resurgence into examining the efficacy of non-promotion or retention was spurred by the publication of A Nation at Risk (NCEE, 1983). The renewed focus on higher standaras, minimum competencies, and escalated curriculum has increased the expectations of both educators and the general public for children's achievement. Consequently, the national preoccupation with excellence, promotional standards, and the literacy rate has created a new interest in the effectiveness of non-promotion in increasing student achievement.

Nationally, school districts continue to practice retention as a means of giving students additional time to achieve the requirements of the current grade (Berger, 1990; Holmes, 1989; Shepard \& Smith, 1990). As House (1989) 
observes, ". . the practice is almost universal in the United States, with estimates that from one-quarter to one-third of American students are retained at one time or another" (p. 209). Some educators, however, are beginning to look at current research and to question the value of non-promotion policies (Cohen, 1990a; Olson, 1990; Staff, 1990).

The problem of what to do with students who have not mastered grade level work has plagued educators for nearly a century. The most common solution to date, has been to have children repeat the grade in the hope that their academic achievement will improve. Justification for retaining students includes such reasons as immaturity, "time to grow," poor social development, or a particular problem with the basic skills of reading, writing, or math. The rationale for such decisions is generally based upon teachers' practical experience and their perceptions of student improvement during the retained year.

While the preponderance of research contradicts teachers' reliance on retention as a solution to student failure, teachers' belief systems and their unfamiliarity with retention research perpetuate this practice (Holmes, 1989; House, 1989; Shepard \& Smith, 1989, 1990). Not to be overlooked as contributing factors are the possible lack of programs which provide for accelerating learning for high risk students, multi-age grouping, tutorial assistance, or 
other strategies teachers might prescribe as options. The lack ố such alternatives makes it difficuit for educators to successfully provide for diverse student populations and works against goals of inclusiveness and equity.

\section{HISTORICAL BACKGROUND}

\section{Beginnings}

The practice of retention began soon after the introduction of graded schools in the 19th century (Ayres, 1909; Ebel, 1980; Labaree, 1984; Shepard \& Smith, 1989). Before the common school system was established, public education was self-paced and individualized. As the numbers of students increased, it was necessary to organize schools into more efficient models. Classroom instruction became geared to groups of students rather than individuals. By 1872, educators began to express criticism of the graded schools (Angus, Mirel, \& Vinovskis, 1988). Promotion emerged as an educational issue when students failed to perform to group standards (Labaree, 1984).

Schools were expected to teach what Labaree (1984) terms "meritocratic values," that is, rewards are to be achieved by one's efforts and not to be simply expected. He states:

This conflict between organizational efficiency and meritocratic values, between the goal of group learning and the goal of individual selection, has been a source of controversy from the time of the first graded schools to the present day. (p. 69) 
This view of earned rewards led to merit promotion emerging as ṫne prễerreà meṫnoâ ỗ maintaining organizational efficiency. The organization of schools by grades led to the need to establish a uniform course of study resulting in examinations over the material learned. The work, or course of study, was organized into yearly segments or grades. The passing of examinations allowed for a student's progression through the grades (Angus et al., 1988) .

Labaree (1984) describes the structure of the school system as pyramidal with schools decreasing in number from the base to the top. Student performance on written examinations determined their admission to high school. As early educators reported, "This classification [of students] is based upon the degree of attainment in studies, regardless of age or condition in life" (Detroit Board of Education cited in Abidin, Golladay, \& Howerton, 1971, p. 7). The creation of this organizational structure also resulted in concerns about retaining students. It became obvious that increasingly large numbers of students were failing to meet the set requirements. students not achieving the criteria established for passing were required to repeat a grade (Goodlad \& Anderson, 1987).

\section{The 1900s-1930s}

By the 1900s retention rates had reached more than $50 \%$ (Abidin et al., 1971). Farley (1936) reported in a review 
of a 1933 study, that the small gains made by the retained students "hardly justify the expense and discouragement of retardation" (p. 38).

As early as 1909 Ayers pointed out in Laggards in our Schools, the financial cost of failure was only one of the problems created by students repeating a grade.

The child who spends much more than the normal amount of time in doing the work in the lower grades finds himself at the age of fourteen, say in the fifth grade instead of the eighth, and, seeing that the prospect of promotion is still remote, drops out of school. (p. 90)

and again:

The term "retarded" is here applied, as previously
explained, to the child who is below the proper
grade for his age. Our schools are crowded with
such children. They often constitute as much as
one-third of the entire membership. (p. 90)

Ayers (1909) questioned the philosophy of the common school system which had resulted in such large numbers of failing students. The high standards held by school systems largely denied average students the opportunity to progress to secondary education. This barrier, which impeded individuals from the opportunities provided those with higher educational levels, was enforced by a philosophy based upon meritocratic ideals. It might be argued that such a philosophy served as a natural process in eliminating unworthy students. Such a view appears unjustified since neither individual student needs or learning styles were studied nor was the instructional effectiveness of teachers questioned. The cost of extending the education of such 
students due to their failure to be promoted was significant. The focus on strict standards for promotion was maintained until the 1930s when doubt increased as to the effectiveness of retention as a policy.

\section{The $1930 \mathrm{~s}-1950 \mathrm{~s}$}

Germain and Merlo (1985) noted that by 1930, educators were beginning to express concern for the effects of retention on students. Emerging research revealed that the socialfemotional well-being of students were important considerations in retention/promotion decisions. The negative impact of recention on children's social and emotional development resulted in a policy shift to a practice of social promotion. For the next 30 years, retention rates fell as children were kept with their peers and provided with remedial help (Rose et al., 1983). This new focus on the child accompanied a broader educational perspective than the earlier subject matter emphasis. As Ebel (1980) notes:

The objectives of this new child centered education turned out to be considerably more variable and diffuse, less clearly definable, less amenable to objective assessment, than the older subject matter objectives had been. It became more difficult to distinguish failure from success in learning, more difficult to make and defend decisions to retain a pupil in grade. (p. 386)

\section{The 1960s-1990s}

By the early 1960s, declining test scores alerted educators and the public to the need for changes in school 
operations. Medway and Rose (1986) reported that between 1963 and 1981, verbal scores of the SAT had dropped by nearly $11 \%$ and mathematics scores by $7 \%$. The scientific advances of other countries also helped spur policy makers to analyze the needs of the nation's schools. During the next three decades, social promotion elicited criticism as the reform movement focused the public's attention on the need for both minimum competencies and higher standards (NCEE, 1983). In a national survey of public opinion, Gallup (1986) found that stricter requirements for grade promotion and for high school graduation were highly supported by the majority of those polled. subsequently, by 1989, the public at large favored a nation-wide curriculum, assessment, and standards for achievement in public schools (Elam \& Gallup, 1989). When asked whether promotion with remediation or retention with remediation was the better alternative for students failing to meet standards of achievement, respondents to the 1990 poll favored retention with remediation (Elam, Rose, \& Gallup, 1991).

Labaree (1984, p. 74) identified four types of reforms which developed from the national focus on higher achievement standards:

1. Back to basics--redefining basic skills into a more narrow, focused view. 
2. Minimum competency testing--the use of standardized achievement tests to determine student achievement of established minimum competencies.

3. Retention--for student who fail to meet the established standards.

4. Remediation--for those who have been retained.

These new standards for pupil performance have surfaced as educators and parents look at the excellence movement for a new direction in regard to school improvement. The agreement with and implementation of such policies by educators would almost certainly escalate the numbers of students unable to meet national requirements. Multiple retentions could result from states adopting stringent promotion policies. This would have the most impact on students in urban settings who failed to meet the minimum standards (Hamilton, 1986).

standardized tests by definition are assessments geared to determine the student's achievement in academic areas and have been normed using a large sample population. They are usually administered at targeted grade levels or at transitions from one level of schooling to the next. Minimum competency tests measure the degree of attainment, at the least acceptable level, in the basic skill areas of reading, writing, and math.

An example of higher standards affecting retention rates is seen in a policy of the New York City schools. A 
mandatory retention policy has been in effect for students in grades four and seven who score low on standardized tests. Joan Mccarty First (cited in Olson, 1990)/, president of the National Coalition of Advocates for students, says:

In a lot of places, where standards have been raised during the last decade, the remedial strategy of choice has been retention. And that means it's made it much more difficult for kids who were having trouble in the first place. (p. 1)

This policy's effect on dropout rates, prompted its removal (Rothman, 1990c). In its place, a summer school alternative was offered to retention candidates (Berger, 1990). According to Bocks (1977), more than one million children were retained in 1971 in the United States. By 1986, Bucko (1986) estimated that retention rates varied between 12 to $15 \%$ across the nation. While no nationwide statistics are available, Shepard and Smith (1990) estimate the number of retentions at 2.4 million students yearly, reflecting an estimated annual percentage rate between $5 \%$ and 7\%. Shepard and Smith contend that non-promotion policies have caused 30 to $50 \%$ of students to have been retained at least once by the time they finish school either by graduating or dropping out. A 1988 survey by the federal government, reported as A Profile of the American Eighth Grader, indicates that nationally, $18 \%$ of eighth graders said they had been retained, while 208 of parents also report their child had repeated a grade (Hafner, Ingels, Schneider, \& Stevenson, 1990). 
The cost of retention is substantial: $\$ 4,500$ per year for each student on the average (Frymier, 1989). Transition room placements and multiple retentions are additional costs. Nationally, the total expenditure is considerable for a practice that has yet to be proven for its effectiveness. The financial impact of retention needs to be questioned in view of the uncertainty of its benefits (Haddad, 1979).

The conflict between increasing accountability and the increasing evidence of retention research is likely to remain unresolved until appropriate alternative practices are in place. The merits of minimum standards versus the benefits of remaining with age-mates will likely be debated for some time (Shepard \& Smith, 1990). Meanwhile, children and parents face the prospect of coping with a questionable practice and one which may be inequitably applied.

\section{THE PURPOSE OF RETENTION}

\section{Retention as an Intervention}

Students entering the education system encounter for the first time the academic expectations of adults and their first formal experiences with success or failure. At age five or six, when this process begins, they may be judged by (a) the successes of their peers, (b) a perhaps undefined set of "readiness expectations," or (c) some kind of standardized criteria for their grade level. 
Kindergarten and grade one have been targeted as optimal grades to "catch up" a child who exhibits indicators of immaturity. The "do it early" proponents argue that retention at such an early age will have no significant impact on self-concept. Until recently, the use of retention as an intervention for younger children in kindergarten and grade one, has had the support of educators and some researchers (Chase, 1968; IIg, Ames, Haines \& Gillespie, 1978; Sandoval, 1982; Scott \& Ames, 1969). Current studies are casting doubt on its use as a method of improving achievement or developing maturity (Holmes, 1986; Holmes \& Matthews, 1984; Shephard \& Smith, 1990).

Teachers often offer the argument that a child is too young or "immature" for his or her age to profit from an academic program. They maintain that an additional year to grow or mature would give the child the necessary time to be ready to settle down, stay on task, retain material presented, and master more of the basic skills. To be "ready for the next grade" is a statement often heard to describe a child's ability or lack of it, while not actually defining the specific skills a child lacks. The purpose of retention then is to provide an additional year at the same grade level for a child's achievement to improve or for social maturation to take place.

Advocates of waiting for a child to develop the skills, abilities and readiness for school tasks cite the 
work of Gesell et al. (1940). Observations of children's behaviors done by Gesell et al. and Gesell \& Ilg (1946) were developed into screening tests used to determine the extent of a child's maturation or behavior age. From these, school readiness measures were developed by Ilg et al. (1978) to assist educators in determining a child's readiness for formal academic programs. Developmental placements occur when children are assessed and their current grade placement is adjusted to correspond to their determined behavior age. Ilg et al. state:

We continue to be of the opinion that one of the most easily spotted, most easily remedied, and most serious reasons for school failure in the primary grades is overplacement; and that such overplacement could to a large extent be done away with by a good developmental placement program. (p. 18)

Developmental screening is advocated by educators who ascribe to the maturational theory that only time, and not teacher intervention, can develop the behaviors, skills or abilities that students need to be successful. In contrast to the view that teachers are unable to impact the learning of immature children or the view of developmental advocates that immaturity will be corrected by time, is that proposed by John Dewey as early as 1916.

In Democracy and Education, Dewey (1916) analyzed the meaning of immaturity and the resulting implications for educators. Immaturity, as defined by Dewey, is a positive condition, a necessary and desirable component for growth. 


\begin{abstract}
- . we are compelled to give up thinking of it [immaturity] as denoting lack of desired traits. Abandoning this notion, we are also forced to surrender our habit of thinking of instruction as a method of supplying this lack by pouring knowledge into a mental and moral hole which awaits filling. - . Hence education means the enterprise of supplying the conditions which insure growth, or adequacy of life, irrespective of age. (p. 61)
\end{abstract}

This differs from the view held by many educators that immaturity is a barrier to further growth and learning, or that time and the resulting maturity will create a readiness for learning. Dewey's definition implies a freedom to pursue learning and the growth and development of children's abilities to react and respond to their environment. It reinforces the belief that learning or growth is continuous and not to be delayed by waiting for growth to occur. Shepard and Smith (1985), in a study of teacher beliefs' about children's development, describe belief systems emerging from extensive interviews with teachers: (a) nativists, those who believe children's readiness develops physiologically over time; (b) remediationists, those who believe that children of school age are ready and able to be taught and any difficulties can be remediated with instruction; (c) diagnostic/prescriptive teachers, those who believe that children of school age who have learning difficulties can be diagnosed and the deficit addressed; and (d) interactionists, those teachers who believe structuring the environment to match the maturational level of the child will stimulate learning 
(Smith, 1989). Smith concludes that teachers' beliefs about development

- . are explicable, internally consistent, and can be seen to reflect extant propositional theories in psychology. Furthermore, these beliefs predict (albeit imperfectly) teachers' retention practices. (p. 147)

Educators in the early grades often assert that a child's size, birth date, visual motor skills, and readiness tests are good predictors of the need to repeat a year's work. Sandoval and Hughes (1981) found that these characteristics were not adequate to predict a successful outcome. One of the objectives of their study was to investigate seven attributes of non-promoted students: (a) intellectual functioning, (b) cognitive development, (c) level of achievement, (d) perceptual/motor ability, (e) self-concept, (f) physical development, and (g) interpersonal relations. A number of measures were given to retained students to measure their ability in the skill areas of reading, mathematics, perceptual motor functioning, and affective development. students were tested twice, in the spring of 1979 and 1980. Predictors of success during the retained year numbered 43 and were regrouped into sets with seven multiple regression analyses done on each outcome. An analysis of these variables revealed that "Almost all of the measures of immaturity were not related to gains during the repeated year" (p. 74). Sandoval and Hughes state: 
- . it appears that achievement, verbal

intelligence, and initial social skills are related to and predict social skills outcomes; reading skill and being retained for social or affective reasons is related most to PBRS [Pupil Behavior Rating Scale] total score as an outcome; and reading, verbal IQ, social skills, and parent attitude are related to achievement status as an outcome. ( $p$. 143)

Sandoval and Hughes (1981) concluded that those children who did do well the second year, had not been exposed to learning experiences during the failed first year, either because of absenteeism or because the mobility of their families was excessive. Low ability had not been a significant factor resulting in their retention. Instead, Sandoval and Hughes noted that the $38 \%$ (29 out of 76 students) who had successfully repeated the first grade were students who, during their prior year of first grade, had already acquired some reading skills, had a good self-concept, and sufficient social skills. Further, they caution that their results were measured after only one year. A longer term of study would reveal if these results could be sustained.

Smith and Shepard (1989), commenting on Sandoval and Hughes' (1981) work, noted that those students who had made the most gains were also those who had needed retention the least. That is, in examining the profiles of those children judged to have completed the retained year with satisfactory academic gains, it was found that the characteristics of those students were similar to students who had had some 
success in their first attempt at first grade. More significantly, they found that even the most successful students from the Sandoval and Hughes study did not have any greater achievement gains than the promoted control group (Shepard \& Smith, 1989).

\section{Retention and Teachers'} Justification

A number of arguments are offered to support retention decisions. Teachers of higher grades expect a student to have mastered a certain degree of basic material. Educators fear standards or grade level expectations may be watered down if students are promoted who have not mastered the content of the previous grade. The child who is unable to do grade level work at his or her present grade may encounter frustration and failure at the next level. Teachers maintain that it is difficult to teach a class where students have a variety of instructional levels. It is not equitable, they reason, for children who have met grade level expectations to be promoted with those who have not done so. Children who have failed to achieve will not profit from the next grade levels' expectations (Goodlad \& Anderson, 1987).

Although the preponderance of current research appears to indicate detrimental effects are associated with retention, educators continue to support and practice nonpromotion. They maintain that retention serves to motivate, 
to create a more homogenous classroom, to preserve the credibility of the diploma, and eases the frustration experienced by students.

Doyle (1989) investigated teacher persistence in defending and using retention. He identified six statements reflecting teacher beliefs. These six statements concerned the use of retention (a) to promote higher achievement, (b) to maintain high standards, (c) to maintain the integrity of the elementary diploma, (d) to create a more homogeneous classroom with respect to ability, (e) to reward accomplishment, and (f) to motivate. Following is an analysis of the six teacher beliefs describing typical teacher responses to questions regarding clarification of their beliefs.

Belief \#1: Retention and Higher Achievement

In a meta-analysis of 63 studies, Holmes (1986) analyzed the effect of retention on academic achievement and personal adjustment. He found that retention in the intermediate grades produced stronger negative effects on achievement than in primary retentions. Students repeating fourth grade were, on the average, .37 standard deviations lower than their promoted counterparts. In surveying primary retention studies, Holmes found the overall effect, though not as strong, still negative rather than beneficial. Using eight studies on achievement in kindergarten and 
twelve studies on achievement in first grade, the mean effect size was -.28 for both. Holmes (cited in Shepard \& Smith, 1989) concludes, "On average, retained children are worse off than their promoted counterparts on both personal adjustment and academic outcomes" (p. 27).

Teachers assume that a second year will automatically produce greater mastery of academics which will then continue for the child's school career. The larger dilemma is the totality of the child's failure to meet the expectations of that grade's curriculum or teacher. Prescribing a simplistic solution such as the repetition of curriculum implies that review is all that is needed to improve achievement. Carstens (1985) asserts that retention, as well as social promotion, fails to meet the needs slower progressing children present: varying learning styles, slower rates in retaining material, and the need for a variety of instructional methods. The persistence of retention practice in view of the research which casts doubt on its benefits will be explored further in the chapter.

Belief \#2: Retention Maintains Higher Standards

stricter standards for promotion, coupled with evidence of grade level mastery, has been thought to be one way of improving test scores (Rose et al., 1983). It also demonstrates that schools and teachers are striving for accountability (Smith \& Shepard, 1989). Children who fail 
competency tests and are retained may prompt teachers to gear their teaching to test-taking skills. Smith and Shepard maintain that in retention decisions, ". . teachers' judgments substitute for test scores in the actual promotion decision, thus making the test an expensive and redundant public relations device" (p. 224). Educators argue that promoting lower achieving students to the next grade would result in their lower test scores reducing the level of that grade's performance. By recaining such students, their lower scores impact less on the lower grade. Maintaining high standards and strict grade level requirements in order to produce higher grade level test scores is not accomplished by simply retaining lower achieving students. The development of alternative strategies and increasing the availability of options to deal with students at risk of academic failure are more likely to accomplish the improved achievement both educators and the public desire (Shepard \& Smith, 1989; Slavin, Karweit, \& Madden, 1989).

Holmes (1983) analyzed eight studies measuring reading, language arts and arithmetic. He concluded:

Even though the nonpromoted pupils were matched with promoted counterparts on the basis of achievement test scores at the time of retention, the retained pupils from that time on scored lower on achievement tests in reading, language arts, and arithmetic. (p. 4) 
If retaining students leads to lower accomplishment of academics, attempting to produce higher test scores by means of retention fails to meet that expectation.

Belief \#3: Retention and the

Integrity of the Diploma

Because of changing expectations in American education, it is now generally expected that children will complete a high school education. Eariler in the century, the eighth grade was a milestone in a child's educational career. Doyle (1989) maintains that an elementary diploma should now be seen simply as a marker, a shifting of the educational arena from the elementary school to the high school and should not signify that a certain level of learning has been attained.

Ayres (1909), in discussing the function of school, expressed his belief regarding the purpose of the elementary school.

What is the function of our common schools? If it is to sort out the best of the pupils and prepare them for further education in higher schools, then the most rigorous system, with the severest course of study and the lowest percentage of promotions and the highest percentage of retardation is the best system. But if the function of the common school is, as the author believes, to furnish an elementary education to the maximum number of children, then other things being equal that school is best which regularly promotes and finally graduates the largest percentage of its pupils. (p. 199)

The function of schools since, Ayres (1909) discussed the retardation problem, has shifted to include accountability as a component (Engel, 1991; Meisels, 1989b; 
Shepard \& Smith, 1989). The concerns for minimum standards of achievement and the development of national educational goals are seen as necessary to ensure that high school graduates will be available to a work force competing internationally (Cavazos, 1989 ; NCEE, 1983; Walker, 1989). The assumption that schools are responsible for educating all children necessitates the development of programs able to assist all students achieve to their fullest potential (Fradd \& Weismantel, 1989). Stainback \& Stainback (1990) stress the inclusion of all students within regular school settings. Instructional programs designed for each child's educational needs are essential components if such inclusiveness is to be achieved.

Belief \#4: Retention and Homogeneous Classrooms

Educators frequently insist that retention decreases the span of abilities found in classrooms and enables a teacher to address the needs of students more effectively and efficiently. Teachers may feel pressure from their colleagues to decrease the anticipated range of abilities by retaining students with lower achievement. However, students having similar achievement levels may be retained by one teacher and not retained by another. In addition, students entering from other schools or school districts may have been exposed to differing standards. Retention does 
not guarantee that variations in ability levels will decrease in a classroom.

The standardization of the revised standford-Binet intelligence test allowed researchers to examine in greater depth the intellectual ability of children. Data indicated a range of up to five years of ability could be expected and considered normal at any age, even when the lowest $5 \%$ and the upper $7 \%$ of the sample were eliminated from consideration (Terman \& Merrill, 1937). Given that such a range of ability exists even in a so called "normal" class, teachers' concern that promoting lower achieving students creates a less homogeneous classroom does not appear to be supported by these findings. As Smith and Shepard (1988) state in referring to kindergarten students, "There are multiple standards and multiple ways of achieving them; children come into kindergarten variable and they leave variable; variability does not mean failure" (p. 316).

Belief \#5: Retention as

Punishment for Failure to

Achieve

The belief in merit promotion, that the rewards of one's efforts should be earned, stems from the meritocratic belief system described earlier which was held as the educational system developed. The Puritan work ethic promoted by early immigrants has been instilled into the fabric of education as well. The system of grading is an example of rewarding accomplishment as well as effort. To 
promote students who have not made acceptable progress in achieving grade level expectations is seen as unfair by many educators. Automatic promotion for some pupils while others by their efforts have mastered the levels of achievement, and thus earned promotion, is difficult for some teachers to accept. Mastery of subject matter as shown by tests, is proof a child "deserves" to be promoted and has "earned" this right. The need for educational efficiency continues the organizational graded structure with its teaching toward group rather than individual needs. As Smith and Shepard (1989) state,

To be genuinely meritocratic, however, would require a return to an organization based on individual, rather then group, instruction, too costly and radical a change for the schools to accomplish. (p. 222)

Belief \#6: Retention as a

Motivator

Using retention as a threat to motivate students has not been shown to be an effective practice. Discouragement with the inability to achieve coupled with the fear of failure are detrimental to children's self-concept and their belief in their potential (Bossing \& Brien, 1979; Goodlad, 1954; Shepard \& Smith, 1990). Retention's effect on discipline problems, on the frustration felt by parents, and its impact on future at-risk indicators need to be considered. Holding high standards for student success needs to be tempered with the recognition of their ability 
to be met. Successful attainment of goals inspires further achievement. Unrealistic standards only increase student frustration and failure. "Repeated failure and retardation defeat their purpose. They do not stimulate effort but on the contrary discourage it" (Farley, 1936, p. 39).

Doyle (1989), in the study referred to previously, surveyed teachers, community leaders, and education majors regarding their adherence to the preceding teacher belief statements. After making a presentation to these groups regarding retention research, he repeated the survey. Post-testing revealed that attitudes of the lay group, who had been the group most in favor of retention, were now more closely aligned with teachers who had also shifted their views toward opposing retention. Education majors, as a group, had made the greatest shift toward opposition to retention.

In his analysis of each belief statement, Doyle (1989) reports that the opinions most resistant to change were those dealing with diploma integrity and using promotion as a reward. Doyle also points to a contradiction elicited from the survey. He found that significant numbers of respondents agreed that retention was not likely to improve academic achievement. When asked if relaxed standards contributed to lower achievement, 268 of the community leaders, $30 \%$ of the teachers, and $41 \%$ of the education majors disagreed. Conversely, 458 of the community leaders, 
$39 \%$ of the teachers, and $72 \%$ of the education majors asserted the belief that social promotion was a factor in low achievement. Doyle explains this contradiction by concluding that certain teacher beliefs have become accepted without the necessity of "evidence or logic to sustain them" (p. 219). His conclusion is that changing retention practice is more likely to be accomplished by stressing to educators and others the negative effects retention has upon the child.

More research is needed in the area of teacher beliefs, teacher thinking, and their influence on teacher decision making practices. Clark and Yinger's (1978) research on teacher thinking found teachers' behaviors were influenced by belief systems often unconsciously impacting on their performance and were guided by variables such as the influence of peers, characteristics of pupils, and the availability of resources. Influencing belief systems to reflect current research on retention's effects on children will be the challenge of policy makers and teacher educators.

\section{THE PRACTICE OF RETENTION}

\section{Retention Criteria}

In the absence of a standardized approach or objective criteria, teachers rely on subjective judgment, pedagogical experience, and personal philosophy when recommending 
retention. A survey in Detroit revealed that teachers, when asked to identify criteria they used in making retention decisions, responded with 49 different items (Leddick, 1988). Poor achievement in the basic skills, poor work habits, or immaturity are general characteristics given by teachers for retention decisions. Children with similar difficulties and characteristics may be recommended for retention in one school and promoted in another, even within the same district. The possibility of such varied application of subjective criteria raises questions of equity since poor and minority students are more likely to be retained and their prospects for future success impaired.

\section{Characteristics of Retainees}

Those children most likely to be retained in grade are Black or Hispanic, male, free lunch participants, and first graders (Schuyler, 1985). A study by walker (1984) identified several retention predictors which put a child at greater risk of failure: having lower achievement scores, a lower IQ, being a member of a minority group or having low socio-economic status. The likelihood of retention is increased if a child has a high activity level, is one of the younger students in class with a July to December birthday, or is being raised by a working mother. Males are retained nearly twice as often as females (Bossing \& Brien, 1979). When retained, children become potential dropout candidates as school failure accelerates feelings of peer 
rejection, discouragement, and lowered achievement (Cuddy et al., 1987). Potential retainees also may have parents who are either unable or unwilling to intercede on their behalf. stringer (1960) found that in the 50 cases of retention he studied, 40 of these children had parents who had not intervened in the decision. In 41 cases of social promotion, the majority (38) involved parents who opposed the recommendation to retain.

A study by Phi Delta Kappan concentrated on students at risk of retention at each of three levels: elementary, middle, and high school (Frymier \& Gansneder, 1989). No students were included who had been placed in special education or other alternative programs. A total of 276 principals were interviewed from the three levels. Researchers found that "almost three-fourths (71\%) of the principals said that they regularly retained students in grade but only $26 \%$ thought that retention was effective" ( $p$. 145). Why principals agreed to retain children when so few thought it effective was not addressed by the report. One assumption might be that alternative programs were unavailable as options.

\section{Retention and Immaturity}

Many educators believe retaining a child early in the grades has the least detrimental effect on the child. Consequently, kindergarten and first grade have become the most frequent years for retention decisions. Research 
regarding the effects of retention on the immature child often fails to acknowledge the differences in retentions for immature but bright children and retentions involving students lacking readiness skills (Shepard, 1989). Shepard asserts,

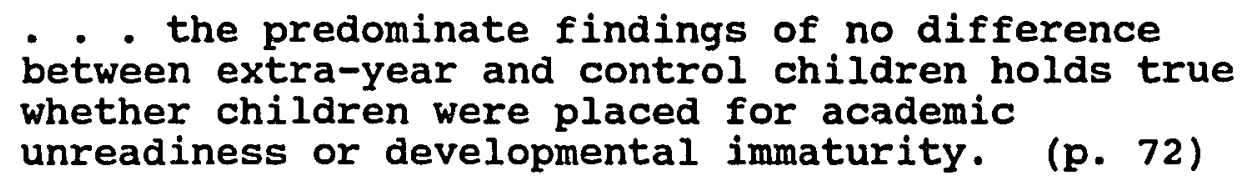

A different philosophy regarding the best course for immature children entering school is expressed by those advocating a developmental placement. They assert that children who are older at school entry do not encounter the difficulties with school work frequently experienced by younger, less mature children (Ilg et al., 1978). Supporters of Gesell's developmental placement philosophy state that by replacing children in a grade appropriate with their mental age, the frustration and struggles with academic demands beyond their abilities to perform will be avoided. "Our position is that repeating is an effective remedy when students are immature and thus overplaced, but that it should not be expected to solve all school problems" (p. 16) .

The concept of success and failure, underlying the institution of school itself, is supported by the structure of the graded system. Gesell and IIg (1946) stressed a "developmental perspective" rather than a success/failure perspective is necessary if education is to be made more 
humane. Sensitivity to the individual developmental pattern of a child would provide educators a more realistic perception of his or her school performance.

This assertion appears to be supported by scott and Ames (1969) who maintain that the only benefit which should be expected from retention is the additional time for the young child to mature. They echo one of the frequent justifications used by teachers of young children:

Repeating, theoretically, should be the solution for children who are too immature for the work of a grade in question and thus need to be older to succeed at the work of that grade. (p. 434)

The study by Scott and Ames (1969) defends the efficacy of retention for immaturity. The study population was composed of 27 children who had been retained for reasons of immaturity. This had been determined either by the use of a behavior scale or by the judgment of their teacher or principal. A teacher and parent questionnaire, regarding the progress and attitude of individual students, was completed during the non-promoted year. Findings indicated that the retained students did better academically and had experienced no adverse effects on their behavior. Scott and Ames comment:

- . for this group of selected subjects, repeating did appear to have a beneficial effect, not only on grades but also on the children's school behavior as reported by their teachers and on school and home behavior as reported by parents. (p. 438)

Sandoval (1984) conducted a study to determine if certain types of children were more likely to be retained 
for immaturity. Students recommended for retention were assessed using both academic and non-academic measures. From the data results, Sandoval looked for clusters or patterns of variables that would group or categorize retainees. One group appeared to be very low in several areas, one group fairly high achieving, and the third group had a variety of characteristics. Sandoval questions whether special education might not have been considered for the first group, and whether the second group of children might not have been promoted. He concludes with the observation that academic competence rather than affective concerns appear to be dominant as educators consider children for retention.

other researchers lend their support to retaining if immaturity is a major factor. Bossing and Brien's (1979) study showed retention to have had some positive effects if immaturity was a factor in the decision. McAfee (1981), also found benefit from the retention decision if students were retained early rather than later in the grades. In addressing the entire issue of immaturity, shepard and Smith (1985) question whether teachers may be confusing personality traits which will persist, with a lack of developmental readiness. Their study found that retained kindergarten children had realized no benefit over a control group in the areas of social maturity, attentiveness, or self-concept by the end of the first grade. "Kindergarten 
retention was ineffective regardless of whether children had been placed for developmental immaturity or deficient academic skills" (Shepard \& Smith, 1989, p. 105).

\section{Retention and Transition}

\section{Rooms}

Transition rooms, an extra grade between kindergarten and first grade, are frequently perceived to be a less damaging alternative than retention. Often termed "Junior First Grade," or "Pre-First," this additional year of instruction is intended to provide a smaller class size, greater teacher attention to specific deficits, and a slower instructional pace. It is hoped this will give the young child more time and the attention he or she needs to acquire basic skills. Proponents argue transition classes protect the child from a sense of failure while at the same time offering a second year to master material (Sandoval \& Fitzgerald, 1985).

May and Welch (1984) found that the positive achievement effects of the transition room year had disappeared by grade three. Leinhardt (1980), studying the effectiveness of transition rooms, reported that promoted students who had been recommended for retention but not retained, received more frequent reading instruction for longer instructional periods and as a result, had greater achievement than transition room students for that year. Transition room settings with their more homogeneous 
populations did not exceed the achievement gains of at risk students promoted into a heterogeneous classroom. Leinhardt concludes, speaking of transition room children,

although they may have gained maturation, they did so at the expense of education. . . Thus, after two grades of school, they were at the same place as similar students with only one grade. (p. 60)

Sandoval and Fitzgerald (1985) studied high school students who had experienced a transition room placement. Three groups of students from one high school were surveyed for this study: students who had been retained, students who had participated in a transition program, and a control group which had been regularly promoted. Data revealed that students' attitudes toward the transition room experience were positive and their grades were comparable with regularly promoted students. Traditionally retained students had made less progress and significantly, the later they had been retained in the grades, the less improvement was noted in their academic achievement.

Subject matter differences were noted for the retained group. A one-way analysis of variance applied to academic measures indicated there were obvious differences in group performance both in general academic progress and specifically in math. In each of these areas, the retained students did less well than the other two groups. Sandoval and Fitzgerald (1985) acknowledge that nothing can be known how these students would have performed had they been socially promoted. 
Gredler (1984) reviewed several studies reporting on the effects of transition room placements. students at risk of school failure and children similarly at risk but promoted to first grade were subjects of the research. Gredler concludes by questioning the

educational payoff obtained with such programs [since] research indicates that transition room children either do not perform as well or at most are equal in achievement levels to transition room-eligible children placed in regular classrooms. (p. 469)

In a study of two-year kindergartens, children who had had an extra year in kindergarten were compared with equally low achieving students who had not been retained (Shepard \& Smith, 1985). When a standardized reading test was administered at the end of first grade, the repeated children had a one month reading achievement advantage. No differences existed between the two groups in math achievement as measured with a standardized instrument. Both groups were seen as similar in other aspects of maturity, readiness, and self-concept. The two year group had slightly less favorable attitudes toward school. Shepard and Smith conclude, "The belief that extra-year programs will give at-risk children a boost, in academic achievement or self-concept, has not been borne out by empirical research" (p. 357).

While a transition grade may be viewed as a more face-saving solution by parents, transition room placement must be considered another form of retention. While 
providing children a second year to master material and become ready for first grade curriculum, it also removes children from their peer group and adds an additional year of schooling. Using kindergarten retention as a solution to low achievement and as an attempt to prevent later school failure, appears generally ineffective if significant and long-term benefits are considered (Shepard, 1989). The effects of early retention on such at-risk students also need to be weighed very carefully for the later effects they may produce (Frymier \& Gansneder, 1989).

\section{THE EFFECTS OF RETENTION}

In one of the most extensive reviews of retention research literature, Jackson (1975) summarized his study by noting that:

those educators who retain pupils in a grade do so without valid research evidence that such treatment will provide greater benefits to students with academic or adjustment difficulties than will promotion to the next grade. (p. 627)

Jackson (1975) argued that flawed designs made most of the study findings unreliable. He concluded that the research evidence left such doubts regarding the effectiveness of retention, that educators were relying on a practice which could not be supported.

One general conclusion about the effects of grade retention relative to grade promotion is clearly warranted by all the results taken as a whole: There is no reliable body of evidence to indicate that grade retention is more beneficial than grade 
promotion for students with academic or adjustment difficulties. (p. 627)

Other analyses offer support to Jackson's (1975) summary regarding the dubious value of retention (Bocks, 1977; Bossing \& Brien, 1979; Gredler, 1984; Haddad, 1979; Holmes, 1986, 1989; Holmes \& Matthews, 1984; Shepard, 1989; Shepard \& Smith, 1986).

Retention and Academic Achievement

The contention that young children who have not adequately mastered the basic skills and thus need an additional year for academic attainment has been contradicted in research (Dobbs \& Neville, 1967; Holmes, 1986, 1989; Holmes \& Matthews, 1984; May \& Welch, 1984; Niklason, 1984, 1987; Shepard \& Smith, 1985, 1987).

In a review of retention studies, Holmes and Matthews (1984) used a meta-analysis technique to analyze the effects by grade level of 44 studies. Meta-analysis integrates results of a number of studies by looking at the averages of the actual differences between the control groups and the treated groups. In their meta-analysis, Holmes and Matthews analyzed the effects of retention in five areas: academic achievement, personal adjustment, self-concept, attitude toward school, and attendance. Using this approach, Holmes and Matthews found a negative effect at all grades and for all subject areas. In 31 of the studies, examined specifically for academic achievement of elementary and 
junior high students, Holmes and Matthews found negative effects at all grade levels. This counters the belief that early retention, in kindergarten and grade one, produces the most positive benefits.

In a 1986 review, Holmes analyzed 17 studies, 14 of which investigated academic achievement, notably reading and math. When the frequency distribution of the 149 effect sizes were plotted, a bimodal picture emerged. One was consistent with Holmes and Matthews' (1984) findings from their review. The second, however, indicated positive benefits were emerging from retention.

Holmes (1986) concluded that two different kinds of retention plans had been investigated. The majority of the positive measures were from five studies and while those five appeared to show successful results, in only one did researchers look at any long-term gains made by retained students. Those gains turned out to be short lived, many disappearing by the end of two years. In addition, researchers in these studies had made comparisons between students in the same grade rather than the same age. Holmes reasons that it could be expected that students who were older and who had had an additional year of school would have higher achievement on normed tests.

significantly, sample populations were mostly white, middle class students drawn from suburban areas. The education program developed for these students had been 
structured to provide for smaller classes, greater attention, and opportunities for experiences with age peers. Holmes (1986) poses the idea that this same type of educational plan could be developed for students in place of a costly retention.

In conclusion, Holmes (1986) asserts that this analysis, continues to support his conclusions from an earlier analysis of the research (Holmes \& Matthews, 1984). That is,

Because this cumulative research evidence consistently points to negative effects of nonpromotion, the burden of proof legitimately falls on proponents of retention plans to show there is compeliing logic indicating success of their plans when so many other plans have failed. (Holmes \& Matthews, 1984, p. 232)

In a more recent meta-analysis of 63 studies, Holmes (1989) concluded that research has demonstrated generally negative effects regarding retention. The criteria used for including research studies in this meta-analysis were (a) the sample population was kindergarten, elementary or junior high students; (b) sufficient information was produced to permit the determination of an effect size; and (c) a comparison group had been included. Only 9 of the 63 studies indicated positive effects. These nine studies had coupled remediation efforts with the retention. In addition, these retained students were not only a more able group of children, but researchers had also failed to provide the control group with a similar remediation 
program. Holmes noted a tendency in those studies showing positive results to have made comparisons by grade rather than by age and most had not pursued any later follow-up. other investigators of non-promotion offer their analyses of retention research. Bossing and Brien (1979), in their review of retention studies, concluded that retention does not significantly impact achievement; neither does the threat of retention motivate students to achieve. Bocks (1977) offers the argument in his summary of the research that non-promotion offers no benefit and may be harmful. After reviewing several studies on the effects of retention on academic achievement and social immaturity, Bocks concludes "It appears from these studies that the majority of the pupils who repeat a grade will achieve no better the second time in the grade than they did the first time" (p. 380). Regarding social immaturity Bocks asserts "Non-promotion for the reason of social immaturity does not receive support from these research findings" (p. 381). Shepard (1989), in a review of transition placement of kindergarten students and regular retained kindergarten students, found no benefit in the extra year. Neither immaturity nor achievement needs were relieved by the retention. Transition students, who were promoted to first grade one year later, did not show any academic advantage over those children who had been considered for retention but who were promoted to first grade. 
In this respect retention, whether it is called by a special name (transition), occurs for special reason (immaturity), or takes place in kindergarten rather than later, is still retention--and still

ineffective. (p. 76)

Nicklason (1984), reporting on a Utah study, takes a

more conservative view. She observes that the issue of any academic benefits of retention has not been fully resolved. In this particular study, children making satisfactory progress after being retained were those in the most highly functioning group of the retained students. In other words, the students needing retention the least experienced the most benefit.

From reviews of the research, it appears that if the goal of retention is the improvement of achievement, the opposite may be occurring. Results appear to be consistently negative in the use of retention to significantly improve achievement. Academic gains need to be addressed by less damaging alternatives.

Retention and Social Development

Using retention to improve the social development and self-concept of young learners is not consistently supported by research. The possibility of negative effects on self-esteem, the rejection of peers, and the risk of early dropout, leave doubt as to the efficacy of the effort. Goodlad's (1954) study of emotional effects found retention may impair children's social adjustment and 
personal self-esteem. This study revealed that there were differences between promoted and non-promoted children in social adjustment as well as personal adjustment. In the area of peer-group relationships, Goodlad found that grade placement appeared to account for differences between the two groups. A comparison was made between two groups of promoted and non-promoted children, first to their own classmates and then to the relative position of each group in their class. He found the promoted group was rejected less by classmates ". . . the important consideration is that non-promoted children thrived less well than promoted children when each group was compared to its own class group" (p. 325).

An analysis by Byrnes (1989) of peer-group relationships showed promoted children experienced less rejection from their classmates than non-promoted children. Retention was perceived by students as a punishment for failure to learn or for misbehaving in class. This was the view of the retained students as well as the high achieving students (Byrnes, 1989). An earlier study by Byrnes and Yamamoto (1984) found that children are cognizant of their failure when retained. Students ranked only blindness and the loss of a parent as more stressful than such failure. Shepard \& Smith (1989), when assessing the effects of kindergarten retention, found that parents reported 
"emotional disruption for their child associated with not making normal progress" (p. 106).

Finlayson (1977) measured the self-concept of children who had either been non-promoted, promoted, or who were considered "borderline" and found different results. The borderline group consisted of children who had demonstrated achievement levels similar to the non-promoted group but who had not been retained for a variety of reasons. Measurement of the children's self-concept over a period of two years revealed that the non-promoted group tended to become more positive in their concept of self than promoted children. However, by the end of the two year period, the ratings of the promoted and non-promoted students were nearly similar. Finlayson's (1977) explanation is that children's positive self-esteem tends to decrease as they progress through the primary grades and as they begin to assess themselves more realistically. The promoted students, probably being more advanced, had come to this same self-assessment stage earlier than the non-promoted students. By the end of the two year period, the nonpromoted students had reached the same conclusion, that is, a more realistic self-assessment. Parents who were interviewed, however, tended to perceive the retention as positive and ascribed more confidence and maturity to their non-promoted child. 
Cuddy et al. (1987) came to different conclusions regarding retention's effect on social and psychological adjustment. Their findings support those of Goodlad (1954), that promoted children experience less peer rejection than non-promoted children. Cuddy et al. found that promotion decreased the rejection of lower achieving children. This is especially significant in view of rejection impacting on later dropout. They caution that their conclusions may be dissimilar from those of others (Plummer \& Graziano, 1982) because of the possible effect of the low rate of retention (5\%) in their subject population.

Plummer, Lineberger, and Graziano in 1986 reviewed the earlier study by Plummer and Graziano (1982) which investigated the effects of retention on the self-concept of children as well as their peer group relationships. Plummer and Graziano had found that retained children had a higher self-concept than non-retained children. Plummer, Lineberger, and Graziano's elaboration on this finding indicates that students, placed for the retained year in a class where their achievement more closely matches those of the group, will react with more positive feelings about themselves. They note that the data indicated that retained children responded they were not smart nor did they want to be. Since the self-concept score was measured by the discrepancy between the real and ideal self-concept scores, 
the child's self-assessment standard is a significant factor.

Plummer and Graziano (1982) also examined the preferences of regularly promoted children for workmates and playmates. In a target population of 219 second and fifth graders, 468 had been retained. Results indicated that $75 \%$ of the second grade sample preferred a retained child to help them with school work, while fifth graders preferred a non-retained child for the same task. In selecting a playmate, a majority of promoted children preferred the non-retained child (55\%) while those retained favored a retained playmate. Differences were noted for individual grades, with second graders more often selecting retained children as playmates than fifth graders. Plummer, Lineberger, and Graziano (1986) concluded that retention does effect peer relations as the retained child matures. "Hence, grade retention could hinder the retained child's social relations with same-age peers" (p. 237).

In a study using a sample population of $624 \mathrm{sixth}$ grade students, it was found that a single retention impaired the self-concept and that multiple retentions increased the negative impact (White \& Howard, 1973). The Tennessee Self-Concept Scale, containing 100 selfdescriptive type statements, was administered to the students. In every instance, children who had never been retained had the highest mean score which demonstrated 
positive self-regard. With one retention and with subsequent multiple retentions, the mean scores became progressively lower. No differences were found between boys or girls. White and Howard concluded that retention is related to the self-concept of elementary students and the resulting feelings of failure experienced by non-promoted children need to be addressed by school counselors. Goodlad and Anderson (1987), in a review of research on retention's negative social affects, conclude:

It becomes apparent that nonpromotion is not conducive to the development of pupil feelings of satisfaction and well-being. Promotion offers greater hope that pupils will develop a sense of personal worth, that they will take pleasure from school life, and that they will want to continue with their schooling. (p. 36)

\section{Retention and Equity}

The impact of retention on minority populations and on children with multiple risk factors are additional reasons to provoke serious attention by policy makers. The potential for unequal treatment exists within schools, within districts, and, certainly, between school districts. Although retention is a questionable educational practice, it is handled differently by school districts across the nation. In some, students simply and automatically repeat the grade, often with the same teacher. Other districts may devise different instructional approaches or grade level configurations to improve the child's learning environment 
the second year. It is doubtful that equity can be maintained with such a variation of application.

Goodlad and Anderson (1987) offer the following observation:

Whether or not a child is promoted appears to depend more upon biological, economic, and social chance than upon sound educational design or how hard he works. In fact, whether or not a child is promoted depends on where he happens to go to school. (p. 31)

The Status of African American Children, a report published by the National Black Child Development Institute asserts that one quarter of children under 18 years of age repeated a grade in 1988 (National Black Child Development Institute, 1990). Further, this study claims that black students had repeated grades nearly twice as often as white students regardless of age group. Educators need to be aware of, and sensitive to, the implications of equity in non-promotion decisions. When standards are raised, children most likely to be non-promoted are of a minority race, male (Schuyler, 1985), or of low socio-economic status (Walker, 1984). Caution needs to be exercised in automatic, perfunctory recommendations for the retention of minority students, especially those who fit the retention profile.

\section{Retention and Later Effects}

The possibility of retention producing negative later effects on children needs to be considered by educators. The increasing numbers of students discouraged with their 
educational progress, transient in their attendance, and exhibiting symptoms of low self-worth are significant predictors of early dropout. The publication of documents such as A Nation at Risk (NCEE, 1983) has stimulated research on retention as a factor in dropout rates. According to Pallas, Natriello, and McDill (1987), if the reforms advocated by reports such as Nation at Risk are implemented, the higher performance expectations may increase the numbers of students who drop out of the system. They assert that "Raising siandards for performance may push the at-risk population out of school at increasingly lower grade levels" (Pallas et al., p. 111).

Most studies investigating dropouts involve high school students overage for their grade. Grissom and Shepard (1989), in their review of studies involving high school dropouts, cite two involving younger children. A study by stroup and Robbins (1972), found that an elementary school retention was a significant factor in leaving high school before graduation. Secondly, a study by Lloyd (1978) involving third grade students indicated a retention by the third grade was a significant predictor of dropping out during high school. Grissom and Shepard caution that districts need to be aware that including retention with other dropout factors increases the risk of students leaving school early. 
The number of dropouts, a matter of concern with the current focus on educational improvement, continues to be between 25-30\% across the nation (Donnelly, 1987). In Oregon, 29.28 of the ninth grade students do not graduate with their class by grade 12 (Oregon Research on Education, 1988) - Grissom and Shepard (1989) note that comparisons of high school graduates and those students who have left early reveal greater numbers of dropouts have had a retention. Separating retention from other achievement factors is essential since rationale for retention decisions are not always based on the lack of academic progress.

While achievement, or the lack of it, remains the primary factor in students leaving school, those possessing several dropout indicators, as described earlier, are more likely to end their education. The impact of these indicators falls heaviest on inner city children. Those who are at risk can include retention as one of the factors leading to their early departure from school. Grissom and Shepard (1989) state ". - . factors that pull students out of school may be more potent for those who are over-age for their grade as a consequence of their retention" (p. 35). The 1990 Gallup poll asked the public specific questions regarding both retention in grade and dropout rates (Elam, 1990). In answer to the question regarding which students were more likely to drop out of school, those failing achievement tests and repeating a grade or those 
failing but being promoted, the majority polled thought failing but promoted students were more likely to leave school early. Sixty percent of public school parents expressed this majority opinion (failing but being promoted would increase the chances of dropping out) while $28 \%$ thought repeaters were more likely to be dropout candidates. Non-whites responding to the question had answers more closely in line with research findings. Forty-four percent of non-whites believed retained students were more likely to drop out as compared with $30 \%$ of white respondents (Elam, 1990). This response is contrary to research by Grissom and Shephard (1989), which asserts that retention is a factor in students leaving school early. The public has apparently not been exposed to the findings of grade retention research.

The goals of retention then, which are the remediation of achievement, self-concept improvement, and improved motivation, have not been conclusively substantiated by researchers. Retention's uneven application leaves it suspect as a discriminatory practice. Its role as one of the factors escalating student dropout rates is increasingly apparent. Retention/promotion policies may need to be re-examined or reformulated where they exist, and created where they do not, in order to ensure equity for all students. 


\section{RETENTION DECISION MAKING PRACTICES AND POLICIES}

\section{Persistence of Retention}

\section{Practice}

Teachers' perceptions of "what works" and their unwillingness to trust the research as it contradicts their practice, may tend to perpetuate retention. This persistence in the face of mounting research evidence of its negative impact has been questioned by Doyle (1989). He states, "We urgently need to explore the reasons why educational practice often resists the findings of educational research" (p. 217). The persistence of retention may not lie with the unfamiliarity of educators with current research. According to Rose et al. (1983), it is a reliance on teachers' personal observations during the retained year and their inability to follow the child through subsequent years' successes or failures, which contribute to the practice. The inability to know what might have happened if promotion had been done, tends to repeat and protect the practice (Rose et al., 1983).

Several factors lead teachers and principals to rationalize their use of retention. Teachers may verbally support their decisions because of their vested interest in having made a correct decision. Parents may be unwilling to admit an error of judgment or be reticent to disagree with the teacher's authority. often, the very lack of remedial programs, tutorial opportunities, or the difficulty in 
qualifying a student for special education, may lead educators to do what they feel is in the best interest of the child, or the only thing left to do, that is, retain.

Curriculum expectations and the graded structure of the school may pressure teachers into escalating their standards for pupil performance (Smith, 1989). Teachers may fear their colleagues' criticism the following year when "unready" students are passed on to the next grade. Although differing philosophies regarding child development may exist among staff members, expectations of parents, colleagues, or district philosophy may result in the perpetuation of non-promotion. As Smith states, "The only alternative available to them [teachers] is the recommendation to retain a child who does not fit the structure" (p. 149).

Those who are of the Gesell persuasion, that children should be placed in school on the basis of their behavioral or developmental age rather than on chronological age, will lean toward retention as a prescription for school success (Ames, 1981). Proponents of a developmental philosophy (or Gesellian frame of reference), as opposed to a psychometric philosophy, acknowledge the need for children to attain academic success at their own individual rate. Their opposition to retention is based on the potential harm to self-esteem and its inequitable application (National 
Association for the Education of Young Children [NAEYC], 1988).

The philosophical biases of educators toward what is, in their view, the best interests of the child and the responsibility and accountability of the school to educate, are important factors in retention decision making. The impact of failure and the dilemma of student versus the school's responsibility for failure, contribute to decision making confusion.

Smith (1989), reviewing a study of teacher belief systems by Shepard ans Smith (1985), found that all teachers interviewed, regardless of their belief system, supported retention in some cases. The lack of a control group, according to smith, makes it difficult for teachers to ascertain the results of retention decisions and perpetuates teachers' attending only to the outcomes of retained children (Smith, 1989). Teachers appear to wield significant power in their recommendations for retention, in their persuasion of parents and colleagues, and in determining the course of the final decision. They are pivotal figures in the decision to repeat the year. Their belief system drives the push toward retention as a solution.

\section{Decision Making Models}

As the national focus on accountability continues, few decision making models for helping educators with retention 
decisions have emerged (Smith \& Shepard, 1989). Light (1977) and Leiberman (1980) have devised models for rating or assessing students. Decision making aids have also been suggested by Walker (1984) who proposes a more systenatic decision making model as a means of reducing retention rates. Walker suggests children should be screened by the same methods as students being considered for special education. He states, "Such a mandate would automatically eliminate much of the subjectivity that appears to exist in retention decisions" (Walker, 1984, p. 3).

Light's (1977, 1981) scale for retention decision making, developed after a review of more than 150 studies, is frequently mentioned in retention literature. It provides teachers with 19 different categories for assessing students. The interpretation of scores range from the assessment of students as excellent retention candidates downward to the determination that a student should not be retained.

Sandoval (1982) cautions that Light's retention scale is neither a valid nor a reliable tool for making retention decisions. In a 1982 follow up of an earlier study of Light's retention scale, Sandoval examined the validity of the scale to predict successful retention candidates. The sample population were 78 first grade students who had been selected for non-promotion but Light's scale had not been used in the decision to retain them (Sandoval, 1982). 
Light scores were not found to be related to academic outcomes (math and reading) nor to affective skills (Sandoval, 1982). Sandoval's findings indicate that only the Light short Form scores predicted the parent's rating of retention success $(.03)$. Sandoval concludes by stating: "The single significant result with the short Form is not sufficient to validate Light's Retention Scale for use with first-grade children" (p. 313).

Using retention research as a rationale for non-promotion decisions is suspect since evidence is divided on retention's effectiveness and the methodological approaches used in some studies are faulty (Jackson, 1975; Leiberman, 1980). He advises a thorough analysis of all the components involved in each decision. He proposes a decision making model which is problem-solving and rational. Factors to be assessed are divided into three groups: child, family, and school. All factors are to be weighted according to the individual case and placed in one of four possible decision categories: for retention, against retention, undecided, or not applicable.

A different view is offered by Clark and Yinger (1978) who propose that teachers' decision making develops from a defining of their experiences. By ranking those experience according to their significance, teachers make judgments as to what is important and what relationships may exist among them. Similarly, Cross (1984), investigating teacher 
decision making practices in a Texas school district, looked particularly at the criteria used in retention recommendations. He found that teachers used a hierarchy of criteria for their judgments along with qualifying factors which influenced their decision. Although immaturity was mentioned frequently in interviews as important, reading achievement as measured by the student reaching a certain level in the basal text, usually the primer, was more important than immaturity.

Secondly, cross (1984) investigated teachers' use of standardized test data in their decisions to recommend retention. He found no significant relationship between the reading achievement test scores and the students who had been recommended for retention. Cross suggests there is a weaker influence of reading achievement in the decision making strategies used by teachers than either immaturity, physical size or parent resistance. Cross urges that "the criteria and procedures for making decisions regarding student retention deserve more scrutiny than they have normally received" (p. 1).

other factors important in decision making include teachers' confidence in the decision (Sandoval \& Hughes, 1981), parent involvement (Lieberman, 1980), and documentation which supports the reasons for the decision (Abidin et al., 1971). Providing a method for receiving input from learning specialists into the promotion/retention 
decision is the first step in developing alternative options for student success rather than failure.

A decision making model using a team approach is proposed by stammer and cooke (1986) and Brown (1981). In Stammer and Cooke's design, data are presented by an education team who conference and make recommendations to parents. This pupil personnel team would handle questions regarding a student's academic difficulties throughout the year and communicate concerns to parents. Further, Brown urges that extensive record keeping be done during the decision making process by the team. Using an approach similar to those used in making special education decisions would provide the structure deserved by promotion/retention decision making (Germain \& Merlo, 1985). Additionally, this approach would provide for evaluation, parental input, and the development of resources for an individual achievement plan.

An area usually neglected is assessment during the retained year. An evaluation of basic skills would demonstrate any gains made and continue the focus on the child. Frequently, the act of repeating the academic program with no further accountability for prior decisions is all that is expected of school staff. This may be contrasted to the decision making approach followed by some schools. In some cases, teachers may make a recommendation to the principal after receiving informal input from other 
school specialists. After a general discussion, a joint decision is made to present that decision to parents, usually by the teacher.

Whatever the model used, it is important that issues of equity are addressed in any set of decision making criteria. An increasing number of states currently use or mandate the testing of young children. Critics fear these instruments may be inappropriately used to make placement/retention decisions and may be inequitably applied to children (Schultz, 1989). The use of subjective data and loosely defined terms such as "immaturity" or "time to grow," allow for the possibility of discrimination of race or social class (Thompson, 1980). Chandler (1984) suggests diagnostic testing, careful assessment of current abilities, and a written prescription be done for the year of retention.

Cross (1984), in his study of teacher decision making practices, questions if students should not have a right to expect similar treatment in similar situations. The individual teacher, in the absence of clear guidelines for decision making, is left to subjective measures, a variety of personal beliefs and rationales, and dependent upon any number of biases, expertise or knowledge of current research. Serious consideration needs to be given to how policy makers fulfill their responsibility for ensuring equity in such a high stakes educational decision. 
Retention Policies

In a survey of 25 school districts, Rose et al. (1983) found that few had written promotion criteria regarding student achievement with regard to academic standards. Retention policies themselves focused on four major categories: current achievement level, student demographics, what was considered best for the student, and the number of previous retentions.

Recommendations for retention were generally made by the teacher, who, along with the school psychologist or learning specialist, had considerable influence on the principal's recommendation. Rose et al. (1983) stress the importance of decisions and policies being made by educators and school psychologists who have a knowledge base of retention/promotion research literature.

According to Chafe (1984), retention policies need to reflect the goals of the school district. He sees two directions for policy makers. A response to the accountability movement would lead to policies for strict grade level standards and increased retention. A response to meeting the needs of failing students would lead to decisions based on each individual's particular educational profile. Chafe suggests:

The optimum policy is one which sets forth broad, research-based guidelines; but which emphasizes that the decision is to be made by a committee which includes the student, parents and educators. (p. 20) 
Retention/promotion policies which take a more individualized approach will result in a more considered method of decision making. That is, districts concerned with the needs of its lower achieving students will attempt to develop programs geared to the identification and remediation of those academic areas in need.

Retention/promotion policies accompanied by a decision making model would provide a systematic method for retention recommendations (Brown, 1981; Lieberman, 1980; Rose et al., 1983; Sandoval, 1984; Stammer \& Cooke, 1986). Teachers' and administrators' decision making behaviors and attitudes were investigated by Graham (1982). Graham suggests that new policies need to be preceded by input from teachers and administrators and advises policy makers to determine if new policies are necessary and they can be made practical. She stresses the need for piloting and revising policy before it is implemented. Graham also asserts that a wrong application or non-implementation of policy will occur if the policy is vague or unclear. Graham concludes,

Therefore, if teachers are not given specific guidelines and criteria to be implemented in the classroom, they will draw upon their experiences to establish a policy that they feel comfortable with. (p. 8)

Retention/promotion policies are increasingly susceptible to legal challenge. Walden and Gamble (1985), advise using several criteria such as students' grades, attendance records, and test scores to create a broader base 
for decision making. Parents need to be included along with teachers and principals in decision making. Walden and Gamble caution, however, that "promotion and retention policies are not immune from judicial scrutiny and must be carefully drawn in order to tailor the policy to educational objectives" (p. 623).

\section{IMPLICATIONS FOR THIS STUDY}

The effects of the non-promotion of students have been studied by researchers for the past several decades. Most analysts concur that retention has generally negative effects on students' academic achievement and social development (Holmes, 1989; Holmes \& Matthews, 1984; Jackson, 1975). The persistent use of retention as an intervention continues even though such research evidence to the contrary is available. Educators' beliefs regarding the developmental readiness of children and in their ability to impact the learning process, influence their decisions. The lack of positive benefit and the probabilities of later school failure indicate the need for educators and policy makers to re-examine policies of non-promotion and the processes by which retention decisions are made. Retention diverts attention away from the school's responsibility for student success and shifts the blame for school failure to the child. It proposes a repetition of failed practices and programs and one which impacts a 
child's educational future. studying, developing, and attempting alternatives are responsibilities of school districts in ensuring student success.

The focus of this study is to examine the retention decision making procedures used by practitioners within four school districts and the belief systems which underlie their decisions to retain. Exploring the rationale used by teachers and principals, the processes they follow in making retention decisions, and the influence of research on their practice, may provide additional insight for future policy makers.

\section{SUMMARY}

This literacure review addresses major factors in the retention/promotion controversy. Retention has been a concern since the common school system began early in the nineteenth century (Angus et al., 1988; Labaree, 1984; Tyack, 1974). Alarm with the numbers of retained students failing to complete their education led educators to research the problem in the early twentieth century. Since that time, retention has been in and out of favor with educators as a method of dealing with students who fail to master the graded curriculum.

studies seeking to determine the merits of social promotion versus retention have had mixed results. The predominate findings appear to indicate retention is of 
doubtful value and generally produces negative effects on student achievement, self-concept, and future school success (Byrnes, 1989; Byrnes \& Yamamoto, 1986; Holmes, 1986, 1989). Retained students have a greater risk of leaving school early, even those students retained only once in the early grades (Grissom \& Shepard, 1989).

Although many retention research designs are considered flawed, reviews of studies, or meta-analyses, indicate that retained students, when compared with promoted children of similar ability, do not perform as well (Haddad, 1979 ; Holmes, 1986, 1989; Holmes \& Matthews, 1984; Jackson, 1975). Any achievement gains made by non-promoted students during the retained year are soon diminished, leaving them with no academic advantage over their promoted peer group (Byrnes \& Yamamoto, 1986; Holmes \& Matthews, 1984; Schulyer, 1985). When emotional and social effects are considered, research conclusions are even more persuasive in favor of promotion (Cuddy et al., 1987; Goodlad, 1954). The impact of retention on academic achievement and self-esteem appears to negatively influence future school success.

It is essential for educators to be aware of current research in the field and use judicious restraint when considering retention. The lack of positive effect and the risk of later school failure indicates the safest course for the failing child appears to be promotion accompanied by planned, collaborative interventions, and appropriate 
support services including parental support (Natriello, MCDill, \& Pallas, 1990; Slavin et al., 1989). Implementing the programs, options, and necessary changes needed to ensure student success will challenge the financial side of school reform as well as those directly involved with policy development and implementation (House, 1989). 


\section{CHAPTER III}

\section{METHODOLOGY}

This chapter outlines the methodology used to describe the practices and belief systems of principals and teachers and their impact on retention decision making. Included in this chapter are the following sections: (a) overview, (b) research questions, (c) sample description, (d) instruments used, (e) procedures of data collection, (f) research framework, and (g) data analysis.

\section{STUDY OVERVIEW}

This study examines the decision making policies used by schools in recommending retention in kindergarten and grade one. It addresses the range of practices currently used by early primary teachers and their principals as they work through district guidelines for the non-promotion of students. It was designed to identify the decision makers within the process and the factors which impact on that process. Typical models currently used for making recommendations regarding pupil placement are:

1. the teacher decides and informs the principal of the decision to recommend retention; 
2. the teacher and principal work together with the principal making the final decision to recommend retention;

3. a building team discusses the recommendation and makes the decision to recommend retention.

This descriptive/exploratory study deals with the perceptions of teachers and principals regarding the processes they use in retention decision making. In addition, this study explores the belief systems of educators toward non-promotion and possible alternatives for improving student achievement in lieu of retention. Gay (1987) noted that a descriptive study explores and describes the existing state or situation. Ary, Jacobs, and Razavieh (1985) stated that descriptive research concerns itself with current practices and attitudes, beliefs, and points of view. Descriptive studies address relationships between non-manipulated variables, test hypotheses, and may result in the generating of theories.

Two formats, interview and survey, were used to develop a full description of current retention practice. The major basis for data analysis was non-random interviews conducted with selected educators representing three job or position groups within three socio-economic status (SES) groups of schools. Information obtained from 56 survey respondents supported and complemented the interview process. This study addresses the following research goal. 
RESEARCH QUESTIONS

The goal of this study was to describe and explain the actual practice, or process, used in retention decision making in kindergarten and grade one as reported by practitioners in high, middle, and low status school groups. The primary research method was in-depth interviews of a chosen subset of teachers and principals who had completed a descriptive survey of retention practices.

The goal was addressed by the following research questions:

1. What is the relationship between the written retention policy of a selected school district and the decision making process used by its schools?

2. What are the influences by district socio-economic level that impact the decision making process used in student retention in each of the following areas:
a. student body characteristics?
b. curriculum expectations of building staff?
c. characteristics of decision makers?
d. parental involvement and priorities?
e. belief systems of practitioners?
f. available program alternatives?
3. What are the perceptions across district socio-economic level of teachers and principals regarding the use of retention as an intervention for students in each of the following areas: 

a. its success/failure with students?
b. the effect of current research on its use?
c. as an intervention option?

\section{SAMPLE}

The sample for the study included 12 elementary schools selected from a pool of over 30 potential elementary schools within four suburban school districts. The survey and interview sample populations were drawn from schools ranging from 275 to 650 students. A stratified sampling was done on the basis of low, medium, and high sEs index and achievement. This resulted in groups of three to five schools for each socio-economic or status level. School group status was established by the oregon state Assessment results for 1991 (Oregon Department of Education [ODE], 1991) .

Grade level configurations for kindergarten and grade one were not considered in selecting schools. Schools selected were stratified on three major variables:

1. Socio-economic status (SES): based on the percentage of free and reduced lunch eligibility as determined by the federal government; the mobility of the student, determined by the student population enrolling and leaving; and the percentage of student attendance. 
2. Reading achievement test scores: based upon the yearly assessment of third grade students as determined by the 1991 Oregon state Achievement tests (ODE, 1991).

3. Math achievement test scores: based upon the yearly assessment of third grade students as determined by the 1991 Oregon State Achievement tests.

The index compiled by the state of oregon provided data on demographics for the oregon state Assessment (ODE, 1991). This index includes composites of free and reduced lunch data, mobility rates, and attendance rates for each school. Following are descriptions of the three variables which determined the comparison group for schools. The SES or socio-economic status of a school is determined by participation in the federal lunch subsidy program based on family income information. Comparison groups were developed for the oregon state Assessment by ranking schools according to the composite demographic of the three variables. The cluster or group of schools which ranked $10 \%$ above and $10 \%$ below each school became the comparison group for that school. Comparison groups for schools which ranked in either the higher or lower 108 of the index, included all of the schools comprising the upper or lower $20 \%$ of schools.

Mobility data provide an overview of the enrollment stability of a school. This data is determined by subtracting the average daily membership (ADM) of a school 
from the number of students (grades 1-12) enrolled during the year. The difference is then divided by the ADM. The resulting percentage is the figure by which the cumulative enrollment, during the year, is greater than the average daily membership. The source for the stability index data used in the 1990 Oregon school assessment was the student Personnel Accounting Report for the school years of 1987-1988 and 1988-1989 (ODE, 1991).

The 1990 Oregon state Assessment was the instrument used to measure student achievement (ODE, 1991). These criterion referenced tests are given in grades three, five, eight, and eleven to measure students' achievement in academic skills in relation to grade level expectations. Some of the schools selected for study may have had differing levels of these descriptive variables which could not be confined to the categories of low, medium, or high. For example, a school might have had a combination of levels such as low SES and low stability but have high student achievement. The researcher categorized such schools into the group most closely aligned with their demographic profile.

Using the Oregon state Assessment index for third grade, the SES range for the high status group was $710-760$ (ODE, 1991). Five schools within two school districts were selected to represent this status group. The two districts, from which the five schools were selected, reflect schools 
in which students consistently perform well above national averages on standardized tests. The academic programs of both districts are strong and known for their excellence. Both represent growing communities where the majority of students come from stable, employed families, characterized by many professionals. Both districts have enjoyed community support of budget and bond issues which has enabled administration and school board to maintain a quality academic program while increasing school sites to accommodate growing populations.

Again, using the oregon state Assessment index for third grade, the sEs range for the middle status group was 660-680 (ODE, 1991). Three schools within one school district represented this group. This district is characterized by its dramatically increasing student population and large schools. It spans a suburban area in which numerous new industries are located. The accompanying residential growth has resulted in boundary issues for the district whose student population exceeds either of the high socio-economic school districts. Many professionals are members of this community with middle class families well represented. Although growth appears to be the major concern for the district, students taking standardized tests continue to exceed state and national averages.

Lastly, the SES index from the oregon state Assessment for the third or low status group of schools is 185-335 
(ODE, 1991). This group is represented by a large suburban district, the largest in area and student population of the districts studied. It is characterized by a mainly middle and lower middle class population with relatively few families representing professional occupations. The economic needs of the population are reflected in the significantly higher numbers of students receiving free or reduced lunch and the higher mobility rate of families. Funding programs in addition to the essential core curriculum is a budgetary issue facing this district.

In each of the 12 schools selected, all kindergarten and first grade teachers, and the building principals were surveyed. Non-random interviews were conducted with a smaller representative sample totaling three kindergarten teachers, three first grade teachers, and three building principals (see Figure 1).

Teachers were defined as those certified instructors working either half-time (as in the case of kindergarten teachers), full-time, or teachers of split classes containing first and second grade students. The inclusive characteristic for teachers was the grade level taught, either kindergarten or first grade. principals were defined as the administrators having responsibility for the educational program implemented in the building, the welfare of its students, and the supervision of staff. In no case had a vice-principal been assigned to a selected school. 


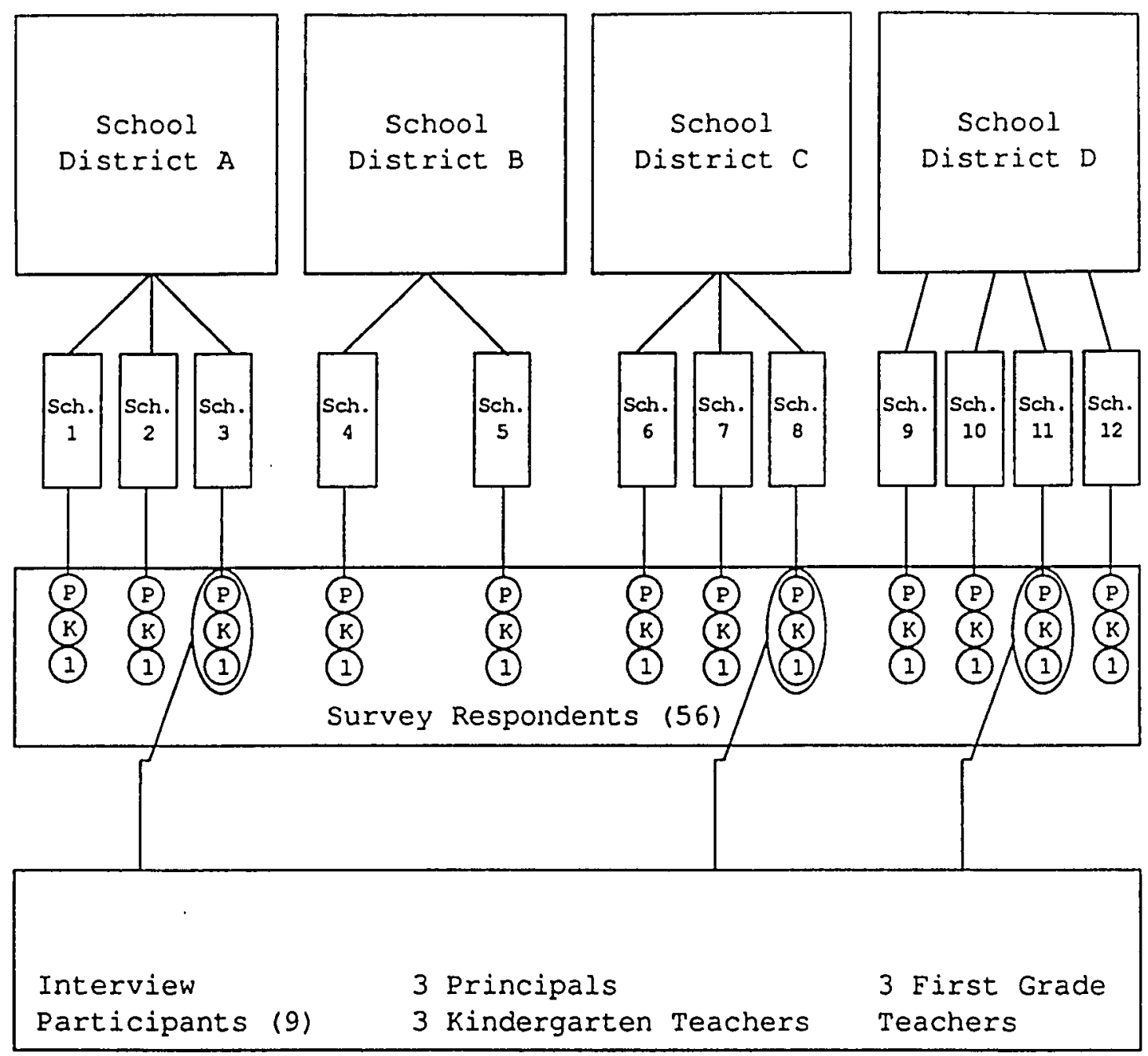

- Four school districts represented high, middle or low socioeconomic levels.

- All kindergarten, first grade teachers, and building principals in 12 schools received a written questionnaire.

- Three schools, one from each of the three socio-economic levels, participated in the interview process.

- One kindergarten teacher, one first grade teacher, and the principal were interviewed from each of the three schools.

Figure 1. Overview of participant selection. 
INSTRUMENTS

This section addresses the rationale for the design and the structure of the survey questionnaire and the interview protocol. Interviews provided in-depth information from a representative sample of educators regarding the research goal. A wider sample of teachers and principals received a researcher developed questionnaire, designed to complement the qualitative focus of the study. Interviews were used to examine the underlying belief systems regarding student retention processes and decisions. Questions were designed to elicit additional information regarding educators' views on slower progressing students and the confidence they expressed in their own ability to impact on the achievement needs of such children. Related questions explored the expectations placed upon teachers for student success, the impact of the curriculum on student achievement, supportive interventions or programs which would impact on retention, and teachers' familiarity with retention research.

Nine interviews were conducted for a critical analysis using an ethnographic interview approach. This method involves identifying significant categories of information as interviews progress. As emerging trends of information are revealed, new lines of questioning result. Information and meanings obtained from interviews serve as additional resources for subsequent data gathering. Which data are 
included and the direction of the process are decided throughout the investigation as similarities and differences surface among the sample. The interview sample for the primary research study included one first grade teacher, one kindergarten teacher, and the building principal representing schools in each of three socio-economic groups. Core questions were structured around the following areas of interest:

1. views or beliefs regarding the efficacy of retention,

2. the use of subjective judgment,

3. procedures used in making recommendations for retention,

4. opinions of the decision making process practiced in their schools,

5. knowledge of current retention research. Open-ended questions provided opportunities for the subjects to discuss in depth their perceptions and concerns. Additional issues raised by the interview subjects were further explored to add richness to the data.

The survey instrument addressed the policies, processes, decision makers, and belief systems involved in retention. The use of actual practices as contrasted to policy mandates was addressed. Survey questions included Likert type, to measure attitudes toward retention and practice, structured items, and demographic information. 
The closed form format of the survey made response easy with completion time estimated at 15-20 minutes.

General information was first solicited regarding the existence of district and building retention policies, how these were developed, who developed them, and if they were used in practice. Two sections of the questionnaire dealt with decision making issues using questions structured with a six choice Likert type scale. A decision making procedures grid was designed to elicit information from principals and teachers regarding their perceptions of decision making participants and the extent of their personal role and responsibility in the decision. The concluding section dealt with the retention beliefs held by teachers and principals and was measured by a five point Likert scale. Participants were asked to react to questions concerning their personal beliefs about the efficacy of retention including which children should be retained and when it was most appropriate. Lastly, educators' perceptions of the reasons for retention and interventions to reduce its use were addressed.

\section{DATA COLLECTION}

This study was conducted in two stages, an initial pilot study and the primary study. Both were composed of two parts, interviews and a survey. Findings from the pilot study were used to finalize methods for the primary research 
stage of the study. The primary stage was composed of a larger and more comprehensive survey and in-depth interviews conducted with individuals from selected job positions and district socio-economic groups.

\section{Pilot study}

The purpose of the pilot study was two-fold. First, preliminary interviews were conducted with selected building administrators and analyzed to target appropriate questions for future, more in-depth interviews with the primary study sample. Information from the interviews also assisted in the construction of the pilot survey. Secondly, the pilot survey provided information for the development of the primary research survey.

The majority of the questions for the pilot study interviews were open-ended, allowing the participants to discuss the topic in depth and openly share their thoughts and beliefs regarding retention practices. Following the first interview, and as new directions emerged during succeeding interviews, the researcher explored and pursued those areas in subsequent interviews. This allowed the respondents to describe fully their experiences and provided the researcher with greater insight into their thoughts, feelings, and beliefs.

Validity for the primary research survey was established by sending an initial pilot survey to teachers and principals outside of the selected school districts. It 
centered around four main topics: (a) personal demographic information, (b) retention policies, (c) decision making practices, and (d) retention beliefs. The pilot survey provided helpful information for the development of the final survey document and increased the likelihood of appropriate and clearly stated questions. Data provided by the pilot survey strengthened the internal validity of the final instrument.

\section{Primary study}

The primary study was conducted in four stages: obtaining school districts' approval for the study, presentations to district and building administrators, survey distribution, and interviews with school staff. Four suburban school districts accepted the purpose and content of the research proposal subject to their input and approval. In nearly all cases, additional presentations were made to individual elementary school principals of the selected buildings.

November was selected for data collection, with presentations made to principals prior to and during that period. This resulted in a variation of time periods for survey as well as interview completion. Distribution of the surveys to staff generally followed the first grading period (November), allowing teachers a time frame more compatible with their schedules. Interviews were completed in December before the winter vacation of the participating school 
districts. Confidentiality was maintained by numbering each survey, with no attempt made to identify individual respondents. All survey responses were reported as status or position data rather than by individual subject or site. Interview information was unidentified other than by category of respondents.

Surveys were delivered for distribution to 60 kindergarten and first grade teachers and 12 principals. A cover letter encouraged respondents to participate in the study. It explained the purpose of the study, the general content of the survey, the importance of respondents' input, and stressed the confidentiality of their responses. A follow-up survey was sent to non-respondents after a two-week period. Personal calls were made to the administrators of participating schools to encourage responses prior to the second mailing of surveys. Reminder cards were sent to any remaining non-respondents at the end of the second two-week period. Although administrators encouraged teachers to respond, participation was voluntary. Copies of the letter to survey subjects and the follow-up letter may be found in Appendix B.

\section{Descriptions of Respondents}

This section provides descriptions of survey respondents by two methods: (a) SES of the school districts and, (b) job of respondents, that is, principal, kindergarten, and first grade teacher. 
As shown in Table I, $88 \%$ of the high status group and $85.7 \%$ of the low status group completed surveys. Only $61.5 \%$ of the middle status group responded. Thus, of the 56 respondents, $39.3 \%$ were from the high status group, $28.6 \%$ from the middle status group, and 32.18 came from the low status group.

TABLE I

DISTRIBUTION OF SURVEY RESPONDENTS

BY DISTRICT STATUS

\begin{tabular}{lcccc}
$\begin{array}{c}\text { Status Group } \\
\text { of } \\
\text { Respondents }\end{array}$ & $\begin{array}{c}\text { Number } \\
\text { Surveyed }\end{array}$ & $\begin{array}{c}\text { Number } \\
\text { Responding }\end{array}$ & $\begin{array}{c}\text { \% } \\
\text { Responding }\end{array}$ & $\begin{array}{c}\text { \& of } \\
\text { Sample } \\
\text { Responding }\end{array}$ \\
\hline High & 25 & 22 & 88 & 39.3 \\
Middle & 26 & 16 & 61.5 & 28.6 \\
Low & 21 & 18 & 85.7 & 32.1 \\
--12 & 72 & 77.7 & 100 \\
Total & & & & \\
\hline
\end{tabular}

The percentages of participants responding according to job position are reflected in Table II. Principals had the highest response rate to the survey with 1008 responding. Kindergarten teachers reflected the smallest percentage responding with $63 \%$, and first grade teachers' response rate was $81 \%$. Classroom teachers represent 798 of the sample and $21 \%$ are principals. 
TABLE II

DISTRIBUTION OF SURVEY RESPONDENTS

BY JOB POSITION

\begin{tabular}{lcccc}
\hline $\begin{array}{c}\text { Position } \\
\text { Group of } \\
\text { Respondents }\end{array}$ & $\begin{array}{c}\text { Number } \\
\text { Surveyed }\end{array}$ & $\begin{array}{c}\text { Number } \\
\text { Responding }\end{array}$ & $\begin{array}{c}\% \\
\text { Responding }\end{array}$ & $\begin{array}{c}\% \text { of } \\
\text { Sample } \\
\text { Responding }\end{array}$ \\
\hline $\begin{array}{c}\text { Kindergarten } \\
\text { Teachers }\end{array}$ & 24 & 15 & 63 & 26.8 \\
$\begin{array}{c}\text { First Grade } \\
\text { Teachers }\end{array}$ & 36 & 29 & 81 & 51.8 \\
$\begin{array}{c}\text { Principals } \\
\text { Rincipals }\end{array}$ & 12 & 12 & 100 & 21.4 \\
\hline
\end{tabular}

The total response to the survey was $73.3 \%$ for teachers and $100 \%$ for principals. The total survey return from the combined categories of participants was $77.7 \%$. This relatively high rate of response may be due to the personal presentations made to building principals, the high interest of the targeted population, or to the responsibility felt by teachers following their principals distribution of the questionnaires. Ary et al. (1985) note that a 70-90\% survey response could be considered a realistic expectation. Babbie (1990) offers a more conservative view with a response rate of 508 to be adequate, $60 \%$ good, and $70 \%$ very good.

subjects for interviews were selected non-randomly from buildings in each of the three socio-economic groups. All four school districts were represented. Schools 
selected for the interview process were determined either by the district's central office administration, by volunteering, or requested by the investigator. Each study participant was contacted individually by telephone to discuss the interview process, the confidentiality of the process, and to arrange the interview appointment. In all cases, interviews were voluntary and conducted with building principals and teachers at their convenience. The interviews were audio-taped with the participant's consent and their confidentiality was maintained throughout the process of transcription and study. In no case was the district, school, or any individual's name identified. In all, three kindergarten teachers, three first grade teachers, and three building principals were interviewed (see Figure 1).

\section{RESEARCH FRAMEWORK}

This section discusses the theoretical framework for the data analysis procedures of the study. The primary research method was ethnographic interviews of nine respondents who represented the views of principals and teachers. Supporting the primary method, the survey responses from 56 principals and teachers were used to provide additional information which resulted in a more complete analysis. The interaction of interview and survey 
information allowed the researcher to obtain a broader perspective of the problem and its meaning for educators. The method of interviewing used in this study was modified from the ethnographic approach espoused by spradley (1979) and the concept of grounded theory as discussed by Glaser and Strauss (1967). According to Glaser and strauss, one of the objectives of theory is to provide perspective on behavior. Discovering data previously unexplored provides the researcher with additional feedback and new lines of questioning for subsequent informants. Glaser and strauss contend that emerging categories of information have more relevance in generating theory than merely selecting data to fit existing theories. If the latter were done, the possibilities for new perspectives or theories would be limited. They define categories as concepts about the problem which become apparent as research data are analyzed. As these categories become saturated, or yield less and less new data to the researcher, they become core or central categories. Core categories have the most significance in impacting on the emerging theory. The continuous comparison and analysis of data serve to reduce and focus core categories and integrate contradictory data.

Similarly, in his discussion of cultural themes, Spradley (1979) provides the following definition: - . any cognitive principle, tacit or explicit, recurrent in a number of domains and serving as a relationship among subsystems of cultural meaning. (p. 186) 
Cultural themes provide a structure to connect existing domains (categories of cultural symbols) or determine relationships among domains. They are used to allow a broader view of the relationships between principal actors in a study. The cognitive principles underlying the belief systems and practices of the informants in this study will be analyzed and compared for their relationships.

Spradley (1979) describes ethnographic analysis as ". . the search for the parts of a culture and their relationships as conceptualized by informants" (p. 93). It is used as a strategy in discovering grounded theory as described by Glaser and strauss (1967). Spradley divides potential questions into three divisions: (a) descriptive questions, telling about a process or event; (b) structural questions, breaking an event into its parts or stages; and (c) contrast questions, discovering definitions or what the informant means. The interview process is designed to reveal information about events which cannot be witnessed and which indicate informants' views or opinions about events (Spradley, 1979).

Interviews provide data from which the researcher can analyze emergent trends and concepts (Glaser \& strauss, 1967; Taylor \& Bogdan, 1984). Significant categories of information become defined as interviews progress. As emerging trends are revealed, new lines of questioning result. Information and meanings obtained from interviews 
serve as additional resources for subsequent data gathering. By this modification of questions, the investigator proceeds until categories are exhausted or saturated. Which data are included and the direction of the process are decided throughout the investigation as similarities and differences surface among the sample.

Schatzman and strauss (1973) suggest a framework be developed by the interviewer and used to discover information, views, meanings, processes, and perspectives from each conversation. The development of an interview guide is helpful in establishing how questions will be stated and in what order they should be asked (Taylor \& Bogdan, 1984). Accordingly, such a guide was used for this study containing the three main categories of ethnographic questions (see Appendix $c$ ). This ensured that key areas would be covered in each interview and also served as a general script for the researcher.

\section{DATA ANALYSIS}

\section{Analysis of the Interviews}

Taped interviews were transcribed and the analysis processed by the software program, Ethnograph (Seidel, Kjolseth, \& Seymour, 1988). Ethnograph offers an efficient way to organize qualitative data for later analysis. In using Ethnograph, transcripts are numbered line by line and codes are assigned according to the category of the 
responses. Such a systematic organization of the data allows for a greater concentration of time for data analysis and interpretation. Following the coding of the interview transcriptions, the researcher can use single codes or a combination of codes to retrieve data for analysis using any of several code combinations.

In this study, data was retrieved according to status groups (high, medium, and low socio-economic school districts), position groups (kindergarten teachers, first grade teachers, or principals), or a combination of these groups. For example, responses from kindergarten teachers (position group) in a high achieving school (high status group) could be analyzed with responses from kindergarten teachers (position group) in a low achieving school (low status group).

Key concepts and categories will change as the research progresses and as the data are analyzed. The final list of code categories used in this study may be found in Appendix c. In summary, the key categories related to: process used in retention decision making; (b) roles of educators, parents, and students in the process; (c) reasons for the process selected; (d) causes of retention; (e) ways of reducing retention; (g) belief systems of educators; ( $g$ ) support systems, and (h) knowledge of the research. The script provided an outline for core questions. The content of interviews varied as subjects expressed 
concepts, ideas, or views which the interviewer judged to be of importance. Positions held by the school personnel interviewed, and which impacted on behavior, were addressed as themes reflecting school culture or belief systems. These themes were analyzed through the ethnographic method.

\section{Analysis of the Surveys}

Survey data were coded and analyzed by using SYSTAT (1990), a computer program designed for the interpretation of quantitative data. Information regarding differences between job groups and socio-economic levels of schools were contrasted with findings from descriptive data. Influences of descriptive data on retention process were explored. The subsequent analysis discussed in Chapter IV contains information surfacing from the two approaches and reflects the dynamics of those data on decision making processes and retention practice.

\section{SUMMARY}

This chapter reviews the methodology used to explore and describe the practices and beliefs of teachers and principals in retention decision making. Two formats, interview and a survey questionnaire, provided information from respondents in three job groups (kindergarten teachers, first grade teachers, and building principals) in high, middle, and low socio-economic school groups. Information from nine in-depth interviews and the survey responses of 56 
practitioners were addressed as a whole, demonstrating the interaction of beliefs, practices, and processes of decision making.

Research was conducted in two stages, a preliminary pilot study and the primary research study involving interviews supported by a questionnaire. An ethnographic approach as discussed by Spradley (1979), Glaser and strauss (1967), and Taylor and Bogdan (1984) was used for collecting interview data. The investigator designed the supporting survey to examine trends and to assist in developing a more complete analysis. The resulting data were analyzed with the computer program SYSTAT (1990) used with questionnaire information and Ethnograph (Seidel et al., 1988), a software program for qualitative data analysis.

The analysis of the interview and survey data in Chapter IV is presented in three sections. First, narratives describe each of the school districts represented in the study and their retention policies. Second, narratives of the nine study participants are grouped by socio-economic level in a discussion of retention practice. Last, the research goal and accompanying questions described in this chapter are addressed. 
CHAPTER IV

\section{PRESENTATION OF THE DATA}

\section{INTRODUCTION}

This chapter provides survey and interview data used to address the research goal and supporting questions. First, descriptions of the retention policies of four school districts are presented. These school districts represent the three socio-economic status groups as described in Chapter III. Survey data describe the perceptions of kindergarten teachers, first grade teachers, and building principals regarding district and building policies and their implementation.

The second and major section of this chapter presents in narrative form the perceptions of three principals, three kindergarten teachers, and three first grade teachers. Discussion focuses on their perceptions of retention decision making, the major influences they view as impactirg on retention, and their beliefs in the practice. Verbatim accounts have been used to portray the thoughts and feelings of practitioners as they reflected on their experiences. The last section of this chapter discusses the use of retention as an intervention. Survey and interview information was used to examine responses regarding the 
success or failure of retention as an intervention, the effects of research on its practice, and the effectiveness of retention as an option for increasing academic success.

\section{DESCRIPTIONS OF SCHOOL DISTRICT POLICIES AND PROCESSES OF RETENTION DECISION MAKING}

This section provides descriptions of school districts' socio-economic status (SES) and the retention policies which have been developed for use in their schools. The four school districts within the three groups of high, middle, and low SES status also vary in their size, wealth, growth factors, and the general achievement of their student populations. They are similar with respect to their suburban location near a large and growing oregon city. The length of time their retention policies have been in use varies from 2 to nearly 10 years.

A study by Rose et al. (1983) indicated that retention policies reflected an awareness of and an adaptability to differences in student progress. These researchers found that most of the policies in the study included one or more of the following four criteria:

(a) students' current achievement level; (b) personal and home factors such as chronological age;

(c) what is "in the best interests of the student"; and (d) the number of times the student has been retained. (p. 203)

The district policies discussed here reflect, in part, some of the attributes found by Rose et al. (1983). The philosophies of the respective districts are expressed 
concerning their expectations for student achievement and their standards for promotion/non-promotion. Indirectly, these policies indicate the direction each district takes for students who present special learning or achievement problems and the degree of their acceptance of retention research.

A brief description follows of each of the districts' (a) description, (b) retention policy, and (c) guidelines for practitioners.

\section{DISTRICT ONE}

\section{District Description}

This is a small and wealthy school district. Three schools represent this district known for its quality educational program and the strong support of the community. students consistently perform well on state and national assessments.

\section{Retention Policy}

This district permits the retention of students when it is considered beneficial in the best judgment of teachers and the principal. The policy requires the written consent of the child's parents or guardian.

\section{Guidelines for Practitioners}

Procedures are outlined which give practitioners step by step directions regarding requirements in the retention 
process. A time-line and the use of the Light's (1977) Retention Scale, or a similar assessment, is mandated. A team including the teacher, school psychologist, and principal, is required for the recommendation to proceed. Any resulting written recommendation for retention is subject to parent/guardian approval. Parental agreement, or disagreement, must be in writing.

staff are directed to develop an educational plan for the retained student during the repeated second year. Its development is assigned to the child's current teacher, the next year's teacher, and the school psychologist. Provision is made for the parent to be informed of the plan.

$$
\text { DISTRICT TWO }
$$

\section{District Description}

This is a small and wealthy school district. The two schools included in this study are examples of the district's growing community and progressive educational system.

\section{Retention Policy}

This district's policy expresses the expectation of normal progression through the grades for the majority of children, but recognizes some children may profit from repeating a grade. For retention to be considered, children must be below expectations for ability and grade level. Retention is viewed as a benefit if the child's 
social/emotional growth would not be negatively affected. The district policy expresses the expectation that a child would usually be retained only once.

\section{Guidelines for Practitioners}

Guidelines are outlined which include the development of a time-line, consultation with other staff involved with the child, parent involvement, and an improvement plan developed to provide immediate interventions with the child. If achievement fails to improve after the implementation of the plan, any decision to retain would be determined with the approval of the parent, teacher, and principal.

\section{DISTRICT THREE}

\section{District Description}

This is a large, midale income district. A rapidly growing student population has challenged the district's ability to maintain a strong educational program. The multiple needs of students contribute to the problems faced by this upper middle class community.

\section{Retention Policy}

The expectation of the continuous progression of students through the grades is stated in this district's policy. Discretion is given to staff to make decisions regarding the appropriate placement of children. It is acknowledged that exceptions may occur. The "professional 
team" is given permission to recommend retention if it considers retention to be in the child's best interest.

\section{Guidelines for Practitioners}

Decision making procedures are somewhat non-specific with regard to a time-line. Notification to the principal by the teacher and communicating the school's concerns to the parent are prescribed but with latitude for when they occur. Any final decision to retain remains with the parents. If in disagreement, parents must signify their refusal by a written release of responsibility statement.

\section{DISTRICT FOUR}

\section{District Description}

This is a large, lower/middle income district. The needs of the district are reflected in the diverse and growing student population. Areas of disadvantaged families challenge district schools in maintaining a quality educational program for students.

\section{Retention Policy}

This district's policy reflects the expectation for students to be on or above grade level. Retention is an option for children unable to make sufficient academic progress. 


\section{Guidelines for Practitioners}

Teachers have the responsibility for making the recommendation, to notify the principal, and to discuss the recommendation with parents. No time frame is outlined for the retention process. Parents have the final decision and are required to sign a statement absolving the district from responsibility if they disagree with the school's proposal for retention.

\section{PERCEPTIONS OF DISTRICT RETENTION POLICY BY TOTAL POPULATION}

As shown in Table III, the majority of survey respondents, 63\%, agreed a district retention policy existed. Combining the no responses of $23 \%$ and the unsure responses of $14 \%$, reveals $37 \%$ of all respondents are unclear regarding a district policy as reflected in Table III.

TABLE III

DISTRICT RETENTION POLICY BY TOTAL POPULATION

count 8

A. This school district has a written retention policy.

No

Yes

Unsure

TOTAL
13

35

8

56
23.2

62.5

14.3

100 
Table IV reflects the perceptions of educators regarding policy development. As is shown, more respondents (27\%) selected a district committee as the method used to develop their district's retention policy than any other method.

TABLE IV

DEVELOPMENT OF DISTRICT RETENTION POLICY

count

q

B. This policy was developed by*:

Principals 5 8.9

Central office Staff 5

8.9

District Committee

15

26.8

Unsure

13

23.2

*Count does not reflect 56 since not all respondents answered.

Other survey data reveal that, from the total sample responding, 548 thought that $90 \%$ or more of the staff followed such a policy. Regarding parental involvement in retention decision making, $63 \%$ indicated parents usually or always participated in the process and $63 \%$ also believed the district policy usually or always allowed parents to challenge the decision to retain.

Discussing these questions by high, middle, or low SES groups reveals a different perspective. As shown in Table 
$V$, $50 \%$ of the middle SES group reported no district policy existed. More than any other SES group, 22.28 of the low SES group were unsure about a district policy. of the high SES group, $81.8 \%$ agreed their district had such a policy.

TABLE V

DISTRICT RETENTION POLICY BY DISTRICT STATUS GROUPS

\begin{tabular}{lccc}
\hline $\begin{array}{l}\text { Status Group } \\
\text { of Respondents }\end{array}$ & q Yes & \% No & \& Unsure \\
\hline A. This school district has a written retention policy. \\
High & 81.8 & 9.1 & 9.1 \\
Middle & 37.5 & 50 & 12.5 \\
Low & 61.1 & 16 & 22.2 \\
\hline
\end{tabular}

The development of the district retention policy as reported by SES status groups is reflected in Table VI. Reporting that a district committee had developed the district policy were $41 \%$ of the high status groups, $25 \%$ of the middle, and $11 \%$ of the low status groups. Most unsure were 448 of the low status groups.

The high SES group also perceived that parents had a larger role in the decision making process than other groups. Responding from the high status districts, $82 \%$ indicated district policy allowed parent involvement, 
compared with $38 \%$ of the middle groups and $50 \%$ of the low status groups.

TABLE VI

DEVELOPMENT OF DISTRICT RETENTION POLICY

BY DISTRICT STATUS GROUPS

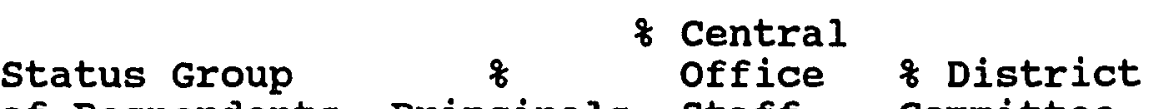

of Respondents principals staff Committee $z$ Unsure

B. This policy was developed by:

$\begin{array}{lcccr}\text { High } & 13.6 & 22.7 & 40.9 & 18.2 \\ \text { Middle } & 12.5 & -- & 25 & 6.3 \\ \text { Low } & -- & -- & 11.1 & 44.4\end{array}$

PERCEPTIONS OF INDIVIDUAL SCHOOL RETENTION POLICIES AS REPORTED BY THE TOTAL SAMPLE

From the total sample responding to the existence of individual schools having a retention policy, $48 \%$ of those responding believed their school had a written policy, 27q responded their school had an unwritten policy, and $16 \%$ reported their school had no retention policy.

In response to how this policy had been developed, the highest percentage (32\%) reported a building committee of the principal and teachers had developed the policy, while 218 were unsure of its origin. of the total sample responding, $63 \%$ reported that $90 \%$ or more of the staff followed the school's retention policy. 
The degree of particj.pation by parents was reported in two areas: (a) the requirement of parental consent and (b) who made the final decision to retain. Regarding parental consent, $86 \%$ reported parental consent was always required and $7 q$ reported it was usually required. The final decision for retention was reported by $48 \%$ as being the parents' decision; $25 \%$ stated the decision was made by the principal, teacher, and parent; and $16 \%$ reported the decision was made by the building team.

\section{PERCEPTIONS OF INDIVIDUAL SCHOOL RETENTION POLICIES AS REPORTED BY STATUS GROUPS}

As seen in Table VII, $68.2 \%$ of the high SES status group reported their school had a written retention policy followed by the 38.98 of the low SES status group. An unwritten policy was reported by 31.38 of the middle SES group with 31.38 also reporting a written policy existed. Based on the reports of SES groups in Table VII, two responses appear noteworthy. The high SES group had a much higher response to the existence of a written policy than either of the other two SES groups. The low SES group had a much higher percentage of respondents stating no policy existed at their schools.

More respondents from all three SES groups selected a building team as the method by which retention policy had been developed: $18 \%$ of the high status group, $50 \%$ of the middle group, and $33 \%$ of the low status group. Respondents 
from the high SES group with $32 \%$ were most unsure compared with $6 \%$ of the middle group, and $22 \%$ of the low SES group.

\section{TABLE VII}

INDIVIDUAL SCHOOL RETENTION POLICIES

BY STATUS GROUPS

\begin{tabular}{lccc}
\hline $\begin{array}{l}\text { Status Group } \\
\text { of Respondents }\end{array}$ & $\begin{array}{c}\text { q } \begin{array}{c}\text { No An } \\
\text { Policy }\end{array} \\
\text { Unwritten } \\
\text { Policy }\end{array}$ & $\begin{array}{c}\text { \& A } \\
\text { Pritten } \\
\text { Policy }\end{array}$ \\
\hline F. Regarding a policy for retention, this school has: \\
High & 9.1 & 22.7 & 68.2 \\
Middle & 12.5 & 31.3 & 31.3 \\
Low & 27.8 & 27.8 & 38.9 \\
\hline
\end{tabular}

The majority of all groups report that 908 or more of staff follow school retention policy: $86 \%$ of the high status group, $56 \%$ of the middle status group, and $39 \%$ of the low status group.

The requirement of parental consent was considered always necessary by $96 \%$ of the high SES group, $81 \%$ of the middle group, and $78 \%$ of the low group. As shown in Table VIII, $54 \%$ of the high status group, $50 \%$ of the middle status group, and 38.98 of the low status group believe the parent has the responsibility for the final decision. The low SES group gives as much responsibility to the building team (38.98) as to parents for decision making. 
TABLE VIII

RETENTION DECISION RESPONSIBILITY BY

DISTRICT STATUS GROUPS

$\begin{array}{lccc}\text { Status Group } & \text { q Parent } & \text { \% } \\ \text { of Respondents } & \text { Teacher } & \text { Building } \\ \text { Peam }\end{array}$

$\mathrm{J}$. Who has the final decision to retain a child?

$\begin{array}{lllr}\text { High } & 54.5 & 27.3 & 9.1 \\ \text { Middle } & 50 & 31.3 & -- \\ \text { Low } & 38.9 & 16.7 & 38.9\end{array}$

\section{SUMMARY OF DISTRICT AND \\ BUILDING POLICIES}

The time span since the adoption of the four district retention policies varies from 2 to nearly 10 years. Three out of four districts' policies are five or more years old. None of the policies indicate a revision has been done since their adoption.

District policies share some common features: (a) the teacher's initiation of a recommendation, (b) principal and parent notification, and (c) some form of written acknowledgment by parents regarding agreement or opposition to the retention recommendation. Written parental agreement is necessary in three of the four districts.

Variation is seen in the guidelines for staff. Time-lines, involvement of specific staff members, and the 
use or non-use of assessment instruments are examples. Only one district addresses the use of an assessment tool to aid decision making. The policies of all four districts include statements regarding expectations for student success. Phrases such as "in the judgment of the professional team" indicate an acknowledgment by the district and school board that exceptions may occur and that practitioners may supersede those general expectations.

Survey data indicate differences are present between the high, middle, and low SES district groups regarding the existence of district and individual building retention policy, policy development, and the role of parents and staff in decision making. The perceptions of respondents in job position groups also show variation in their awareness of retention policy and its application. Following are summaries of SES status groups responses to survey policy questions.

High status district groups appear to be more knowledgeable regarding the existence of district and building policy, more likely to believe such policies are followed, and more likely to be aware of district guidelines for parent participation. High status groups are more knowledgeable regarding the existence of building policies, but are most unsure of how such a policy was developed. They are more sure than other groups regarding the requirement for parental consent and most likely to believe 
the parent has the final decision in any retention placement.

Middle SES groups are less knowledgeable regarding district retention policy than other groups. Combining a no response of $50 \%$ and an unsure response of $13 \%$, reveals that 63 of this group are unclear as to the existence of a district policy regarding retention. They are least likely to believe teachers follow district policy and are least likely than other groups to be aware of the decision making role assigned to parents.

Middle status groups believe a building policy exists but are unclear if it is a written or unwritten policy. More than other groups, middle sES respondents give a building committee credit for policy development. Middle groups more than other groups believe parents as well as the combination of parent, principal, and teacher have final decision making responsibility.

Low SES district groups have the greatest percentage of respondents unsure if a district policy exists and are more unsure than any other group of how a policy was developed. Low status groups have the largest percentage of respondents stating their schools have no retention policy. They report fewer teachers follow such policies and assign as much responsibility to building teams as to parents for making the final decision. They are least likely of the 
three groups to believe parent consent is necessary for a retention to occur.

\section{NARRATIVES OF JOB GROUP RESPONDENTS BY DISTRICT}

Following are narratives of principals, kindergarten, and first grade teachers who work within the four districts. These narratives briefly describe their perceptions of the process involved in retention decisions and their views of retention as an option for children. They highlight educators' belief systems, past experiences, and current concerns on issues surrounding retention. Narratives are divided into three parts representing individuals from each of the three job groups within each of the three SES groups of districts.

Keeping in mind the phenomenological approach to the research, the narratives present, as closely as possible, the account as told to the researcher using the respondents' own language. Headings were added by the investigator to organize and add clarity to the discussions as they applied to the research goals. The narrative accounts focus on a discussion of the decision making process, the role of educational practitioners in that process, and the philosophical basis for the approach used in decision making. They address the several influences impacting on retention as perceived by these practitioners as they work within the school setting. 


\section{NARRATIVES FROM THE HIGH}

STATUS DISTRICTS

The high status group is represented by two small and wealthy school districts. The administrator represents one of the two districts with both teachers representing the second district.

\section{Decision Making process}

The process for retention decision making is described in the following section by a building principal, a kindergarten teacher, and a first grade teacher. They represent views of two high SES districts.

The building administrator stressed the importance of using a team process in decision making. Including everyone who has an interest in the child is critical to a good decision. She stated, "It has worked out so well because everybody had a piece of it and some ownership in it. We involved all the teachers who were working with the child." She believed that such a collaboration of staff provided a wide spectrum of expertise in child development, testing, and greater perspective. "I think the more people you have involved, the more opinions you get. The more information you get the better decision is made."

According to the administrator, a teacher/principal based process had probably occurred in the past. The current team concept had evolved from general meetings held to discuss the problems of particular children into the more 
current structured process. "When I came here, they weren't doing anything like this . . . so I started it. . ." and "Now it is mandated that you have a multi-disciplinary team." The team concept is reinforced by directly referring teachers back to the process with such statements as "Well, it needs to go by the team, make sure you get the child on the agenda and let's talk about it." This reliance on a collaborative decision making model reveals her confidence in the value of staff members working together to provide a thoughtful assessment of a student's needs. She would be unwilling to change processes. ". . I wouldn't want to move to anything that involved fewer people."

Her role on the team is "asking a lot of questions" and "making sure that everybody is aware of the information that we have and have access to, and really being a questioner." Support, facilitate, and critique were themes she stressed regarding her responsibility. Her active participation signals that the process as well as the decision are important. "It [the team] is more or less effective depending on how much importance you attach to it." Although the team arrives at a consensus regarding any proposal, recommendations for retention are subject to parent approval and support. The principal has never retained a child over a parent's objection. The principal considers the teacher not only the initiator of the process but having important information 
for the team. Decisions are collaborative, since "the team wouldn't make a decision without the teacher, because the teacher is part of the team." She advises teachers to develop a philosophy about children and their progress but to be realistic regarding what children face as they move through the grades.

Teachers involved in this status group emphasized two key elements in decision making: the significance of the teacher as a member of the building team and the importance of the teacher's role as a key communicator in retention decision making.

From the kindergarten teacher's perspective, the classroom teacher is the pivotal person in retention decisions even if a team process is used. "To me, they [the team] can't be an active part, they can only give me another piece, or the parents and I another piece so that we can make this decision." Assessments by other team members do not always coincide with her view of the child. "Sometimes the testing is very good but I still feel the child is socially just lost. other times, the testing to me doesn't reflect what I see in the classroom." She reasoned that other specialists report on what they have tested, while she, having worked with the child all year, held a more comprehensive view of the child's progress. "If they haven't had a year's experience with the child I don't know what they can tell." 
She contrasted the more teacher directed decision making process used in the past with the current team approach. "I used to make the decision with the parents. Things used to be done sort of casually. Now it has become very paper oriented." From her perspective, changing to a team process was probably due to more children being retained than necessary. She speculated that the threat of lawsuits might also account for team rather than individual decisions.

You just need to have yourself covered. You need to have several signatures on there saying this is what we recommend . . . so that they know that it was studied, that it wasn't just one person, a teacher saying this.

Although conceding she liked having the support and information, she thought the informal process she had used in the past would have resulted in the same decisions as those reached by the team.

The first grade teacher relies on informal discussions which frequently take place with team members. This provides her with helpful information in making recommendations. "We get a different look at the child; each person has their own specialty."

She emphasized the teacher's role and responsibility as the communicator in the decision process. This ranged from the initial recommendation to the team to discussing concerns with parents. Although the teacher usually 
communicated the team's recommendation to parents, she emphasized that parents made the final decision.

\section{Influences on Retention}

student characteristics. The principal in this high SES district viewed immaturity as the major descriptor most given by teachers in justifying repeating a grade. While conceding children might need more time, she thought a language-rich primary program would provide children with the basic instruction needed for success. "When it does click in, when it does make sense, it is not going to take him very long to catch up, whatever that means." Children should not be labeled as failures but given the opportunity to move ahead with their peers.

Teachers in this SES group considered the causes of retention to be multiple, though the various descriptors they used indicated immaturity as the focal point for student failure. A kindergarten teacher described a typical case as "if the child doesn't fit in socially... if it is not a savvy child, age wise young." Evaluating kindergarten children consists of many "little assessment kinds of things" where the teacher comes to the conclusion that another year seems necessary. "If they fall low, that is when you would want to retain."

The first grade teacher expressed more concern with academic failure than immaturity. A child who struggled with learning and not finding it [school] fun or who had 
poor attendance might profit from another year in first grade. But if a child was likely to be ridiculed or teased, then retention was not a good idea. In such situations she would promote the child but hope to modify the curriculum for the following year. "I think that it would be best if adjustments could be made in their programs in the next grade." She conceded sending children on who were having difficulty would create a "huge adjustment" for them. In general she would:

- . look at the age, the development of the child, and the environment that the child came from. Then, of course, I would look at if she was having difficulty with her studies."

Curriculum Expectations. Teachers, who work daily with and among their colleagues, have a unique perspective on the expectations of other staff. A kindergarten teacher elaborated on the curriculum expectations of first grade teachers and their influence on kindergarten instruction. Although believing in and using developmentally appropriate practices, the knowledge that a similar philosophy was not shared by the teachers in the next grade tended to shape and restrict her instructional program.

They have had a really rich choosing environment in kindergarten. Then you get into first grade and it becomes, well it is much more teacher directed projects. Much more working at your desk kinds of things.

She felt pressure from other teachers and observed that additional expectations in kindergarten were "too great for children." Her speculation as to the origin of these 
expectations ranged from the "state department" to textbooks. "Are textbook adoption companies ruling what we instinctively know is right for children?"

She reasoned that retention as a practice helped to reinforce higher first grade expectations. Holding students back resulted in passing on an older group of children. By sending children to first grade who were not quite ready, those expectations would not be reinforced.

Unless I think it extreme, I am sending on more children now than I used to. It is probably frustrating to first grade teachers, but in my heart of hearts I think we have got to continue to do that. . - . I think we are not doing what we are supposed to be doing. We are not teaching children where they are, we are wanting children to be where we are. If we could really get that, I think there wouldn't be a problem . . . But we have these expectations and where they are isn't right.

Her frustration extended to the school district's kindergarten program. "There is nothing wrong with any of the programs they have adopted except that I have only got the children for two and a half hours and I am supposed to give them choosing time." Her concerns were expressed by her questions. "Couldn't kindergarten not have to worry about so much? couldn't kindergarten be more like preschool? Couldn't first grade be more like kindergarten?" She perceived schools, teachers, and parents were racing to have students read and suggested a slower approach.

In fact, I think children without us doing anything would learn to read, except those few that have real learning disabilities would learn to read at the end of second grade without us doing reading groups and all that kind of thing. 
The first grade teacher viewed a lack of achievement in the basic skills, including students who were achieving but struggling, would be factors for recommending retention, Going on to the next grade "with the fringe" might be possible if support staff were available to give individual help. Reading achievement concerned her more than math achievement when considering non-promotion. She coupled the negative effects of a retention with the observation that adjustments should be made in the second grade program to accommodate slower students.

Characteristics of Decision Makers. The principal viewed changing practice more a process of educators' doing what educators preach and looking at issues very carefully. She stated that teachers have become more knowledgeable regarding developmentally appropriate practices and discuss issues with colleagues. She observed that increasing numbers of building principals have advanced degrees. The information they share with other educators has a significant influence on the re-educating of practitioners. "I think that has made a major impact on what is happening with schools." She advocated developing study groups, providing research articles, and initiating discussions as ways to challenge old patterns of believing and behaving. "Teachers ought to be doing for kids what a principal ought to be doing for the teachers, make it easier for them to learn." 
A kindergarten teacher pointed to her continuing education as changing her philosophy to a more developmental approach. She felt pressure from colleagues and wished for confirmation from "above" that her emerging new approach was the appropriate one to pursue. She stressed the necessity for educators to have a "vision" but saw this as difficult to achieve because of their immersion in the system. Parent Involvement. Parents' involvement with their children's education was viewed by both teachers and principals as highly important. The principal educated her parent group by using the same processes she had used with teachers. That is, she provided parents with articles on educational issues and discussed these at parent study group meetings. In this way, parents were made aware of the concerns facing their children and their children's teachers. Increasing parents' knowledge regarding appropriate expectations and developmental practices created a better climate for an acceptance of their children's progress. "Parents need to be accepting enough to know that it is oK if their child's reading ability is not there yet." Because parents frequently had negative school experiences, the kindergarten teacher would oppose retaining a child if she sensed any parent opposition. The first grade teacher stressed the impact of parental nurturing. She thought retention was caused by children not receiving sufficient time and attention from their parents. She saw 
children needing more security from parents and time to share their school experiences. Parents who neglected to do so because of their "self-centeredness" or who did not reinforce the importance of school contributed to children's problems.

Retention Belief Systems. Belief systems underlie and help to explain educational practice. According to smith (1989), the articulation of belief systems is difficult for some educators and their beliefs are usually expressed in what Smith discusses as practical knowledge (Shepard \& Smith, 1989). That is, teachers and principals refer to personal experiences as examples explaining their beliefs. Some respondents in this study also related examples to the researcher in explaining their rationale for the retention decisions they had recommended.

The principal in this high sEs group expressed her belief that retention probably helps some children. This assertion was tempered by an awareness of her inability to predict the few children retention would benefit. She stated, "I don't feel as if I am that accurate. I have real reluctance to repeat any child." She observed that a flexible grade structure or multi-grade classrooms within the first three years of school, would be one way to allow time for maturation and the development of learning skills. It would also accommodate the time educators need to make appropriate assessments. ". . by the time those kids are 
finished third grade, you are going to know pretty well whether or not they are ready to keep going." current information regarding the negative impact of retention on dropout statistics had increased her reluctance to retain. The kindergarten teacher believes the system fails to act in the best interests of children or their progress. That failure justifies retention, with limitations, as being permissible providing all involved agree it would be in the child's best interest. The system would need to change before she could abandon the practice altogether.

I would just have to say, I really don't know. Given where we are right now, yes, I guess I would have to say it is OK for some kids. Because of the expectations. If we could somehow lower our expectations . . I don't know, it is tough.

She cited research as a factor against retention. "Research is showing that it does damage, that it really maybe isn't proven to help them." The awareness of retention literature is due to her recent education classes and professional development. She stated,

All of those NAYC (National Association for Young Children) conferences which I have joined and I go to the meetings and things like that. All of that is starting to sink in. So you are constantly frustrated.

Self-esteem was the deciding factor in whether this teacher made a recommendation to retain. If retention would damage a child's self-esteem, she would oppose repeating a year. On the other hand, if she believed a child's self-esteem would be enhanced, she viewed the retention as 
"an important thing to do." She recalled a student she had previously retained and his reaction to the retention.

It has never left him. Some kids that have been retained, it is just like they just started school late. They don't think of it as being held back. He doesn't forget it. So I really don't know if it was a wise thing to do for him. He is going to carry it all of his life.

The final, following comments reveal her confusion between her understanding of what is best for young children and the reality of what she perceives children face in school.

That is where I don't know what to do any more. Like I said, in the big picture I want to send them all on, and I want them to take them where they are. It is a "we/they" . . . I hate that. Then I want them to provide a program so that these children don't have to feel bad. If you are doing developmentally appropriate programs, nobody would ever ask a child to do something they can't do. No teacher does that. So you put them in a group with children that are like them. You put other children together in a group with children that are like them. What ends up happening, is they do feel they are not doing it as quickly as somebody else. Nobody is saying that is wrong, except the children start feeling that. So what can you do? I don't know.

The first grade teacher expressed ambivalence in her belief in retention. This had been tempered by a personal experience with her own child. She was aware of research which did not support retention and asserted research showed it had little positive impact on academics and a great negative impact on self-esteem. She decided that retention might be considered if a student was struggling with work but not a good decision if the student had strong feelings 
against it. She indicated she had not followed the progress of any of her previously retained students.

Program Alternatives. To prevent retention, the high SES administrator believes children need exposure to a quality learning environment at an earlier age. She is convinced that schools must begin to offer what homes and preschools do not provide. "We are seeing a real need for children to be exposed to more enrichment earlier. You know, we are talking about three, four, and five year olds instead of just six year olds." The implementation of both a preschool program and an all day kindergarten program in the public school setting could impact both maturation and the earning program already in place. While conceding that physical maturation such as physical size or motor control, which are often reasons children are retained, would not be affected by what is done in schools, she emphasized, ". . you can sure change the other ones!"

Teachers in this group were both philosophical and practical in their suggestions for reducing retention. A first grade teacher suggested an assistant in the classroom, either paid or volunteer, would make a difference in children's progress. She also supported greater flexibility in adapting programs to children's levels of learning. The kindergarten teacher suggested the use of more developmentally appropriate practices and an ungraded program for kindergarten through the third grade. She 
supported a longer kindergarten day to accomplish tasks and decrease the pressure she now experiences. Reducing curriculum expectations would also lessen the retention problem. "If we could just realize they are all gifted in their own way, and they will make it. So don't worry when."

\section{NARRATIVES FROM THE MIDDLE STATUS DISTRICTS}

The middle status group is represented by a large, moderately wealthy district. The rapidly growing community provides a challenge to the district to expand programs for an increasing student population while working within a restricted budget.

\section{Decision Making Process}

The decision making process used for retention recommendations is described in the following section by three position group educators, a building principal, a kindergarten teacher, and a first grade teacher from the same middle SES district.

The principal believed a team process for decision making had resulted in more responsible decisions. Although he conceded that the more involved process might hinder a teacher from approaching the team, he did not think it had done so. "It has been a role of the teacher almost welcoming some more information." He had considered formalizing the process with a written policy but expressed 
the concern that this might "send a message to teachers that they ought to be retaining more kids." Although he thought retention was of benefit to only a very few children, some students were currently being considered for repeating a grade.

In his view, the team process is valuable for several reasons. He speculated that teachers are often so close to the child's problems that new information tends to be filtered out through their already established perspective. A mind set for retention established early in the year might lead the teacher to concentrate on convincing others to support her conclusion. By having other staff assess the student, the teacher would have an opportunity to consider different perspectives and new information. Another benefit was the variety of options team members could develop to help children with learning problems. He observed that using a team process avoided decisions based on "intuition" or "one person's observations."

The kindergarten teacher also judged the decision making process to be currently more of a team approach. Her prior experiences with other principals had been that of principals making decisions based on their philosophy of retention practice. She considered a retention decision so difficult that she welcomed input and direction from the team. A joint decision relieved the teacher of some of that difficulty. She believed parents were also more comfortable 
with a team recommendation rather than one made by an individual.

It is really a heavy decision. I think it is one of the hardest and most difficult decisions for a teacher to make. Those qualified people involved make it a little bit easier, and ease your mind a little bit that you are not the sole person making this decision. I am making decisions that are going to affect the whole rest of their lives.

She defined the classroom teacher as the key decision maker in the process. "I just don't feel unless you have worked with the child closely, you don't know." The principal might attempt to give support, but in her view that person was not able to do that unless he or she had a background in kindergarten teaching or in early childhood education. Although she believed her years of experience enabled her to make better judgments, she considered each retention to be an individual decision. "There is no textbook retention, there is no textbook child."

Although she agreed with the team process, she expressed the determination to do what she thought was right. She recalled a past experience with a principal who had opposed any retention and how she had persevered. "There is no way someone is going to tell me that I am wrong when I know that I am right." she stressed the importance of parental agreement with any retention decision and felt her role was to "guide them." Without parental agreement, retention would not be successful because "I think in the long run the child would suffer tremendously." Parents who 
wavered with the decision gave her the most difficulty. Then she felt she must convince them this was right for their child. "Then you do feel really alone." Her dilemma was that although she considered the kindergarten year to be the time to retain, "it is also the hardest to decide. How do I know that next year they are just not going to bloom?"

\section{Influences on Retention}

Student Characteristics. To the principal, student characteristics which might justify a retention are large blocks of poor attendance, a younger age with a lack of maturity, or a lack of background experience prior to kindergarten. Balancing these is the possible damage retention might cause to a child's self-esteem. He recounted an encounter with parents whose previous experiences with retention had affected their perspective. The parents related stories of a student who had been teased and "never getting over it." While the principal believed there was some truth to the possibility, he believed taking a positive approach would be more helpful. He admitted, "when I have conversations with sixth grade kids they talk about being retained, and they often refer to it as flunked." He feels it is important that children view retention as another chance to succeed and "as a kind of relief and another chance to do something."

Criteria which centered on maturation and children who are "just slower and just taking a longer time to catch up 
to where the other kids are," were important to the kindergarten teacher. Typical characteristics would be a lack of fine motor skills, poor social development, crying easily, and unable to attend or stay on task. In recounting the difficulty of retention decision making, she returned to the term "youngness." She equated "youngness" with immaturity, and the main reason she would recommend retention.

The first grade teacher considered a child's potential. She would be reluctant to retain a child only for reasons of immaturity but if immaturity was accompanied by poor achievement, she would be more concerned. She spoke of the value and the connection between a supportive home environment and school in reinforcing student success and believed students reflected their background of experience.

Curriculum Expectations. The principal saw a need for supporting teachers as they worked with students having a wide range of abilities. Developing that instructional support base concerned him.

. . The teachers that have the largest variety of teaching strategies available to them that they understand and they can use, that those teachers are dealing with it just fine. But teachers that are looking at the three options of standard ability grouping, individualization, or whole group instruction, those teachers are struggling.

He was concerned with the program accommodating the child rather than the child adapting to the existing program. In his view a rich, supportive environment in the early grades, 
with less pressure, would create better attitudes toward learning.

The kindergarten teacher was aware of the expectations of first grade and of comments made by other teachers regarding students who were promoted but not "ready." She had structured her program to contain elements of both academic and developmental approaches to accommodate those expectations. She explained ". . . if my kindergartners were going into a developmental first grade, I would say great. But they don't" and ". . you try to get them as ready as you can."

Instructional methods concerned the first grade teacher. Ability grouping was not practiced in her school but enrichment was provided for capable students and remediation for those who had difficulty. She considered reading to be the important subject to master for promotion. "To me, reading is the key." She did not consider retention to be that much of an issue because she depended on kindergarten teachers to make those decisions.

Characteristics of Decision Makers. The principal expressed his conviction that teachers are not limited in their ability to teach only a certain range of children. He viewed alternative programs, such as transition rooms, not reinforcing that belief and would not consider developing a transition room as an alternative option. "I feel like that is not good in terms of thinking of teachers as lifelong 
learners and continuing to develop and grow and learn new strategies." From his perspective, teachers welcomed and used the additional input received from team members in doing what they believed to be right for children.

The kindergarten teacher had taught multiple grade levels and worked for several principals. Although this background had helped establish her basic belief in using retention, this belief was changing as her awareness of research increased. She reflected on the isolation she experienced at her current grade level. "Kindergarten is not a real big deal to anybody except kindergarten teachers, that is just the way that it has been in every school I have been at."

When a child is having difficulty, she actively seeks input and advice from primary grade colleagues. "I do a lot of bouncing back, telling my concerns and asking how they would do things, because they deal with five and six year olds." She expressed her feelings about making a retention recommendation. "It is a tough decision. Any some you think, 'that was a good one,' and some you think, 'boy, did I blow it."

The first grade teacher also preferred collaboration in decision making and supported parents having the final decision. She approved of the principal's move toward a structured plan for teacher assistance with children having academic needs. Although uncertain about the value of an 
ungraded school model, she supported additional help for the classroom teacher with instructional assistants or a counselor to work with students. She expressed clear ideas about her beliefs and thought her position on non-promotion had remained relatively constant.

Parental Involvement. All respondents in this middle status group stressed the importance of parents both in preparing a child for school success as well as in retention. The principal shared his opinion that many parents had "distorted views" regarding the process stemming from their own or others' past experiences and stressed looking at parent motives in retention and promotion recommendations. Parent support was critical for a successful retention. As the first grade teacher commented, "If you don't havi the support of the parents it is not going to work" and "I don't think it is going to be of benefit to the child at all, if there is that conflict." Both teachers wanted parents to take more responsibility for retaining their child before the child was sent to school. "Parents targeting the child before they even enter school, parents able to see their child was not school ready" was favored by the kindergarten teacher as easier on the child, especially on slower maturing boys. The first grade teacher saw retention being most appropriate in kindergarten or preschool. Many children in the district has preschool experience and she surmised those teachers 
counseled parents with statements such as "you know, you child is just not ready," "he can't sit still and listen to the story," or "they are having trouble interacting with the group." She believed this input resulted in some parents holding their children out of school for an additional year. Retention Belief systems. Having read the research and tracked retained students through the grades the principal stated "it is a questionable practice to use a lot." While there could be a stigma attached to retention, that stigma could be lessened if a child viewed retention as an "opportunity." He expressed optimism that children could achieve and become competent even if they experienced slower process at the beginning of their school career.

The kindergarten teacher's beliefs revolved around her thinking on immaturity and focused on the issue of "time." "It is time and you can't buy it. That is why you can't rush maturation. You can't rush self-growth." Because of her acceptance of the interconnectedness of immaturity and time, she believed neither she nor anyone else could impact it. Only "time" could impact immaturity. "If a child comes in not ready there isn't much I can do. Money and services wouldn't make a whole hill of beans." Children who did not succeed were those who had been pushed into frustration. Reading retention research resulted in reinforcing the anxiety she experienced with retention decision making. 
Careful decisions and early retention were stressed by the first grade teacher. Retention was appropriate at times, especially in kindergarten, but "not very often." For a first grade retention to occur, a child would need to exhibit such a struggle with work, especially reading, that the opportunity to try the grade again would be a relief. Although she thought retention would benefit some children, she cautioned that it would not put them at the top of their class, only reduce their struggle with work.

The potential damage to self-esteem caused her to be cautious about retaining older children.

I think it is very hard, they would have to have a pretty good feeling about themselves and parents that are real positive and even friends that are willing to accept them, one way or the other.

She told a story of a boy who had difficulty with reading after months of struggle and work and it finally began to "click." She wondered, "what if you had sent him on and it clicked in second grade, would you still want him in first?" She thought her beliefs about retention had remained constant during her years in teaching.

Program Alternatives. As earlier related, promoting children who otherwise would have been retained creates problems for teachers who find themselves with students having a wide range of abilities. To support staff as they deal with these issues, this principal is developing a prereferral process to assist teachers with students having achievement problems. Teachers will work in mini teams to 
help each other with a variety of interventions prior to a formal referral to a building team.

Another option was implementing a ungraded primary program and using developmentally appropriate practices to reduce retention. He believed extended day programs, prior to school entry, would provide additional enrichment for children. He had past experience with transition rooms, but indicated he would not develop another. As he described his earlier experience, "It was like we were fitting kids into an existing program that was pretty structured and kind of the same thing for everybody rather than fitting the program to the student."

Alternatives favored by the kindergarten teacher were a June birthday cutoff to create an older class of kindergarten children and, unlike the principal, the development of transition rooms. "I think that really is a perfect situation for many children." This alternative placement would help alleviate students' feelings of failure. Asked if she thought she would retain more children if such a program was available, she replied "Probably, yes."

The first grade teacher considered a recently implemented new procedure to be helpful. A small cadre of staff advise teachers who have students exhibiting academic or behavior problems. Parents are notified before students are referred to this committee. She observed that having to 
notify parents may tend to discourage this particular process. "I guess in the end you would like to be able to fix things and not have to make a big worry to the parents." She did not think other options, such as an ungraded primary or full day kindergarten, were that beneficial.

\section{NARRATIVES FROM THE LOW STATUS} DISTRICT

This low status group is represented by a large and generally poorer middle class district. The community is a growing area of mainly middle class working families with many students presenting economic and educational needs.

\section{Decision Making Process}

This low SES group of educators discussed the value of the team process in contributing to retention decision making, the influence of the teacher on the team, and the importance of having parental agreement with the decision. One principal, one kindergarten teacher, and one first grade teacher represented one school district in this low SES group.

The principal of this lower sEs district considered retention decision making to be a lengthy process, involving discussion by staff, early communication with parents, and assessment of the student. She was usually approached first by the teacher considering a retention. After a discussion and sharing of research, the teacher's concern would either 
be dropped or referred on to the building team. The principal indicated she was most comfortable when these discussions occurred early in the school year to allow time for reflection. "It is a very major decision. I think some time to think about all the pros and cons helps. I see that as one of my really important roles."

The building team, whose usual function is the identification of: special education students, is composed of all of the special education staff, the principal, and the classroom teacher. The principal's role is to give input. Her beliefs on the efficacy of retention revolve around the agreement of everyone involved. As she explained, "I think it only works if the child, the parents, and the teacher all feel it's good, and then we have to be pretty sure it is for the right reasons."

The kindergarten teacher described her decision making process as a documented approach. She collected data prior to making a referral to the building team. All of the collected data, including a completed Light's Retention Scale, would be discussed by the team members. She would change the process only by including an additional classroom teacher. Having a colleague "to come and give me some kind of an idea of what I am looking at, or what they see," would assist her in her assessment of the child. She remarked that retention was often discussed at district kindergarten in-service meetings which was helpful in clarifying 
concerns. The process followed at her building is not necessarily used at other schools.

She preferred non-promotion decisions be made by a team and not solely by the teacher. She recounted her past experiences in which the process was handled by the classroom teacher and indicated a reluctance to have that responsibility totally. "I don't think I have the answers that well, I don't want to be responsible for saying this is the absolute truth and that is the way it is going to be."

She emphasized that parents must agree with the decision to retain or the retention would not be successful. Parents had told her stories of former teachers who had insisted, over parents' objections, that students be retained. She viewed such negative parent attitudes to be detrimental to any real progress a child might make during the second year. "The gains aren't made because the self-confidence is not there, and they [the students] don't care." Only if the parents and the child agreed that retention would be positive and helpful, would the retention be likely to succeed.

The first grade teacher described the usual sequence of events which began with the classroom teacher indicating a concern with a particular student. Parents were notified followed by some kind of an assessment. The results would be shared and a recommendation regarding retention might be 
proposed to the parents. If the parents were in agreement, retention would then occur.

She stressed the team's value in lending support and as a source of information. "We talk about using different approaches to it because nobody learns the same way, of course." The team also provided additional input as well as support for the final decision. "This isn't a decision made by a single person." However, the classroom teacher should have more influence than other staff members. The teacher was the one person who had worked exclusively with the child and was most familiar with the child's lack of progress and problems.

\section{Influences on Retention}

\section{Student Characteristics. Educators in this group} differed in their views of the characteristics of a child at risk of retention. The principal considered appropriate reasons for retention to be (a) a lengthy absence where a student has missed a great deal of school or (b) the very immature child. She considered both of these situations to be uncommon. Regarding absence she stated, "Although even then, if they were mature physically and socially, it would be pretty awkward to do that" and of immaturity, "It is a rare child, because they tend by the time they are maybe fourth grade, to have evened out."

Developmentally younger children with slower social and emotional growth concerned the kindergarten teacher. "A 
development in my mind is the total child, not just one or two academic areas. I don't look at the academics as being my primary reason for retaining." Taking an opposing view, the first grade teacher was concerned with academics and considered retention appropriate for a child having difficulty keeping up with grade level work. "Not everybody can do things at the same rate of speed and there is nothing wrong with having to take a little more time." Her awareness of the impact of retention on self-esteem led her to avoid it if possible. "There is a social stigma."

Curriculum Expectations. In the principal's view an ungraded classroom model would have a positive impact not only on teacher expectations but also accommodate slower students. "I have tried to encourage teachers to think about not getting ready for the next grade, but teaching the grade they are in." An ungraded approach would help reduce the anxiety some teachers felt about the expectations held by the next grade's teacher.

Also helpful in accelerating student achievement was having high expectations, "there are so many studies that show that, too, that if you have high expectations you get high results"; cooperative learning, "it seems to me such a variety of abilities and pretty soon these are the children that are learning a lot"; integration of children, "we are going to start moving kids out of the resource room and into the mainstream because I think the attitude is different"; 
and a mind set of acceleration rather than remediation, "I would like to see it in action."

Teachers in this low SES group echoed the principal's views regarding high expectations. The kindergarten teacher thought some teachers worried about the next year's teachers' comments regarding students they had promoted. She did not consider that a problem for herself but conceded it may have happened to other teachers. The first grade teacher believed the role of early primary education was to hold high expectations even though children came from environments not conducive to school success. She felt teachers must take children where they are and do the best they can.

We can't make up time that the kids lose out on, we have to kind of take them where they are and do the best we can. In our situation, I think that we can't use that as an excuse. That we still have to set expectations. We can't say "these kids are totally deprived and haven't had this or that." so we are just kind of left.

Characteristics of Decision Makers. To explain her views on the appropriateness of retention, the principal reviewed anecdotes from her personal experience and professional background. She underlined her belief in the value of high expectations especially with students having lower achievement. Of special concern to her was what she termed the "mind set" of teaching "middle of the road" children. She described this as being the tendency of teachers to focus on the average child in their instruction 
and to avoid children who were on either ends of the ability spectrum. To in-service the staff, she promotes a research based decision model by providing and discussing examples of research studies with teachers contemplating a retention. Teachers pointed to advanced course work increasing their awareness of research and to personal experiences in shaping their practice. The kindergarten teacher stated she had used in-service opportunities to discuss retention with colleagues having less experience and struggling with the issue. The first grade teacher recounted personal examples in retaining children and critiqued her performance as a teacher whenever a child had difficulty. She used these opportunities to analyze her practice in adapting instruction. "So I think it is an evaluation for me to take a look at what I am doing and maybe make some changes there."

Parental Involvement. Educators viewed the role of parents in nurturing their children a key factor in school success. The building administrator speculated that children came to school unready to learn because parents lacked parenting skills and were unaware of how to prepare their children for formal learning. Children coming from such "deprived backgrounds" must catch up first in areas already a part of other children's experiences. "So many of our children spend their entire first year adjusting to things that a child that has not been in such a deprived 
background, already has in place." The primary years become a struggle as these children work to master skills expected of an average third grader. She stressed these children were not solely from welfare families but from "working parents who have lost sight of their job as a parent." The first grade teacher emphasized the difficulty parents have with working and being under stress. Greater support was needed from schools for working parents and she suggested that school. provided parenting classes would be helpful. This would, in turn, help children be more successful at school.

The kindergarten teacher also put responsibility on parents for preventing retention and felt they should delay their children's entry into kindergarten. "I think that parents should have kept them out of school in the first place, actually. If they knew that child that well, they should have kept them out." Although totally opposed to retention in the upper grades, if she felt strongly a retention should occur with a child at a lower grade level and if it was supported by the parents, she would also support it. Generally, she thought she was more negative toward retention than favoring it.

I am not that strong an advocate of retention. I would say I am much more the other way. I think it is done far too easily and without consideration of what happens at the other end of their learning career. 
Retention Belief Systems. The role of research, views on immaturity, and expectations for student success were central themes in the belief systems of this status group. The principal referred to research as influencing her beliefs over the span of her career. ". . with the research out now, we are not doing too much retention." She did however, consider retention appropriate in limited circumstances. A late entry into school was a better alternative. She referred to studies which indicated that an attitude of high expectations for student achievement yielded high results.

Research had also strengthened the kindergarten teacher's opinion in opposing retention to the extent that she thought it should be reconmended "very, very seldom." This had been reinforced by experience as a special education teacher where she was involved with children who had been retained. "The only thing that was behind was their academics. I used to hear these horrible feelings of self-worth and that kind of thing." The issue most pivotal to her evolving belief had been her experience on how important entering school and then staying with their peer group was to children. She cited her experiences as a mother and her growing awareness of the significance of maintaining a child's perception of himself. She justified retention if it was to provide more time for the child to gain experience. 
But as far as getting over that problem [the learning problem], time is going to take care of that. You are asking them to do things that they are physically, socially, and emotionally unable to do at this time.

In the view of the first grade teacher, immaturity was the most significant reason for retaining a child. She felt the answer to this was time. "I think there just comes that point in time when they are ready. I mean, you can't push them to do something if they are not ready to do it." While she considered children held back for immaturity as experiencing more positive results from retention, negative results would occur if children continued to experience learning problems. "They have never caught up, they are still having troubles." She recounted stories of children experiencing both positive and negative results from being retained, but argued that many of life's decisions have mixed benefits.

program Alternatives. Although some children might need the help of additional programs such as Head start, others would benefit from not beginning first grade if they had a longer kindergarten experience according to this principal. She suggested a preschool experience or a second year of kindergarten as valuable if "they are continuing their progress and they are not repeating the same thing." She viewed this as an alternative to retention and having a different impact on a child's self-esteem. 
Lower class size was perceived as helpful but not realistic. However, before and after school day care, a breakfast program, and changing the presentation of curriculum so that students were more actively involved were all program possibilities. A team to assist teachers was in the planning stages which would help teachers who had concerns about student behavior or learning. This team "will be kind of a pre-referral, pre-consideration, where teachers are trying to be teachers."

Lower class size was very important to both the kindergarten and the first grade teacher in preventing retention. The increased student contact time was seen as crucial in avoiding achievement problems.

If we had smaller class sizes we could all be better acquainted personally with each child and we could help them at their own level instead of pushing them along with everybody else.

The first grade teacher also stressed the importance of programs prior to regular school entry such as preschool or a summer prekindergarten experience. All-day kindergarten and later entry were also considered major ways to avoid retention. "Who is to say that every five year old by the first of september is ready for Kindergarten, or every six year old on september one is ready for first grade?" A longer day, ungraded classrooms, and more teacher assistance were also considered important in impacting children's success. 
RETENTION AS AN INTERVENTION

Using retention as an intervention for slower achieving students or as a remedy for immature students was addressed in the primary study by both the general survey and the interviews. Following are the narratives by teachers and principals from three sES levels of districts regarding their perceptions of retention as an intervention. Addressed will be their views of its success or failure in remediating both academically and social needs, the influence of research upon their use of retention, and their perceptions of the appropriateness of retention as an intervention.

Retention: Successes and Failures

The educators who were interviewed frequently used personal examples in describing their successes with retention. A principal from a high sEs district recalled a mother who was concerned about the progress of her kindergarten child. The principal recounted the events leading the mother to accept her child's slower rate of learning. The principal stressed the need for parent education and cited parent study groups as one way to inform parents about child development and encourage acceptance of their children's educational growth.

Similar views were expressed by principals from middle and low SES districts. A successful retention was one seen 
as an opportunity and a relief for the child who was struggling. It was important for the child to be comfortable with the decision. The administrator from the low SES district considered an agreement by a team of teachers as necessary for a successful retention. "Then it can work." She conceded however, that "You never know if it was better or not bacause you don't see life's parallel." citing a personal example to illustrate her point, she emphasized it was not possible to really know the outcome of a retention decision even after it had occurred since a different decision might have worked out just as well. Teachers gave specific examples to explain their motives for using retention or as explanations for their non-use of the practice. Indecision was revealed by comments both for and against retention. One first grade teacher reflected on a child not making much progress as a candidate for retention. She was both concerned about the negative impact on self-confidence and how difficult it was for students struggling academically. They would "be able to do better by trying it again."

A kindergarten teacher stressed the use of developmentally appropriate practices and "taking them where they are." She felt there was "nothing to this 'not ready' business" and explained if she had only one child not ready to move to first grade, she would be more inclined to retain that child. If a group of children were unready, she would 
be more inclined to promote them. The expectations of first grade teachers were important in her practice of retention/promotion.

Parents' attitudes about retention were seen as critical factors in successful retentions. A kindergarten teacher stated that parents' personal experiences, either positive or negative, caused her to meet with parents during the process of her decision making.

I think if the parents are really behind it and think it is important, then it may work. If it is a threat to the parents, then I don't think it is effective either. They somehow get the kids to feel uncomfortable with it.

Some teachers and principals mentioned the importance of children's views on retention. One first grade teacher stated that not only parents must be positive about retention. The child's friends must also be accepting of the retained student or she would not consider the retention of benefit. A kindergarten teacher recalled a child she had retained.

I asked her, because she was in my room the following year, how she felt about it. And she said, "I have more friends this year." I felt very good about this particular retention. I never questioned whether I made the right decision or not.

Responses to a survey question on the effectiveness of retention in children's success in school are shown in Table IX. 
TABLE IX

RETENTION BELIEFS OF PRINCIPALS AND

TEACHERS--QUESTION 12

\begin{tabular}{|c|c|c|c|c|c|}
\hline $\begin{array}{l}\text { Position } \\
\text { Group of } \\
\text { Respondents }\end{array}$ & $\begin{array}{c}\stackrel{8}{8} \\
\text { Strongly } \\
\text { Agree }\end{array}$ & $\stackrel{8}{8}$ & $\stackrel{8}{\text { Disagree }}$ & $\begin{array}{c}q \\
\text { Strongly } \\
\text { Disagree }\end{array}$ & $\stackrel{q}{q}$ \\
\hline
\end{tabular}

12. Retention is effective in helping children be successful in school.

$\begin{array}{lccccc}\begin{array}{c}\text { Principals } \\ \begin{array}{c}\text { Kindergarten } \\ \text { Teachers }\end{array}\end{array} & 80 & 8.3 & 58.3 & 16.7 & 8.3 \\ \begin{array}{c}\text { First Grade } \\ \text { Teachers }\end{array} & 13.8 & 31 & 17.2 & 10.3 & 24.1\end{array}$

Regarding the statement, retention is effective in helping children be successful in school, the largest group of disagreement was principals, 75\%. Kindergarten teachers had the largast percentage, 60\%, of respondents who were undecided about the effects of retention. Combining the responses of strongly agree $14 \%$ and agree $31 \%$, a total of $45 \%$ of the first grade teachers agreed with retention's effectiveness for success in school.

The perceptions of teachers and principals regarding the role of academic progress in retention are shown in Table $x$. 
TABLE X

RETENTION BELIEFS OF PRINCIPALS AND

TEACHERS--QUESTION 14

\begin{tabular}{|c|c|c|c|c|c|}
\hline $\begin{array}{l}\text { Position } \\
\text { Group of } \\
\text { Respondents }\end{array}$ & $\begin{array}{c}q \\
\text { Strongly } \\
\text { Agree }\end{array}$ & $\stackrel{\text { f }}{\text { Agree }}$ & Disagree & $\begin{array}{c}q \\
\text { strongly } \\
\text { Disagree }\end{array}$ & $\stackrel{\gtrless}{\&}$ Undecided \\
\hline \multicolumn{6}{|c|}{$\begin{array}{l}\text { 14. If a child is struggling } \\
\text { usually in his or her bes }\end{array}$} \\
\hline \multirow{3}{*}{$\begin{array}{l}\text { Principals } \\
\text { Kindergarten } \\
\text { Teachers } \\
\text { First Grade } \\
\text { Teachers }\end{array}$} & - & -- & 50 & 50 & -- \\
\hline & 6.7 & -- & 46.7 & 20 & 26.7 \\
\hline & 6.9 & 3.4 & 48.3 & 31 & 6.9 \\
\hline
\end{tabular}

Two survey questions regarding immaturity were mentioned by interviewees as a factor in retention recommendations (see Table XI).

TABLE XI

RETENTION BELIEFS OF PRINCIPALS AND

TEACHERS--QUESTION 15

\begin{tabular}{lccccc}
\hline $\begin{array}{l}\text { Position } \\
\text { Group of } \\
\text { Respondents }\end{array}$ & $\begin{array}{c}\text { Strongly } \\
\text { Agree }\end{array}$ & $\begin{array}{c}q \\
\text { Agree }\end{array}$ & $\begin{array}{c}q \\
\text { Disagree }\end{array}$ & $\begin{array}{c}\text { Strongly } \\
\text { Disagree }\end{array}$ & Undecided \\
\hline
\end{tabular}

15. Retention is beneficial if a child is young and immature.

\begin{tabular}{|c|c|c|c|c|c|}
\hline $\begin{array}{l}\text { Principal } \\
\text { Kinderqarten }\end{array}$ & -- & 16.7 & 16.7 & 25 & 33.3 \\
\hline $\begin{array}{c}\text { Teachers } \\
\text { First Grade }\end{array}$ & 20 & 33.3 & 13.3 & -- & 33.3 \\
\hline Teachers & 24.1 & 44.8 & 13.8 & 3.4 & 13.8 \\
\hline
\end{tabular}


The majority of teachers, $53 \%$ of the kindergarten teachers, and 698 of first grade teachers, either agreed or strongly agreed with retention benefiting immature students. Only 17\& of principals agreed with 428 of principals disagreeing. The largest undecided groups were principals $33 \%$ and kindergarten teachers, $33 \%$.

Table XII addresses immaturity and retention from a slightly different perspective.

TABLE XII

RETENTION BELIEFS OF PRINCIPALS AND TEACHERS--QUESTION 20

\begin{tabular}{|c|c|c|c|c|c|}
\hline $\begin{array}{l}\text { Position } \\
\text { Group of } \\
\text { Respondents }\end{array}$ & $\begin{array}{c}q \\
\text { Strongly } \\
\text { Agree }\end{array}$ & $\stackrel{8}{8}$ & $\stackrel{8}{8}$ & $\begin{array}{c}q \\
\text { Strongly } \\
\text { Disagree }\end{array}$ & $\stackrel{q}{\text { Undecided }}$ \\
\hline 20. Retentio & allows a & child & time to $\mathrm{g}$ & \multicolumn{2}{|c|}{ and develop. } \\
\hline $\begin{array}{l}\text { Principals } \\
\text { Kindergarten }\end{array}$ & -- & 25 & 33.3 & 16.7 & 25 \\
\hline $\begin{array}{l}\text { Teachers } \\
\text { First Grade }\end{array}$ & 33.3 & 40 & -- & -- & 26.7 \\
\hline Teachers & 20.7 & 51.7 & 10.3 & 3.4 & 13.8 \\
\hline
\end{tabular}

In response to the statement that retention allows a child time to grow and develop, $73 \%$ of the kindergarten teachers and $72 \%$ of the first grade teachers responded either as strongly agreed or agreed. However, only $25 \%$ of the principals agreed, with 50 f responding that they disagreed or strongly disagreed with the statement. Kindergarten teachers were most undecided with $27 \%$ 
responding in that category, followed by $25 \%$ of the principals, and $14 \%$ of the first grade teachers.

\section{Retention: Effect of}

Research

All principals discussed the influence of research in changing retention practice within their schools. A high SES group principal recounted several cases where teachers, through being exposed to research studies, had changed their opinions regarding the use of retention as an intervention. Another principal recalled a teacher who had reduced her recommendations for retention because of research. She told this principal, "I think there may be a place for it, but I would never repeat as many kids as I used to."

Teachers' increasing awareness of developmentally appropriate practices and early childhood literature has modified their reliance on retention. She commented, "that teacher . . did more studying on the early childhood area and what developmentally appropriate meant, and has really done a turnabout." As the principal stated,". . you need to support teachers' belief in themselves" and ". . . I haven't heard anybody mention retention . . . in probably three or four years." She thought administrators with advanced degrees had helped to accelerate educators' awareness of research because of the information they shared from their graduate work. She reflected on the importance 
of experience by commenting that if our reading does not match our experience, we rely more on our experience.

Principals held different views on the amount of retention currently being practiced. A middle SES district principal, after extensive reading of the research, indicated he felt few children would benefit from retention and that it was a questionable practice. He considered that two students, currently being discussed for retention, was appropriate for his large school. A principal from a low SES district thought, because of research, little retention was being recommended in her district. She stressed that her practice is to give articles from retention literature to teachers and parents who might be considering non-promotion.

Although one first grade teacher indicated she had not seen any research on retention, most teachers mentioned research as influencing their practice of promotion/ retention. As a kindergarten teacher from a high status district related,

The way I used to look at retention, was that if there was any doubt in my mind of the child's ability to be successful in first grade or whatever, I would retain them. If I thought they were young and there was any of this I would keep them. I would want to keep them in kindergarten another year just to give them more time. But research is showing now, that it does damage, that it really maybe isn't proven to help them, that we are supposed to be taking them where they are. 
Others gave credit to recent course work influencing their practice. "The little glimpses that I read, it is very negative against keeping them back" and

The research I know is showing that retention is not a plus, it doesn't make that big a difference in their academic standing and that is what we are hoping for, whereas it does make a big difference in the way they feel about themselves.

Research had not always convinced teachers to change their beliefs. A first grade teacher admitted that while she had read some things on retention, her reading had not changed her opinions. "I am somewhat informed on different peoples' feelings. . . I think I still feel the same."

\section{Retention: An Intervention}

\section{option}

A principal in a high sES district group cited information regarding dropout statistics of retained students as an argument against retention. "This is not what we ought to be doing, having a negative impact on kids." She thought any retention decisions should be made individually on individual children. "I think if you could identify the $5 \%$ of kids for whom it would be effective and know that you had the right 5\%, it is probably going to help them." The uncertainty of knowing which students to retain has led her away from using retention at all. She recalled that this direction was prompted by staff members who called her attention to the negative impact of labeling children as failures. 
One principal stressed retention was such a a major decision that she would proceed only if the parents and teacher, after reading some research, still wanted to pursue it. She also considered the child's view toward retention essential, "because if they are uneasy for any reason, it is not going to work either; if they just think they are a failure." This administrator had several ideas for helping parents make decisions. If she sensed retention was a wrong course of action, she would conference with the parents and have them observe their own child and other children. She reassured parents that children were taught at their individual reading or math level regardless of their grade and pointed out the social advantages of staying with the peer group. This was done to relieve any pressure parents felt about advancing their child.

In this district and with the research out now, we are not doing too much retention. I think it only works if the child, the parents, and the teacher all feel its good, and then we have to be pretty sure it is for the right reasons.

A middle sES district principal perceived that parents' views of retention are often distorted because of earlier experiences. The way retention is approached makes the difference in its success. For example, a retention could be managed within a child's home school; moving a child to another building to avoid teasing was unnecessary. Similar comments were expressed by teachers. Retention needed to be accepted as a positive decision. A 
first grade teacher relied on the kindergarten teachers in her building to "take care of it there" but emphasized it was important to be careful which child was retained. Retention should be done early before kindergarten or at the end of kindergarten. A positive retention was when the student expressed a sense of relief with remaining in first grade or if the child and the family were in agreement that it was a positive move ". . something helpful to them and not a failure." As one teacher stated, "And that is what I am hoping, that by retaining someone, that is what I am hoping to give them, the time to develop." If parents expressed strong negative feelings against retention, "I guess I see that as a very strong reason not to retain. If the parents feelings are negative, dead set against, and nobody is even willing to discuss it, then you don't pursue it." Expressing her personal views further, she related:

I am not that strong an advocate of retention, I would say I am much more the other way. . . I think it is done far too easily, and without consideration of what happens at the other end of their learning career.

A kindergarten teacher from a high sES district stated retention was an acceptable decision for some children because of the expectations of the next grade. "I guess I would have to say it is ok for some kids. Because of the expectations. If we could somehow lower our expectations - ." She conceded that retentions had decreased but that her expectations for her students had also changed, with an 
increase in the amount of drill and emphasis in academic areas. She expressed concern that the important issue to consider was the self-esteem of the child.

- . the self-esteem is the issue that I think is critical here and if you feel it is going to hurt the child's self-esteem I don't think it is a good idea to do it, no matter what. If it will enhance their self-esteem then I think it may be an

important thing to do.

\section{SUMMARY OF RESULTS}

The summary of study results will be organized around the three major questions of the research.

1. What is the relationship between the written retention policy of a selected school district and the decision making process used by its schools?

2. What are the influences by district status level that impact the decision making process used in student retention in each of the following areas:

a. student body characteristics?

b. curriculum expectations of building staff?

c. characteristics of decision makers?

d. parental involvement and priorities?

e. belief systems of practitioners?

f. available program alternatives?

3. What are the perceptions across district status level of teachers and principals regarding the use of retention as an intervention for students in each of the following areas: 

a. its success/failure with students?
b. the effect of current research on its use?
c. as an intervention option?

\section{Question 1}

What is the relationship between the written retention policy of a selected school district and the decision making process used by its schools?

Decision Making Process. The perception of district policy varied between SES groups and among job position groups responding to the survey instrument. This variance extended to the existence of policy, its development, and the responsibility such policies gave to participants in the retention decision making process. Briefly, high status group respondents appeared to more accurately perceive the existence of policy and its guidelines at the district and building level. Middle status groups appeared to be the most uncertain regarding district and building policy and the role of participants in policy. They were least likely to believe teachers followed district policy. They assigned authority to parents in retention decision making and, more than other status groups, gave importance to a team composed of the principal, teacher, and parent in making decisions. Low status groups had more uncertainty regarding district policy than other groups. They assigned as much responsibility to building teams as to parents in retention 
decisions and were less likely to believe parent consent was necessary for retention.

A clearer definition of these differences was achieved by the interviews done in selected schools within status groups and from individuals in job position groups.

All interview participants identified a team concept as the process used in their schools' retention decision making. Their responses also reveal the extent of that practice and the amount of acceptance it has achieved. The evolution of the concept to include team recommendations for retention appears to have occurred as an outgrowth of special education "identification" teams. While some participants reported previous experiences with other forms of decision making, all indicated they liked the support of a team decision when advising parents. Team meetings were often described as times to share and receive information from specialists.

Some principals and teachers suggested that the formation of pre-retention teams created to assist teachers with particular students was also helpful in identifying alternative strategies. Providing teachers with the benefit of others' experience and expertise was one of the ways principals attempted to intervene early with slow achieving children and avoid retentions. 
Question 2

What are the influences by district status level that impact the decision making process used in student retention in each of the following areas.

Student Body Characteristics. Most participants agreed that more children were entering school "unready to learn" and offered a variety of solutions. All-day kindergarten was supported by some as providing the necessary time to accomplish the socialization and readiness skills children lacked but opposed by others as too tiring for children. Ungraded or multi-graded classes were seen as helpful by some in relieving the pressure caused by escalated curriculum demands and unnecessary by others who wanted a slower pace within their own traditional placement classrooms. Holding children out of school and entering them at an older age was viewed as favorable by many. others, especially principals, indicated these children might not have the advantage of preschool and would simply spend another year out of school becoming more unprepared. Equity issues surfaced when educators considered such solutions for children who exhibited lack of school readiness or greater achievement needs due to social issues. Curriculum Expectations of Building staff. The expectations of first grade teachers was expressed by some kindergarten teachers as influencing their teaching styles and the expectations they held for students. They expressed 
frustration with their awareness of research on developmentally appropriate practices and early childhood literature and the pressure they felt to hurry academics with their students. Kindergarten, more than first grade was mentioned as the "place" for retention to occur. Several teachers indicated the problem of retention would not exist if children came to school more ready to learn. They expressed the responsibility for sending such "ready" children to school rested with preschool teachers or parents who should keep unready children out of school for an additional year.

others felt retention would be reduced if schools accepted children at their developmental level and changed or lowered curriculum and achievement expectations. One administrator expressed disagreement with lowering expectations and suggested that a stronger work ethic needed to be developed to assist lower achieving students succeed and accelerate their progress.

Characteristics of Decision Makers. Though teachers welcomed the input of building and district specialists, they frequently elaborated on the importance of their own opinions at decision time. Teachers defined their beliefs that the classroom teacher was the primary source of information to the team and therefore had an important role in the decision making. They reaffirmed their significance as the primary educators of students by recounting personal 
experiences and examples. Teachers' descriptions of actual recommendations often depicted the importance of the teacher's view of the child. A retention caused teachers to evaluate themselves, the methods they used and how they structured learning. A child's failure was expressed as a time of self-evaluation for a teacher and a reflection on what they could have done differently for that child. Kindergarten teachers more than first grade teachers, discussed their beliefs on the developmental level of children determining the expectations teachers should have. They elaborated on the differences between the two grade levels and the exclusion and isolation they felt because of differing expectations.

Principals expressed confidence in their staff's ability to teach children at all levels and gave importance to the classroom teacher's opinion of a child over their own. They saw themselves as providers of resources for decision making as well as alternatives for children needing additional help.

Parental Involvement and Values. Under the rubric of parental involvement and values, several key elements were mentioned by most teachers and administrators. They expressed their concern about the lack of parental nurturing of children which resulted in children being unprepared for the school experience. They expressed the need for the school to assist the child at an earlier age and provide 
services parents were unable to do. They observed that the neediness of parents and their inability to cope with their own problems placed additional responsibility on the school to provide after school care and breakfast programs for such children. Some educators from high status districts elaborated on parents' greater awareness of their children's readiness for school and the provision they made for preschool experiences for them.

Belief systems of Practitioners. Characteristic of the discussions with teachers and principals was the ambivalence they expressed toward retaining a student. All considered holding a child back to be a serious decision and one which they made with difficulty. However, all indicated they would support a retention if certain conditions existed. Those conditions usually centered either on issues of immaturity or large blocks of student absences. Decisions to retain were frequently explained with anecdotes relating a previous experience with a successful retention. These personal experiences supported their rationale for such decisions.

Teachers and principals had varied perceptions regarding their ability to impact on the achievement of a child or a child exhibiting signs of immaturity. These belief systems regarding child development, as discussed earlier in Chapter II, have been identified and defined according to Smith (cited in Shepard \& Smith, 1989) as 
typically nativist, remediationist, diagnostic-prescriptive teachers, or interactionist. Examples of these belief systems emerged as discussions of the causes of retention were explored. Teachers expressing views similar to those of nativist beliefs perceived themselves unable to impact on immaturity. Time was felt to be the solution to children who exhibited such characteristics as "young for their age," "socially immature," or "unable to sit still." Maturation was viewed as a "natural process" which could not be hurried. Retention was viewed as "giving them the time to develop it" [maturation], or "another chance to grasp the experience."

Teachers who expressed views similar to those of what Smith (1989) as remediationist, frequently described their efforts with assisting a child to become more organized, develop skills, and plan goals for achievement. Statements such as "there are things a teacher can do" and ". . these kids that come and don't seem ready are that way because they haven't had prior training. . ." exemplify the belief that teachers can impact immaturity with effort and understanding.

Educators with views described as diagnostic/ prescriptive referred to screening or testing students. specialists were asked to help students and identify suspected iearning problems. Teachers expressed a self-evaluation and critique of their performance with 
students who had challenging problems. Analyzing the child's instructional needs and adapting strategies to meet those needs are examples of this approach.

Teachers and principals reflecting an interactionist belief system described changing the way learning was viewed and used such statements as "Everybody is ready wherever they are. There is nothing to this 'not ready' business." Using developmentally appropriate practices and reducing the demands of curriculum expectations for the grade level were discussed as ways of accommodating to differing student achievement.

\section{Available Program Alternatives. Teachers from upper} socio-economic area districts indicated a proclivity to retain or to try retention type alternatives, such as delayed entry, additional preschool, or a desire for all-day kindergartens or transition rooms. They may reflect the opinions of higher income, more highly educated parents who are concerned and involved with their children's achievement. First grade teachers indicated most retentions were handled in the kindergarten year, while kindergarten teachers sought solutions for slower achieving students with preschool alternatives and parental responsibility for delayed entry decisions. 
Question 3

What are the perceptions across district status level of teachers and principals regarding the use of retention as an intervention for students in each of the following areas:

1. Its success/failure with students?

Teachers and principals used examples of retentions having been positive decisions for students, speculated on others with indecision, and generally qualified their support of retention with conditions they felt important. Those educators familiar with retention research commented that the practice showed no real academic benefits, but could impact a child's self-image. Most could cite specific examples from their own experience where they felt retention had been the right decision.

Teachers and principals stipulated certain conditions where retention could be a correct course of action. Generally these conditions included the agreement of everyone involved, including the child; if the retention was seen as an opportunity and not a failure; or if the child was unable to physically, socially, or emotionally meet grade level expectations. Most teachers and principals expressed great ambivalence with retention and usually qualified their responses with uncertainty over the practice, the likelihood of retention helping students becoming school successful, and their ability to predict who would benefit from being retained. 
2. The effect of current research on its use?

Most teachers and principals indicated they were acquainted with current retention research and expressed their awareness of retention's potential damage to students. Because of this knowledge, they expressed the importance of making careful and selective decisions. Using a team who could assist with making that decision was one way to accomplish this goal. Two out of the three administrators used research findings to develop an awareness on the part of staff and parents to the ineffectiveness of retention as demonstrated by research.

3. As an intervention option?

Retention was viewed as one way of impacting a student's lack of success in school. Teachers and principals discussed other options such as transition rooms, additional years of preschool, additional tutoring for more than one year, and high expectations for students. Most interviewees considered retention to be a major decision and therefore an infrequent intervention for children. Most cited research findings regarding retention's negative impact on the self-image of the child and the likelihood of little academic benefit over time as influencing their willingness to retain many children. Most indicated if all conditions were met, they would be inclined to retain a child but infrequently, and only with the agreement of other professionals and parents. 
In conclusion, the data presented are the perceptions, from the primary research survey and interviews, of kindergarten and first grade teachers and building principals regarding the process of retention decision naking, practice, and belief systems. It reflects those perceptions and practices surrounding retention which are driven by the personal belief systems of practitioners. Information from study participants provides implications for educational policies and practice and a foundation for further study and research. These are discussed in Chapter V. 
CHAPTER V

\section{CONCLUSIONS AND RECOMMENDATIONS}

\section{INTRODUCTION}

The purpose of this study was to explore the perceptions of teachers and principals regarding the processes they use in retention decision making and the belief systems which underlie the practice of non-promotion. The study also addressed factors which influence retention and educators' perceptions of retention as an option for improving student achievement. Three research questions were discussed:

1. What is the relationship between the written retention policy of a selected school district and the decision making process used by its schools?

2. What are the influences by district socio-economic level which impact the decision making process used in student retention?

3. What are the perceptions across district status levels of teachers and principals regarding the use of retention as an intervention for students?

Although the discussion in this chapter is primarily based upon what the study participants reported, the 
researcher addresses the study questions from her own perspective, drawing conclusions from the ideas presented.

This chapter contains the following sections: (a) Conclusions and Implications, (b) Limitations of the study, (c) Recommendations, and (d) Summary.

\section{CONCLUSIONS AND IMPLICATIONS}

The conclusions and implications from the study are presented in response to the primary situdy questions, referring to the survey and interview narratives.

\section{guestion 1}

What is the relationship between the written retention policy of a selected school district and the decision making process used in its schools?

Retention policies from all four districts have some commonality with regard to (a) teacher initiation of a retention recommendation, (b) notification given to the principal and the parent, and (c) written|acknowledgement by the parent regarding approval or disapproval of the recommendation. The requirement for a written acknowledgement by parents, specifically in cases of parental disagreement, may indicate a wariness by districts in the event of later legal implications concerning their failure to act in the child's best interests.

The latitude in district policy guidelines for specific staff involvement, time-lines, and the use of 
assessment instruments, allows individual school staffs generous parameters in developing building procedures for assessment, parent notification, and specific processes of decision making.

Although not specifically included in any of the policies studied, a variety of assessments would be helpful in determining a promotion or retention decision rather than relying solely on the professional judgment of educators (Walden and Gamble, 1985). As Walden and Gamble caution - . it is plain that promotion and retention policies are not immune from judicial scrutiny and must be carefully drawn in order to tailor the policy to educational objectives. (p. 623)

The issue of subjective judgment, in light of considerations of equity, has legal implications based upon unequal access to alternatives or treatment.

A significant percentage of the staff, including principals, had worked at their buildings for the relatively short time of one to three years: high SES group, 68.2\%; middle and low SEs groups, 50\%. It could be argued that these groups had had less time to familiarize themselves with district policy. However, the group with the highest percentage of recent employment, $68.2 \%$ of the high SES group, also represented the group with the greatest familiarity with policy.

The uncertainty of staff regarding the existence of district policy impacts building decision making processes anci needs to be addressed. District mandates regarding 
time-lines, parent communication, and the participation of staff members in decision making, if previously communicated to staff, need to be reinforced. The high percentage of low status group respondents, $22.2 \%$ reporting they are unsure regarding the existence of a district retention policy, also provides information to policy makers and building administrators regarding the need for clarification of retention guidelines.

District policy guidelines failed to acknowledge or recommend research information for building staffs. Any distribution of retention literature was done at the discretion of individual building principals. Policy makers should be encouraged to update district mandates using support from research as the foundation for policy changes or modifications. The current latitude given to building staffs in interpreting and applying policy does accommodate the wide belief system of educators. However, the absence of supportive evidence from research or from district retention data allows retention to occur without any evidence of its efficacy in promoting student achievement. Table XIII summarizes the relationships between district retention policy and the decision making process. 
TABLE XIII

\section{SUMMARY OF DISTRICT RETENTION POLICIES \\ AND DECISION MAKING PROCESSES \\ (RESEARCH QUESTION I)}

\begin{tabular}{|c|c|c|}
\hline & Policy & Process \\
\hline $\begin{array}{l}\text { High Status } \\
\text { Districts } \\
1 \text { and } 2\end{array}$ & $\begin{array}{l}\text { District 1: } \\
\text { - Permits retention. } \\
\text { - Requires written consent. } \\
\text { District 2: } \\
\text { - Permits retention if student } \\
\text { is below grade level, social/ } \\
\text { emotional growth not negatively } \\
\text { effected. }\end{array}$ & $\begin{array}{l}\text { Ieam } \\
\text { Respondents: } \\
\text { - Aware of policies and guidel ines } \\
\text { at district and building levels. }\end{array}$ \\
\hline $\begin{array}{l}\text { Middle Status } \\
\text { Districts }\end{array}$ & $\begin{array}{l}\text { Permits retention if in child's } \\
\text { best interest. }\end{array}$ & $\begin{array}{l}\text { Team } \\
\text { Respondents: } \\
\text { - More uncertain of district/ } \\
\text { building pol icy. } \\
\text { - Uncertain of acherence to } \\
\text { guidel ines. } \\
\text { - Gove importance to principal/ } \\
\text { teacher/parent teans. } \\
\text { - Gave authority to parents. }\end{array}$ \\
\hline $\begin{array}{l}\text { Low Status } \\
\text { Districts }\end{array}$ & $\begin{array}{l}\text { Permi ts retention for children } \\
\text { making unsatisfactory academic } \\
\text { progress. }\end{array}$ & $\begin{array}{l}\text { Team } \\
\text { Respondents: } \\
\text { - Uncertainty regarding district } \\
\text { pol icy development. } \\
\text { - Uncertainty regarding need for } \\
\text { parent consent. } \\
\text { - Gave teans and parents } \\
\text { responsibility for final decisions. }\end{array}$ \\
\hline
\end{tabular}

Question 2

What are the influences by district socio-economic level which impact the decision making process used in student retention?

The options available to districts and the needs of the student population of those districts strongly influence the instructional decisions of building staffs and consequently the development of appropriate programs. High socio-economic districts focused on the immaturity of students as a retention characteristic, the necessity for 
preschool opportunities for children, and the escalation of curriculum impacting on school success. Lower SES districts tended to stress high expectations, parent education and support, the needs of disadvantaged students, and the need for additional program support. Middle SES districts were concerned with several of the major issues of both high and low status districts. They stressed both immaturity and lack of basic skills in retention decisions, additional assistance for teachers, and the restructuring of building teams to support teachers working with failing students. Schools from all SES levels used building teams to assist with the decision making process in retention recommendations. Teachers in this study indicated they welcomed the team's input and the shared responsibility for retention recommendations. They also emphasized the importance of their input in team decisions. Lieberman (1980) suggested including specialists, teachers, and parents on building teams to provide a wider base for decision making. School personnel throughout this study indicated similar models were used in their buildings. However, parent involvement was generally limited to notification of the teacher's concern, access to assessment data, and a meeting, usually with the teacher, to hear the team's recommendation. In two cases, principals talked to parents, shared research and, in some cases, invited parents to observe in classrooms. 
Teams must be observed carefully for their impartiality. The importance of the classroom teacher as a key actor in the decision process must not be overlooked. As Smith and Shepard (1989) warn, building teams are suspect for their appearance of being collaborative and impartial. We regard this staffing process as a way the school attempts to appear rational, scientific, and fair in the process, while the outcome of the decision is anything but valid or beneficial. (p. 226)

Lieberman (1980) suggested that a building team be developed, similar to those used in special education placements, to facilitate a more collaborative model for retention decisions. According to Smith and shepard (1989), the rationale supporting such a model is the belief that although retention does not benefit most children, in some cases, it might be justified. A principal in this study provided an example of this rationale; he thought some children might profit from repeating, but knowing which ones was the dilemma. "I don't feel as if I am that accurate. I have real reluctance to repeat any child."

The team process should be restructured to first address appropriate interventions before any discussion of retention occurs. Modifying decision making processes by providing teachers a network of collegial support may replace unilateral conclusions and broaden the scope of possible alternatives. According to slavin et al. (1989) schools need to make significant changes in their approaches to students at risk for academic failure including school 
organization. District policy makers need to consider alternatives in the restructuring of the graded system and the achievement standards which impact curriculum and thereby relieve the pressure felt by teachers.

Teachers view themselves, and rightfully so, as key people in decision making. Teacher and principal judgments are central to retention decisions. Administrators and other building specialists, by sharing retention research and providing in-service opportunities, may help teachers more clearly understand the long range effects of retention. As Natriello et al. (1990) caution, "Students who obtain low grades, fail subjects, and are retained in grade have a much higher probability of performing poorly and subsequently leaving school before high school graduation" (p. 99). Secondly, communicating to educators and parents regarding current research will be essential to changing persistent belief systems. Consequently, administrators and district policy makers need to assemble information on retained students' progress throughout the grades as data for future decision making. House $(1989$, p. 212) asserts this is not an unreasonable expectation for school districts.

The second research question was supported by several elements in chapter IV. Three of these have special significance: (a) curriculum expectations of building staff; (b) belief systems of practitioners, and (c) available program alternatives. 
Curriculum Expectations of Building staff. Teachers indicated that the expectations of other staff and their district's curriculum goals impacted their practices. This was evident in interviews with kindergarten and first grade teachers in schools from each of the three socio-economic levels. The expectations of first grade teachers in having students ready for their grade, coupled with an awareness from the literature and in-service training regarding developmentally appropriate practice, have increased pressure on kindergarten teachers. The contrast between the structure and content of the first grade curriculum, and what kindergarten teachers consider appropriate instruction is significant. The following examples of comments made by kindergarten teachers from each socio-economic level illustrate their anxiety: "I think some teachers worry a great deal about what the next teacher will say about the kids . ." of uncertainty, ". . they [children] are letting us know that we are doing things that are not appropriate, constantly" of frustration, "We are not teaching children where they are, we are wanting them to be where we are," and of accommodation ". . . if my kindergartners were going into a developmental first grade, I would say great, but they don't."

The realignment of current grade level curriculum standards would be assisted by a re-educating of primary teachers with a research based model of curriculum trends, 
especially in the area of developmentally appropriate practice. The variation of content in teachers' current training and the lack or unfamiliarity with current curriculum thinking underlies the frustration they express. Consequently, the desire and expectation for parents and preschool teachers to address the "readiness" and subsequent retention issue, was reflected by the comments of teachers in both grade levels.

The escalating curriculum and promotional standards for kindergarten children serve to delay the entry of children considered unready for formal schooling. They provide barriers for children progressing through the grades with their peer/age groups. Maintaining high standards is not accomplished by the retention of early primary children or by having children wait to enter school (Balow \& Schwager, 1990; Shepard \& Smith, 1986; Smith \& Shepard, 1987) .

District policy makers and curriculum and staff development specialists can help to address this issue through in-service programs for both teachers and principals. The reorganization of the graded structure can be accomplished through ungraded models thereby reducing the appearance of segmented curriculum approaches. Smith and Shepard (1989, p. 231) suggest delaying literacy until later in the primary grades. The idea of reducing literacy concerns was also suggested by kindergarten teachers in this 
study. They proposed an extension or overlapping of curriculum between grade levels as one way to avoid rigid expectations of next grade teachers.

Belief systems of Practitioners. The beliefs of teachers and principals are at the heart of retention practice. Although typically, educators neglect to use and apply research to their practice, the problem does not appear to be strictly an unfamiliarity with current research. All study participants admitted to having some knowledge of retention research. Rather it is the confrontation between personal experience and research which causes educators, while acknowledging retention's possible harm, to keep the option available for those children it might "benefit." Conditions for optimum retentions included the agreement of all involved, especially the parents, that retention was in the child's best interest and that the additional time would allow the child to grow and develop. The belief that the immature child needed additional time to mature and master the work of the grade, was mentioned repeatedly as the major reason for retention. Acquiring the basic skills, especially reading, was secondary to immaturity as the cause of non-promotion.

Teachers' rationale for retention is based upon their beliefs regarding child growth and development and the ways children learn (Smith \& Shepard, 1989). Comments by teachers reflected the structure of teacher beliefs about 
child development to be defined by Smith (1989, pp. 137-138): nativists, remediationists, diagnostic/ prescriptive, or interactionists. According to Smith and Shepard, teachers believe that retention allows the child more time to learn skills and become proficient in work which is too difficult in their present grade. Peterson (1989, p. 177) supports this by suggesting that teachers' belief systems regarding learning influence their practices in the classroom as well as their retention practice. She asserts that providing teachers access to research and the time to assimilate research findings will have a significant role in changing practice.

This researcher believes that school district policy makers must themselves become aware of retention research, analyze retention practice in district schools, and concentrate their efforts in providing teachers with both information and support in its application. Changing practice by changing beliefs must be accompanied by constructive alternatives to retention.

Available Program Alternatives. While participants in this present study had few alternatives available at the time for students failing to achieve, several were mentioned as having potential benefit. Currently, remedial programs such as Chapter one, the use of instructional assistants, tutors, and parent volunteers provided extra help to children. When asked regarding additional alternatives, 
teachers and pxincipals had many suggestions. Teachers considered a transitional or developmental kindergarten to be beneficial. others mentioned that a one or two year preschool experience would specifically benefit immature children and those from disadvantaged backgrounds. Both teachers and principals viewed parent support programs as essential to address long range student needs. A longer kindergarten day, smaller class size, counselors on staff, and ungraded primary departments were mentioned as beneficial options. Study participants from a lower socio-economic school believed that holding high expectations for student success was important. The accelerated schools model, as a method of increasing student achievement, was another example of program options under review.

Natriello et al. (1990) suggest that educators need to focus on factors which are amenable to change in the present rather than on long term conditions in need of remediation. In other words, educators should focus on what they can probably change, should view children as individuals, and use environmental factors as background information to trigger early intervention programs. Focusing on unchangeable factors or long-term remediation conditions may limit educators' perspective for change.

Natriello et al. (1990) list five risk factors which put children in danger of school failure: (a) being Black 
or Hispanic; (b) living in poverty; (c) living with a single parent; (d) having a poorly educated mother; and (e) limited English proficiency (p. 30). These authors also assert, "A conservative estimate is that at least $40 \%$ of these children are at risk of failure in school on the basis of at least one of these five disadvantaging factors" (p. 31). Schools with numbers of children having one or more of the indicators listed by Natriello et al. are faced with creating and providing programs, instruction, and school structure to accommodate these needs. How to accomplish these tasks in light of budget shortfalls is the challenge confronting schools and school districts. Guidelines in developing programs for disadvantaged children may be helped by including seven attributes identified by Slavin, Karweit, and Madden (1989). These seven factors they consider as contributing to effective programs are: (a) a positive school climate; (b) a definition of school goals and objectives; (c) a coordination of special programs with regular instruction; (d) involved parents and community, (e) on going staff development; (f) evaluation results used for continued improvement of programs; and (g) a strong instructional leader (Slavin et al., 1989, pp. 267-269). Accelerating student instruction, enriching the learning environment, and improving the quality of instruction which students receive 
must be considered as necessary components of an effective school.

The primary years set the tone for later school success or failure. Slavin et al. (1989) suggest that effective kindergarten programs are critical for establishing school success for children. Attention focused on these early years of learning will reduce the need for later remedial programs. A current trend toward all day kindergarten programs is also producing a shift of focus from social development programs to more academic kindergarten programs (Natriello et al., 1989). Natriello et al. suggest that district policy makers first determine goals for the kindergarten year and develop programs accordingly (Natriello et al., 1989, p. 94).

House (1989) suggests promotion and remediation is preferable to retention and remediation (p. 205). For retained students, depending on remedial programs to accomplish what regular classroom instruction has not is depending on a failed practice. Furthermore, such dependance may result in the lack of development of alternative options. Interviewees from only one of the study schools (low SES) mentioned using the accelerated schools model as an attempt to improve student achievement and one school (high SES) discussed the enrichment of the students' learning climate as an important component in accelerating their achievement. 
Table XIV summarizes key influences by socio-economic level which impact the decision making process.

TABLE XIV

$$
\begin{aligned}
& \text { SUMMARY OF INFLUENCES ON DECISION MAKING } \\
& \text { PROCESS (RESEARCH QUESTION 2) }
\end{aligned}
$$

\begin{tabular}{|c|c|c|c|}
\hline & High & Middle & Low \\
\hline $\begin{array}{l}\text { Student body } \\
\text { characteristics } \\
\text { (of retention } \\
\text { candidates) }\end{array}$ & $\begin{array}{l}\text { Social immaturity; } \\
\text { failure to achieve; } \\
\text { poor attendance. }\end{array}$ & $\begin{array}{l}\text { Poor at tendance; } \\
\text { social immoturity; } \\
\text { younger age; immaturity } \\
\text { coupled with poor } \\
\text { ochievement. }\end{array}$ & $\begin{array}{l}\text { Poor attendance; } \\
\text { immaturity; poor } \\
\text { ocademic skills; } \\
\text { slower social } \\
\text { growth. }\end{array}$ \\
\hline $\begin{array}{l}\text { Curriculum } \\
\text { expectations }\end{array}$ & $\begin{array}{l}\text { Principal: Encourages a } \\
\text { realistic philosophy } \\
\text { of expectations. } \\
\text { Teachers: Curriculum } \\
\text { expectations too high. } \\
\text { Adjustments need to } \\
\text { be made for slower } \\
\text { students. }\end{array}$ & $\begin{array}{l}\text { Principal: Supports staff } \\
\text { working with wide range } \\
\text { of students. } \\
\text { Teachers: Adjusts program } \\
\text { to meet grade } 1 \\
\text { expectations. Reading } \\
\text { is the key. }\end{array}$ & $\begin{array}{l}\text { Principal and } \\
\text { Teachers: High } \\
\text { expectations } \\
\text { despite multiple } \\
\text { needs of children. }\end{array}$ \\
\hline $\begin{array}{l}\text { Characteristics } \\
\text { of decision makers }\end{array}$ & $\begin{array}{l}\text { Principal: Support, } \\
\text { facilitate, critique. } \\
\text { Ieachers: Key } \\
\text { communicators; hold } \\
\text { most comprehensive } \\
\text { view. }\end{array}$ & $\begin{array}{l}\text { Principal: Facilitate a } \\
\text { thought ful decision. } \\
\text { Teachers: Key decision } \\
\text { makers; seek advice/ } \\
\text { collaboration. }\end{array}$ & $\begin{array}{l}\text { Principal: Provide } \\
\text { research and input } \\
\text { into decision. } \\
\text { reachers: Key person } \\
\text { wo provides data. }\end{array}$ \\
\hline $\begin{array}{l}\text { Parental } \\
\text { involvement/ } \\
\text { priorities }\end{array}$ & $\begin{array}{l}\text { Principal: Holds parent } \\
\text { discussion groups; } \\
\text { shares research. } \\
\text { reachers: Parents have } \\
\text { final decision; are } \\
\text { key to student success. }\end{array}$ & $\begin{array}{l}\text { Principal: Parent support } \\
\text { critical. } \\
\text { Ieachers: Parents need to } \\
\text { take responsibility; } \\
\text { retain early before } \\
\text { kindergarten. }\end{array}$ & $\begin{array}{l}\text { Principal: } \\
\text { Comminicates with } \\
\text { parents; establ ish } \\
\text { programs to } \\
\text { support/help. } \\
\text { reachers: Parental } \\
\text { nurturing key } \\
\text { factor in student } \\
\text { success. }\end{array}$ \\
\hline $\begin{array}{l}\text { Belief } \\
\text { system of } \\
\text { practitioners }\end{array}$ & $\begin{array}{l}\text { Principal: } \\
\text { research hareness of } \\
\text { practice. } \\
\text { Teachers: Retention } \\
\text { acceptable in some } \\
\text { cases. }\end{array}$ & $\begin{array}{l}\text { Principal: Research has } \\
\text { persuaded that retention } \\
\text { is a questionable } \\
\text { proctice. } \\
\text { reachers: Retention } \\
\text { beneficial for some } \\
\text { children. }\end{array}$ & $\begin{array}{l}\text { Principal and } \\
\text { Teachers: } \\
\text { Retention } \\
\text { acceptable in } \\
\text { limited } \\
\text { circumstances. }\end{array}$ \\
\hline $\begin{array}{l}\text { Available } \\
\text { progrem } \\
\text { al ternat ives }\end{array}$ & $\begin{array}{l}\text { Principal: Ungraded } \\
\text { primary; quality } \\
\text { learning environment. } \\
\text { Teachers: Teacher } \\
\text { assistant; volunteer } \\
\text { help/tutors. }\end{array}$ & $\begin{array}{l}\text { Principal: Pre-referral } \\
\text { teams; developmentally } \\
\text { oppropriate practice. } \\
\text { Teachers: Want creation } \\
\text { of : Toter entry: } \\
\text { transition rooms. }\end{array}$ & $\begin{array}{l}\text { Principal and } \\
\text { Teachers: } \\
\text { Volunteers/tutors } \\
\text { remedial programs. } \\
\text { Principal: Hants } \\
\text { longer preschool } \\
\text { experience; } \\
\text { breakfast } \\
\text { program; before/ } \\
\text { after school day } \\
\text { care. } \\
\text { Teachers: Want } \\
\text { lower class size; } \\
\text { sumer program; } \\
\text { preschool } \\
\text { program. }\end{array}$ \\
\hline
\end{tabular}


Question 3

What are the perceptions across district status levels of teachers and principals regarding the use of retention as an intervention for students?

Teachers and principals from every socio-economic level discussed situations in which they considered retention would be an acceptable option for students. They verbalized the negative effects of retention, the difficulty in making an appropriate judgment of who should be retained, the necessity of parental agreement, and offered restrictions on its use. Nevertheless, all participants viewed retention as an acceptable alternative to use in certain circumstances, for the immature child, and to a lesser extent, for the student having difficulty with the basic skills, especially reading. Those conditions, however, rested upon parental and team agreement, and, to a lesser degree, the child's agreement. The assertion that it was most desirable to retain in the early years of schooling, when students would not experience a sense of failure, was used as further support for this rationale. To support this mind set of "the sooner the better," some kindergarten teachers expressed the hope that non-promotion decisions could be made earlier by preschool teachers or even the child's parents. Preschool teachers should share information about the child's readiness for 
formal schooling so that a second year of preschool would be acceptable to parents.

Delaying a child's entry was seen as preferable to entering school and facing the possibility of being retained. Nearly all first grade teachers expressed their reliance on kindergarten teachers to make the decision regarding a student's readiness for first grade.

Nearly all interviewed educators mentioned a familiarity with some retention research and could verbalize some of the negative aspects of non-promotion. This awareness may have created a more cautious approach and may be encouraging teacher's reliance on team recommendations as support for their decisions. It has left teachers more uncomfortable about recommending a retention, ". . I don't want to be the one that says Yes or No," and "I like having a team behind you . . ." and may have encouraged a greater reliance on the input and support of other staff members. The available alternatives to retention included a varying degree of the resources previously mentioned: preschool experience, school remediation programs, tutors and classroom assistants, and parenting help for parents. The available assistance varied across districts and schools and was not always sufficient to impact on children's academic or social needs. In those cases, teachers and some principals indicated retention should be considered. 
In discussing those instances, teachers and principals recited former experiences with successful retentions. Teachers elaborated on their process in making those decisions, the difficulty in convincing parents, or expressed in detail the needs of the child. Although no teacher or principal indicated they had made a wrong decision to retain, they reflected on the possible results if different outcomes had occurred. Their advocacy for both sides of the decision revealed a lack of certainty in predicting a successful retention.

Changing practice appears to be a complex issue using research, information about child growth and development, and the restructuring of schools and school programs. More than any other suggestion, the restructuring of curriculum goals and a rethinking of a philosophy of early childhood education were mentioned by teachers as essential for changing retention practice. As House (1989) asserts, "The point is not that many students do not need extra help but rather that retaining them is not the way to provide it. It will take a strong re-educative program to counter the beliefs of teachers in this matter" (p. 211). Tables XV, XVI, and XVII summarize responses by socio-economic level regarding retention as an intervention. 
TABLE XV

SUMMARY OF RESPONSES OF HIGH SOCIO-ECONOMIC GROUPS (RESEARCH QUESTION 3)

\begin{tabular}{|c|c|c|c|}
\hline & Principal & $\begin{array}{l}\text { Kindergarten } \\
\text { Teacher }\end{array}$ & $\begin{array}{l}\text { First Grade } \\
\text { Teacher }\end{array}$ \\
\hline $\begin{array}{l}\text { The success or } \\
\text { failure of } \\
\text { retention. }\end{array}$ & $\begin{array}{l}\text { A successful retention: } \\
\text { - parent ectucation } \\
\text { necessary } \\
\text { - acceptance of child's } \\
\text { ability by parents } \\
\text { Cited personal examples }\end{array}$ & $\begin{array}{l}\text { A successful retention: } \\
\text { - parent nust agree } \\
\text { - must not hurt child's } \\
\text { self-esteem } \\
\text { Majority undecided } \\
\text { regarding effectiveness } \\
\text { Cited personal examples }\end{array}$ & $\begin{array}{l}\text { A successful retention: } \\
\text { - must consider age, } \\
\text { development, } \\
\text { enviroment, } \\
\text { difficulty with } \\
\text { achievement } \\
\text { Majority disagreed } \\
\text { regarding } \\
\text { retention's } \\
\text { effectiveness } \\
\text { Cited personal examples }\end{array}$ \\
\hline $\begin{array}{l}\text { Effects of } \\
\text { research. }\end{array}$ & $\begin{array}{l}\text { Research: } \\
\text { - has increased } \\
\text { reluctance to } \\
\text { retain } \\
\text { - is shared with } \\
\text { staff and parents }\end{array}$ & $\begin{array}{l}\text { Research: } \\
\text { - data has increased } \\
\text { frustration with } \\
\text { decision making }\end{array}$ & $\begin{array}{l}\text { Research: } \\
\text { - has limited her } \\
\text { reasons to retain } \\
\text { - has increased } \\
\text { concern with self/ } \\
\text { concept }\end{array}$ \\
\hline $\begin{array}{l}\text { Retention os an } \\
\text { intervention } \\
\text { option. }\end{array}$ & $\begin{array}{l}\text { Retention: } \\
\text { - has probably helped } \\
\text { some children } \\
\text { - uncertainty of } \\
\text { predicting successful } \\
\text { retentions has } \\
\text { limited practice }\end{array}$ & $\begin{array}{l}\text { Retention: } \\
\text { - is helpful in some } \\
\text { cases }\end{array}$ & $\begin{array}{l}\text { Retention: } \\
\text { - is acceptable for } \\
\text { some children }\end{array}$ \\
\hline
\end{tabular}


TABLE XVI

\section{SUMMARY OF RESPONSES OF MIDDLE SOCIO-ECONOMIC GROUPS (RESEARCH QUESTION 3)}

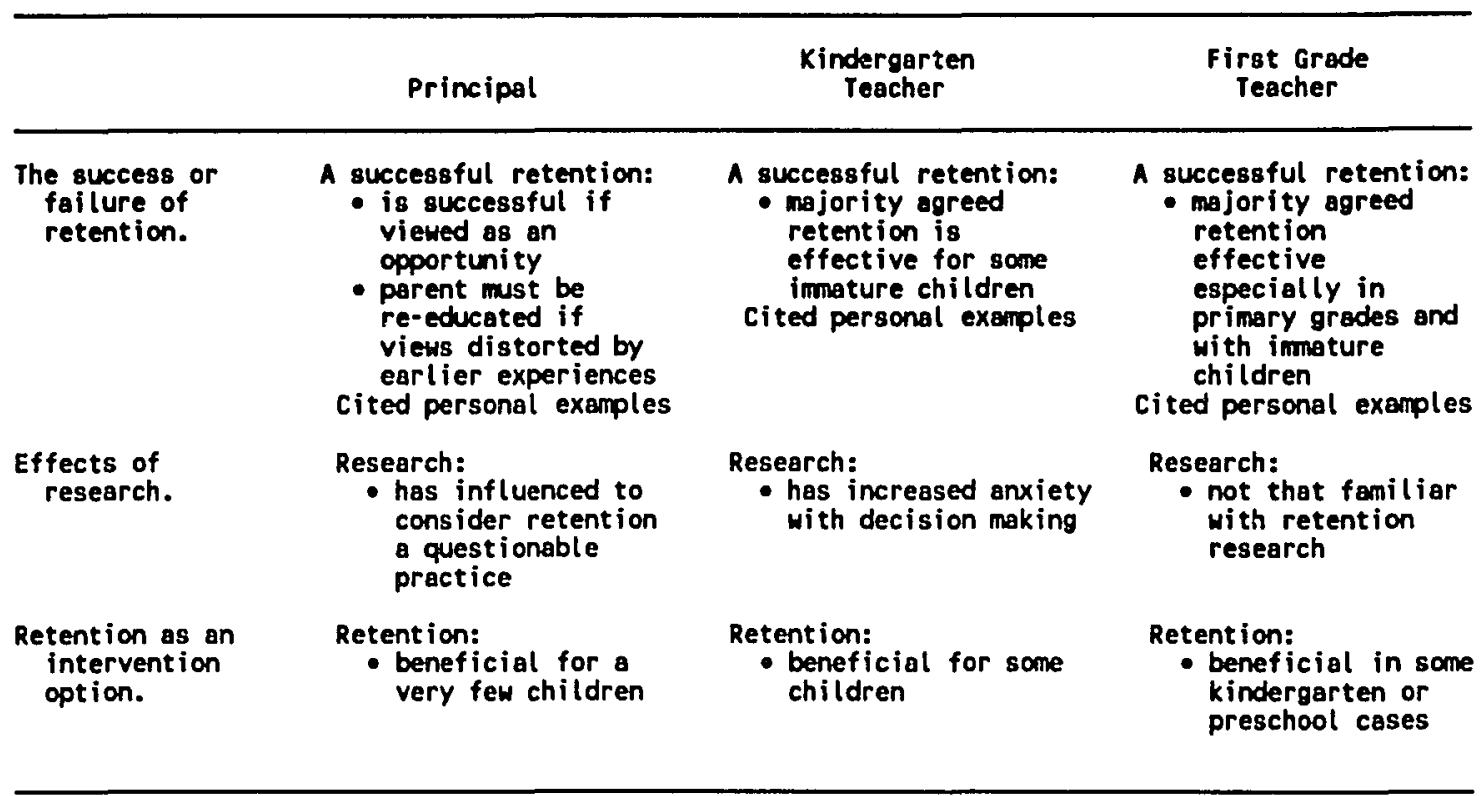

TABLE XVII

SUMMARY OF RESPONSES OF LOW SOCIO-ECONOMIC GROUPS (RESEARCH QUESTION 3)

\begin{tabular}{|c|c|c|c|}
\hline & Principal & $\begin{array}{c}\text { Kindergarten } \\
\text { Teacher }\end{array}$ & $\begin{array}{c}\text { First Grade } \\
\text { Teacher }\end{array}$ \\
\hline $\begin{array}{l}\text { The success or } \\
\text { failure of } \\
\text { retention. }\end{array}$ & $\begin{array}{l}\text { A successful retention: } \\
\text { - child must agree } \\
\text { - tean must agree } \\
\text { impossible to predict } \\
\text { cited personal examples }\end{array}$ & $\begin{array}{l}\text { A successful retention: } \\
\text { - parents must agree } \\
\text { - has administrative } \\
\text { support } \\
\text { Majority undecided } \\
\text { regarding effectivness } \\
\text { cited personal examples }\end{array}$ & $\begin{array}{l}\text { A successful retention: } \\
\text { - majority agreed } \\
\text { regarding } \\
\text { retention's } \\
\text { effectivness } \\
\text { cited personal examples }\end{array}$ \\
\hline $\begin{array}{l}\text { Effects of } \\
\text { research. }\end{array}$ & $\begin{array}{l}\text { Research: } \\
\text { - has influenced } \\
\text { beliefs } \\
\text { - is shared with staff } \\
\text { and parents }\end{array}$ & $\begin{array}{l}\text { Research: } \\
\text { - has impacted decision } \\
\text { making } \\
\text { - confirmed opinion of } \\
\text { detrimetnal effects }\end{array}$ & $\begin{array}{l}\text { effectiveness } \\
\text { Research: } \\
\text { - has influenced } \\
\text { decision making }\end{array}$ \\
\hline $\begin{array}{l}\text { Retention as on } \\
\text { intervention } \\
\text { option. }\end{array}$ & $\begin{array}{l}\text { Retention: } \\
\text { - is acceptable in } \\
\text { limited circumstances }\end{array}$ & $\begin{array}{l}\text { Retention: } \\
\text { - should be used very } \\
\text { seldom } \\
\text { - all involved need to } \\
\text { be in agreement }\end{array}$ & $\begin{array}{l}\text { Retention: } \\
\text { - is useful in } \\
\text { limited } \\
\text { circumstences }\end{array}$ \\
\hline
\end{tabular}




\section{LIMITATIONS OF THE STUDY}

A self-administered questionnaire was one of two methods used to collect research data. While the survey response rate was high, $77.7 \%$, the target population of 72 was relatively small. Using a larger base for survey distribution would have enhanced the significance of the responses and formed a greater base for comparison among the categories of job respondents and the three socio-economic levels of school districts.

Interviewing individuals from all three job positions, kindergarten teacher, first grade teacher, and principal, using one school was the original intent of this researcher. Due to mechanical difficulties with recording, one principal interview was replaced with a subsequent principal interview from a similar socio-economic level. While the results were interesting and helpful, any cross school comparison was not possible at that site.

In addition to the interviews with teachers and principals, the opportunity to obtain the perceptions of parents with regard to their personal experiences with retention would have added interest and enhanced the study results. It remains to future researchers to include parent perspectives from varying socio-economic levels on retention decision making.

The responses from the small numbers of respondents in this study do not reflect the perceptions of teachers and 
principals in other locales. Future researchers should explore similar questions using a larger population to build on the lines of inquiry obtained from participants in this present study.

In conclusion, the participants in this research, while reflecting a diversity of job positions and socio-economic areas, do not reflect the views and perceptions of all teachers and principals. They do provide some insight into the current procedures of retention decision making, the rationale and beliefs of educators regarding the non-promotion of students, and the complex issues surrounding changing educational practice.

\section{RECOMMENDATIONS}

Based upon the results of this study and the review of retention literature, the researcher proposes the following in a reconsideration of current practice.

\section{Toward a Reconsideration} of Current Practice

According to Slavin et al. (1989, p. 306) who reference Will (1986), an estimated 20 to $30 \%$ of school-age children are experiencing difficulty in school. These children are at risk of school failure and of becoming future dropouts of the system.

Creative, innovative alternatives which focus attention on deficient areas need to be developed within the 
resources of the district or building. Peer tutoring, district provided summer school, volunteer tutoring within the classroom, before and after school remedial help, and full day kindergarten are typical alternatives. Developing individual education plans for children at risk of failure similar to those mandated by special education, and encouraging parental involvement in those achievement plans, will help focus attention on the need for alternatives. Early assessment of children at risk of school failure is an important preventive measure. Such kindergarten and pre-kindergarten informal assessments will provide school personnel with data for educational enrichment in the critical early years. Caution needs to be exercised in the use of standardized measures to delay the entry of students into kindergarten and grade one or in the development of any two-year kindergarten/transition programs for students. According to slavin, "the majority of academically deficient students can achieve both academic and social success (Slavin et al., 1989, p. 305). Focusing on quality instruction, early assessment of remediation needs, systematic decision making using a collaborative approach, and the development of retention alternatives will help ensure the academic success of those students currently at risk. Continuous progress designs, direct instruction, cooperative learning, small group instruction, and effective pull-out or in-class remedial programs are achievement 
geared interventions. The restructuring of the traditional school will assist in the rethinking of children's development as learners and help to break rigid curricula based upon grade levels. These alternatives need to be accompanied by staff development opportunities to provide teachers with information in using such strategies and the time needed for collaboration with colleagues. The building administrator should not be underestimated as a provider of resources, as a communicator of expectations, and as a facilitator of policy development. The positive support and influence of administrators are essential in encouraging the development of new, more effective instructional programs and strategies, in stimulating innovative practice, and in creating an environment of possibilities and high achievement. The following examples are but a few of the strategies which are available to building administrators:

* Advocate for the school, its students, and staff. * Target a majority of school resources, people and money to the primary grades where student needs are more easily remedied.

* Familiarize yourself with current research and provide it to staff and parents.

* Create a stimulus for continued staff development; create staff and parent study groups for discussion of 
innovative ideas and strategies and to challenge beliefs and practices.

* Talk about expectations and new ways of looking at old problems, e.g. acceleration vs. remediation; if it is important to the principal, it must be important.

* Include alternatives to retention in discussions regarding providing student achievement.

* Encourage staff to visit innovative programs in other schools and to try new ideas; be creative in covering their classes while they observe colleagues.

* Support ideas with grant monies; "piloting" a program frequently inspires district approval and assistance * begin new programs on a small scale; create a few ungraded classrooms with those teachers who are ready.

* Create a teacher assistance team for teachers with student concerns.

* Maintain a positive environment; be persistent with positives, e.g. we are equal to the task.

* support and encourage staff publicly; communicate their needs in accomplishing the school's mission to district personnel and to the community.

* Provide parenting information and classes to parents; their support is essential.

Although the availability and effective use of additional resources are important, communicating to educators and parents regarding current research will be 
essential to changing persistent belief systems. Concentrating on the negative aspects of retention and providing in-service opportunities to teachers and principals regarding current research will enhance a change in practice. As discussed by Peterson (1989) it is necessary for educators to have opportunities to re-think practice and to reflect on the ways children learn in order to bring about change. As Peterson expands this concept, the teacher is the central focus of educational reform and as such must be viewed as a "thoughtful professional" who is the key to changing practice (p. 196). This researcher believes it is critical to address first the knowledge base and subsequently the belief system of teachers if retention practice is to be altered.

While this is occurring, modifying decision making processes by providing teachers a network of collegial support may reduce the use of subjective judgment and broaden the scope of possible alternatives. Key school personnel need to collaborate on promotion policy development and create alternative programs for promoted students to remediate deficiencies. The acceleration of student learning, especially in those schools with significant numbers of disadvantaged children, needs to be implemented. Lastly, it is up to teachers and principals to seriously reconsider the effects of a practice which has 
doubtful benefits and probable harm on the future success of young children.

\section{SUMMARY}

This study deals with the retention policies of four Oregon school districts and the process used by teachers and principals in making retention decisions. These processes of decision making are significantly diverse and changing, reflecting the complex organizations that practitioners and researchers alike understand educational organizations to be. The belief systems held by educators and the influence of those belief systems on recommendations for student retention should provide policy makers a greater understanding of the persistence of the practice. The primary orientation of this study was to describe and explain the processes used in retention decision making in grades kindergarten and one as reported by practitioners in high, middle, and low socio-economic school groups. The implications for practice are significant as teacher belief systems are challenged and alternatives other than retention are considered. A more studied, rational approach to the remediation of a child's academic deficiencies is suggested. Objective rather than subjective analyses regarding the child's future progress in school need to be implemented. The effectiveness of retention with regard to its positive and negative aspects and the unfamiliarity of 
educators with past and current research were not the major concerns of the researcher. Rather, this study proposed to address the use of retention as currently practiced by teachers, the process used to make retention decisions, and to explore ways to reduce its use as an alternative for more effective programs of remediation. 


\section{REFERENCES}

Abidin, R. R., Golladay, W. M. \& Howerton, A. L. (1971). Elementary school retention: An unjustifiable, discriminatory and noxious educational policy. Journal of School Psychology, $9(4), 410-417$.

Across the nation: Public schools spent $\$ 4,890$ per pupil last year, N.E.A. says. (1990, October 3). Education Week, p. 2 .

Ames, L. B. (1981, March). Retention in grade can be a step forward. Education Digest, 46, 36-37.

Angus, D., Mirel, J., \& Vinovskis, M. (1988). Historical development of age stratification in schooling. Teachers College Record, 90(2), 211-236.

Ary, D., Jacobs, L. C., \& Razavieh, A. (1985). Introduction to research in education (3rd ed.). Fort Worth, TX: Holt, Rinehart and Winston.

Ayres, L. P. (1909). Laggards in our schools: A study of retardation and elimination in city school systems. New York: Russell Sage Foundation.

Babbie, E. R. (1990). Survey research methods (2nd ed.). Belmont, CA: Wadsworth.

Baenen, N. R. (1988, April) . Perspectives after five years: Has grade retention passed or failed? Paper presented at the annual meeting of the American Educational Research Association, New Orleans, LA.

Balow, I. H., \& Schwager, M. (1990). Retention in grade: A failed procedure. Riverside, CA: University of California, California Educational Research Cooperative. (ERIC Document Reproduction Service No. ED 315 710)

Bear, G., \& Modlin, P. (1987, January). Gesell's developmental testing: What purpose does it serve? Psychology in the Schools, 24, 40-44.

Beckman, V. (1985). Evaluation of a kindergarten to first grade transition room. ERS Spectrum, $3(2), 44-46$. 
Berger, J. (1990, May 13). Is flunking a grade ever for a pupil's own good? The New York Times, p. E20(N).

Berliner, D., \& Casanova, U. (1986, April). Do failing students benefit from being retained? Instructor, pp. 14-15.

Bocks, W. M. (1977). Non-promotion: A year to grow? Educational Leadership, 34(5), 179-182.

Bogdan, R. C., Biklen, S. K. (1982). Qualitative research for education: An introduction to theory and methods. Boston: Allyn and Bacon.

Bogdan, R. C. \& Taylor, S. J. (1975). Introduction to gualitative research methods: A phenomenological approach to the social sciences. New York: John wiley and Sons.

Bohl, N. (1984, January). A gift of time: The transition year. Early Years, p. 14 .

Bossing, L., \& Brien, P. (1979). A review of the elementary school promotion/retention dilemma: A position paper. Murray, KY: Murray State University. (ERIC Document Reproduction Service No. ED 212 362)

Bredekamp, S., \& Shepard, L. (1989). How best to protect children from inappropriate school expectations, practices, and policies. Young Children, 44(3), 14-24.

Brown, E. L. (1981, April) . Retention: The team approach. The clearing House, 54, 348-349.

Bucko, R. L. (1986, April). Elementary grade retention: Making the decision. Paper presented at the annual meeting of the National Association of Elementary School Principals, Las Vegas, NV.

Byrnes, D. A. (1989). Attitudes of students, parents, and educators toward repeating a grade. In L. A. Shepard \& M. L. Smith (Eds.), Flunking grades: Research and policies on retention (pp. 108-131). Philadelphia: Falmer.

Byrnes, D. A., \& Yamamoto, K. (1984). Grade repetition: Views of parents, teachers, and principals. Logan: Utah State University, School of Education. 
Byrnes, D. A., \& Yamamoto, K. (1985). Academic retention of elementary pupils: An inside look. Education, $\underline{106}(2), 208-214$.

Byrnes, D. A., \& Yamamoto, K. (1986). Views on grade repetition. Journal of Research and Development in Education, 20(1), 14-20.

California state Department of Education. (1988). Here they come: Ready or not! (Report of the school Readiness Task Force). Sacramento, CA: Author.

Caplan, P. J. (1973). The role of classroom conduct in the promotion and retention of elementary school children. The Journal of Experimental Education, 41(3), 8-11.

Carstens, A. (1985). Retention and social promotion for the exceptional child. School Psychology Review, $\underline{14}(1), 48-63$.

Caswell, H. L. (1933, May) . Non-promotion in elementary schools. Elementary School Journal, 33, 644-651.

Cavazos, L. F. (1989) - For at-risk children. Principal, $\underline{68}(5), 6-15$.

Chafe, D. (1984). Grade retention: Research, policies and design techniques. Washington, DC: Department of Education. Research, Evaluation, and Accreditation Commission.

Chandler, H. N. (1984). Retention: Edspeak for flunk. Journal of Learning Disabilities, 17(1), 60-62.

Chansky, N. M. (1964) . Progress of promoted and repeating grade one failures. Journal of Experimental Education, 32(3), 225-237.

Chase, J.A. (1968, November). A study of the impact of grade retention on primary school children. Journal of Psychology, 70, 169-177.

Clark, C. M., \& Yinger, R. J. (1978). Research on teacher thinking (Research Series No. 12). East Lansing: Michigan State University, Institute for Research on Teaching.

Cohen, D. L. (1989, November 15). Georgia developing new kindergarten assessment. Education Week, p. 8. 
Cohen, D. L. (1990a, August 1). Elementary principals issue standards for early-childhood program quality. Education Week, p. 14.

Cohen, D. L. (1990b, August 1). Texas boards votes to forbid retention before the 1st grade. Education Week, p. 1 .

Cohen, D. I. (1990C, March 21). Two tiered school-entry age approved in Virginia. Education Week, p. 13 .

Cross, R. (1984, April). Teacher decision making in student retention. Paper presented at the annual meeting of the American Educational Research Association, New Orleans, LA.

Cuban, L. (1989). The "at-risk" label and the problem of urban school reform. Phi Delta Kappan, 70(10), $780-784,799-801$.

Cuddy, M. E., Frame, C., \& Devincentis, C. (1987, November). The effects of grade retention upon the social and psychological adjustment of elementary children. Paper presented at the annual convention of the Association for Advancement of Behavior Therapy, Boston, MA.

Cunningham, W. G., \& Owens, R. C. (1976). Social promotion: Problem or solution? NASSP Bulletin, $\underline{60}(402), 25-29$.

Dawson, M. , \& Rafoth, M. (1991). Why student retention doesn't work. Streamlined Seminar National Association of Elementary School Principals, 9 (3), $1-5$.

Dewey, J. (1916). Democracy and education: An introduction to the philosophy of education. New York: MacMillan Company.

Dobbs, V., \& Neville, D. (1967). The effect of non-promotion on the achievement of groups matched from retained first graders and promoted second graders. The Journal of Educational Research, 60(10), 472-475.

Dolan, L. (1982). A follow-up evaluation of a transition class program for children with school and learning readiness problems. The Exceptional Child, 29(2), 101-111. 
Donnelly, M. (1987). At-risk students (ERIC Digest Series No. 21). Eugene, OR: ERIC Clearinghouse on Educational Management. (ERIC Document Reproduction Service No. ED 292 172)

Donofrio, A. F. (1977, June/July) - Grade repetition: Therapy of choice. Journal of Learning Disabilities, $10(6), 349-351$.

Doyle, R. P. (1989). The resistance of conventional wisdom to research evidence: The case of retention in grade. Phi Delta Kappan, 71(3), 215-224.

Ebel, R. L. (1980). The failure of schools without failure. Phi Delta Kappan, 63(6), 386-388.

Egertson, H. A. (1987). The shifting kindergarten curriculum. Urbana: University of Illinois, ERIC Clearinghouse on Elementary and Early Childhood Education.

Elam, S. M. (1990). The 22nd annual gallup poll of the public's attitudes toward the public schools. Phi Delta Kappan, 72(1), 41-55.

Elam, S. M., \& Gallup, A. M. (1989). The 21st annual gallup poll of the public's attitudes toward the public schools. Phi Delta Kappan, 71(1), 41-54.

Elam, S. M., Rose, L. C., \& Gallup, A. M. (1991). The 23rd annual gallup poll of the public's attitudes toward the public schools. Phi Delta Kappan, 73(1), 41-56.

Elkind, D. (1989). Developmentally appropriate practice: Philosophical and practical implications. Phi Delta Kappan, 71(2), 113-117.

Engel, P. (1991). Tracking progress toward the school readiness goal. Educational Leadership, 48(5), 39-42.

Engle, D. (1988). What research reveals about dropouts and at-risk youth. The Bridge, 1(1), 3 .

Farley, E. S. (1936). Regarding repeaters--sad effects of failures upon the child. Nation's Schools, 18(4), 37-39.

Finlayson, H. J. (1977). Nonpromotion and self-concept development. Phi Delta Kappan, 59(9), 205-206.

Finn, C. E., Jr. (1991). The ho-hum revolution. The Wilson Quarterly, 15(3), 63-76. 
Fitzgerald, S., Ronk, J., \& Howe, D. (1984) . School readiness: Teacher judgment versus formal assessment. Ann Arbor: Michigan State University. (Eric Document No. Ed 264 045)

Foulks, B., \& Morrow, R. D. (1989). Academic survival skills for the young child at risk for school failure. Journal of Educational Research, 82 (3), 158-165.

Fradd, S. H., \& Weismantel, M. J. (Eds.). (1989) . Meeting the needs of culturally and linguistically different students: A handbook for educators. Boston: College-Hill.

Frymier, J. (1989, December 6). Retention in grade is "harmful" to students. Education Week, p. 32.

Frymier, J. (1990). A tale of two crises. Principal, $69(3), 52-53$.

Frymier, J., \& Gansneder, B. (1989). The Phi Delta Kappa study of students at risk. Phi Delta Kappan, 71(2), 142-146.

Galloway, J. E., \& George, J. (1986). Junior kindergarten. Educational Leadership, $44(3), 68-69$.

Gallup, A. M. (1986, September). The 18th annual Gallup poll of the public's attitudes toward the public schools. Phi Delta Kappan, 68, 43-59.

Gay, L. R. (1987) . Educational research: Competencies for analysis and application (3rd ed.). Columbus, OH: Merrill.

Germain, R. B., \& Merlo, M. (1985). Best practices in assisting in promotion and retention decisions. In $A$. Thomas \& J. Grimes (Eds.), Best practices in school psychology (pp. 171-180). Kent, OH: The National Association of School Psychologists.

Gesell, A., Halverson, H. M., Thompson, H., Ilg, F. L., Castner, B. M. Ames, L. B., \& Amatruda, C. S. $(1940)$. The first five years of life. New York: Harper and Brothers.

Gesell, A., \& Ilg, F. L. (1946). The child from five to ten. New York: Harper and Brothers.

Glaser, B. G. (1967) - The discovery of grounded theory: Strategies for qualitative research. Chicago: Aldine. 
Glaser, B. G., \& Strauss, A. L. (1967). The discovery of grounded theory: Strategies for gualitative research. Hawthorne, NY: Aldine.

Glaze, L. (1989). Grade retention: Administrative considerations. The oregon Elementary school Principal, 50(2), 8-9.

Goodlad, J. (1954). Some effects of promotion and non-promotion upon the social and personal adjustment of children. Journal of Experimental Education, $\underline{22}(4), 301-328$.

Goodlad, J. I., \& Anderson, R. H. (1987). The nongraded elementary school. New York: Teachers College Press.

Gorton, J. I., \& Robinson, R. L. (1970, May) . Non-promotion: Concern of a nation. Pennsylvania School Journal, 118, 264-266.

Gottfredson, G. D. (1988). You get what you measure, you get what you don't: Higher standards, higher test scores, more retention in grade (Report No. 29). Baltimore, MD: Center for Research on Elementary and Middle Schools. (ERIC Document Reproduction Service No. ED 301325 )

Graham, D. R. (1982, March). An investigation of teachers' and administrator's decision-making behaviors and attitudes concerning the promotion and retention of elementary students. Paper presented at the annual meeting of the American Educational Research Association, New York.

Gredler, G. R. (1978). A look at some important factors in assessing readiness for school. Journal of Learning Disabilities, 11(5), 25-31.

Gredler, G. R. (1984). Transition room classes: A viable alternative for the at-risk child? Psychology in the Schools, 21(4), 463-470.

Grissom, J. B., \& Shepard, L. A. (1989). Repeating and dropping out of school. In L. A. Shepard \& M. L. Smith (Eds.), Flunking grades: Research and policy on retention (pp. 34-63). Philadelphia: Falmer Press

Haddad, W. D. (1979). Educational and economic effects of promotion and repetition practices. Washington, DC: The World Bank. (ERIC Document Reproduction Service No. ED 195 003) 
Hafner, A., Ingels, S., Schneider, B., \& Stevenson, D. (1990). National education longitudinal study: A profile of the American 8th grader (Report No. NCES 90 458) Washington, DC: National Center for Education statistics.

Hagaman, N. C. (1947). Transition first grade classes and their values. California Journal of Elementary Education, 15 $(3 / 4), 171-192$.

Hagen, J. M. (1980). I kept eight students back - . $\cdot$ and I'm still alive to tell about it. Teacher, 28(1), 47-49.

Hagin, R. A. (1984). Effects on first-grade promotion practices of a program for the prevention of learning disabilities. Psychology in the Schools, 21(4), 471-476.

Hallenbeck, M. J. (1981, February). Considerations for retention in the elementary grades. Kappa Delta Pi Record, 17(3), 66-69.

Hamilton, S. F. (1986). Raising standards and reducing drop-out rates. Teachers college Record, 87(3), 410-429.

Hammond, C. H. (1986). Not ready! Don't rush me! Childhood Education, 62(4), 276-280.

Harvard Graduate School of Education. (1991) . Retention: Can we stop failing kids? The Harvard Education Letter, I(3), 1-3.

Hatch, J. A., \& Freeman, E. B. (1988) . Who's pushing whom? Stress and kindergarten. Phi Delta Kappan, 70(2), 145-147.

Hechinger, F. M. (1988, September 14). Repeating kindergarten: Does it hurt more than it helps? New York Times, p. 24 .

Hills, T. W. (1987). Hothousing young children: Implications for early childhood policy and practice. Urbana IL: ERIC Clearinghouse on Elementary and Early Childhood Education. (ERIC Document Reproduction Service No. ED 294 653)

Holloman, S. T. (1990). Retention and redshirting: The dark side of kindergarten. Principal, 69(5), 13-15.

Holmes, C. T. (1983). The fourth r: Retention. Journal of Research and Development in Education, 17(1), 1-6. 
Holmes, C. T. (1986, April). A synthesis of recent research on nonpromotion: A five year follow-up. Paper presented at the annual meeting of the American Educational Research Association, San Francisco, CA.

Holmes, C. T. (1989). Grade level retention effects: A meta-analysis of research studies. In L. A. Shepard \& M. L. Smith (Eds.), Flunking grades: Research and policies on retention (pp. 16-33). Philadelphia: Falmer.

Holmes, C. T., \& Matthews, K. M. (1984). The effects of nonpromotion on elementary and junior high school pupils: A meta-analysis. Review of Educational Research, 54(2), 225-236.

House, E. (1989). Policy implications of retention research. In M. L. Smith \& L. A. Shepard (Eds.), Flunking grades: Research and policies on retention (pp. 202-213). Philadelphia: Falmer.

Ilg, F. L., \& Ames, L. B. (1966, August). Your child may be in the wrong grade. Reader's Digest, pp. 56-60.

Ilg, F. L., Ames, L. B., Haines, J., \& Gillespie, C. (1978). School readiness (rev. ed.). New York: Harper and Row.

Jackson, G. B. (1975). The research evidence on the effects of grade retention. Review of Educational Research, 45(4), 613-635.

Johnson, D. S. (1981). Naturally acquired learned helplessness: The relationship of school failure to achievement behavior, attributions, and self-concept. Journal of Educational Psychology, 73(2), 174-180.

Johnson, J. (1984) . Synthesis of research on grade retention and social promotion. Educational Leadership, 41(5), 66-68.

Kilby, G. (1984, May) . Heading off failure before it starts. Principal, $\underline{44}(3), 28-31$.

King, M. J. (1984). Ready or not, here they come: A sourcebook on developmental readiness for parents, teachers, and school boards. Unpublished master's thesis, California State University, Fresno, CA.

Koons, C .L. (1977). Nonpromotion: A dead-end road. Phi Delta Kappan, 58(9), 701-702. 
Labaree, D. F. (1984). Setting the standard: Alternative policies for student promotion. Harvard Educational Review, 54(1), 67-87.

Leddick, L. (1988). Factors related to promotion and retention decisions (ED 309524). Detroit, MI: Detroit Public Schools, Department of Research and Evaluation.

Lehr, F. (1982). Grade repetition vs. social promotion. The Reading Teacher, $36(2), 234-237$.

Leinhardt, G. (1980). Transition rooms: Promoting maturation or reducing education? Journal of Educational Psychology, 72(1), 55-61.

Lieberman, L. (1980). A decision making model for in-grade retention (nonpromotion). Journal of Learning Disabilities, 13(5), 268-272.

Light, H. W. (1977). Light's retention scale. San Rafael, CA: Academic Therapy Publications.

Light, H. W. (1981). Light's retention scale manual (rev. ed.). Novato, CA: Academic Therapy Publications.

Lindau, M. S. (1987, April 8). Holding a child back may be beneficial. This Week, p. 2 .

Lindelow, J. (1985). The grade retention/social promotion debate. Research Roundup, National Association of Elementary School Principals, 2(1), 1-4.

Lindvig, E. K. (1983) . Grade retention: Evolving expectations and individual differences. clearing House, 56 (6), 253-256.

Lloyd, D. N. (1978). Prediction of school failure from third-grade data. Educational and Psychological Measurement, 38, 1,193-1,200.

Martin, A. (1988). Screening, early intervention, and remediation: Obscuring children's potential. Harvard Educational Review, 58 (4), 488-501.

Mateer, K. H. (1956). Stay or go? Grade Teacher, 73 (8), 139 .

May, D. C., \& Welch, E. L. (1984). The effects of developmental placement and early retention on children's later scores on standardized tests. Psychology in the schools, 21(7), 381-385. 
McAfee, J. K. (1981, April). Towards a theory of promotion: Does retaining students really work? The annual meeting of the American Educational Research Association, Los Angeles, CA. (ERIC Document Reproduction Service No. ED 204871 )

McDill, E. L., Natriello, G., \& Pallas, A. M. (1985). Raising standards and retaining students: The impact of the reform recommendations on potential dropouts. Review of Educational Research, 55(4), 415-433.

McNergney, R., \& Haberman, M. (1989, November). Retention holds kids back. NEA Today, p. 32 .

Medway, F. J., \& Rose, J. S. (1986). Grade retention. In T. R. Kratochwill (Ed.), Advances in school psychology (pp. 141-175). Hillsdale, NJ: Lawrence Erlbaum.

Meisels, S. J. (1987, January). Uses and abuses of developmental screening and school readiness testing. Young Children, $42(2), 4-6,68-73$.

Meisels, S. J. (1989a). Can developmental screening tests identify children who are developmentally at risk? Pediatrics, 83(4), 578-585.

Meisels, S. J. (1989b). High-stakes testing in kindergarten. Educational Leadership, 46(2), 16-22.

Miller, M., Frazier C., \& Richey, D. (1980). Student nonpromotion and teacher attitude. Contemporary Education, 51(3), 155-157.

Millex, W. D., \& Norris, R. C. (1967). Entrance age and school success. Journal of School Psychology, $6(1)$, 47-60.

Morrison, I. E. \& \& Perry, I. F. (1956). Acceptance of overage children by their classmates. Elementary School Journal, 56(5), 217-220.

Mullis, I., Owen, E., \& Phillips, G. (1990). Accelerating academic achievement (Report No. 19-0V-01). Princeton, NJ: National Testing Service, U.S. Department of Education.

Murphy, D. M. (1986). Educational disadvantagement: Associated factors, current interventions, and implications. Journal of Negro Education, 55(4), 495-507. 
National Association of Early Childhood Specialists in state Departments of Education. (1987). Unacceptable trends in kindergarten entry and placement: A position statement. Paper presented at the annual meeting of the National Association of Early Childhood Specialists in State Department of Education, Chicago, IL.

National Association for the Education of Young Children. (1986). Position statement on developmentaliy appropriate practice in early childhood programs serving children from birth through age 8 . young Children, 41(6), 4-29.

National Association for the Education of Young Children. (1988). Position statement on developmentally appropriate practice in the primary grades, serving 5 through 8 year olds. Young Children, 43(2), 64-84.

National Association of School Psychologists. (1988). position statement, student grade retention. Washington, DC: Author.

National Association of state Boards of Education. (1988). Right from the start: The report of the NASBE task force on early childhood education. Alexandria, VA: Author.

National Black Child Development Institute. (1990). Status of African American children twentieth anniversary report 1970-1990. Washington, DC: Author.

National Commission on Excellence in Education. (1983). A nation at risk: The imperative for educational reform (S6059-S6065). Washington, DC: U.S. Department of Education.

Natriello, G., McDill, E. L., \& Pallas, A. M. (1990). schooling disadvantaged children: Racing against catastrophe. New York: Teachers College Press.

Niklason, L. (1984). Nonpromotion: A psuedoscientific solution. Psychology in the Schools, 21(4), 485-499.

Niklason, L. B. (1987). Do certain groups of children profit from a grade retention? psychology in the Schools, 24 (4), 339-45.

Norton, M. S. (1983). It's time to get tough on student promotion--or is it? Contemporary Education, 54(4), 283-286. 
Oakes, J. (1983). Tracking and ability grouping in American schools: Some constitutional questions. Teachers College Record, 84(4), 801-819.

Olson, L. (1990, May 16). Education officials reconsider policies on grade retention. Education Week, pp. 1, 13.

Opperman, P. W. (1980). Transitional class program, 1979-80. Brooklyn, NY: New York City Board of Education, Dee Evaluation Report, Office of Educational Evaluation.

Oregon Department of Education. (1991). Oregon state assessment. Salem, OR: Author.

Oregon Research on Education. (1988, June). Population and enrollment trends in oregon education. Salem, OR: office of Educational Policy and Planning.

Ostrowski, P. M. (1987). Twice in one grade: A false solution. A review of the pedagogical practice of grade retention in elementary schools: What do we know? Should the practice continue? Providence: Rhode Island state Department of Education.

Overman, M. (1986). Practical applications of research: student promotion and retention. Phi Delta Kappan, $\underline{67}(8), 609-613$.

Owen, S. A., \& Ranick, D. L. (1977). The Greensville program: A commonsense approach to basics. Phi Delta Kappan, 58 (7), 531-539.

Palardy, J. M. (1984). An analogy for reviewing promotion/retention and minimum competency decisions. Education, 104(4), 401-404.

Pallas, A. M., Natriello, G., \& MCDill, E. L. (1987). The high costs of high standards. Urban Education, 22 (1), 103-113.

Peck, P. (1989). Closing in on success. Instructor, $98(6), 30-32$.

Pennsylvania state Department of Education. (1985). promotion/retention: Policies and quidelines. Turning the tide: An agenda for excellence in Pennsylvania public schools. Harrisburg: Pennsylvania state Department of Education. (ERIC Document Reproduction Service No. ED 260 499) 
Peterson, P. L. (1989). Alternatives to student retention: New images of the learner, the teacher and classroom learning. In L. A. Shepard \& M. I. Smith (Eds.), Flunking grades: Research and policies of retention (pp. 174-201). Philadelphia: Falmer.

Peterson, S. E., DeGracie, J. S., \& Ayabe, C. R. (1987). Longitudinal study of the effects of retention/promotion on academic achievement. American Educational Research Journal, 24(1), 107-118.

Pipho, c. (1978). Minimum competency testing in 1978; A look at state standards. Phi Delta Kappan, 59(9), 585-588.

Plummer, D. L., \& Graziano W. G. (1982). The impact of grade retention on the social development of elementary school children. Unpublished manuscript, University of Georgia, Psychology Department, Athens, GA.

Plummer, D. L., Lineberger, M. H., \& Graziano, W. G. (1986): The academic and social consequences of grade retention: A convergent analysis. In L. G. Katz (Ed.), Current topics in early childhood education, (pp. 224-252). Norwood, NJ: Ablex Publishing Company.

Rachal, J. (1986). Student placement study: 1985-86 state-funded compensatory/remedial program evaluation placement report (Bulletin 1765). Baton Rouge: Louisiana state Department of Education, Office of Research and Development.

Rachal, J., \& Hoffman, L. M. (1986). A four-year longitudinal study of the sustained effects of promotion-retention and skill-specific intervention relative to identified deficiencies on the performance of elementary students. Baton Rouge: Louisiana state Department of Education, Office of Research and Development.

Rafoth, M. A., Dawson, P., \& Carey, K. (1988, March). Retention promotion practices: A review of the literature and survey of state school psychology consultants. Paper presented at the annual convention of the National Association of School Psychologists, Chicago, IL.

Ralph, J. (1989). Improving education for the disadvantaged: Do we know whom to help? Phi Delta Kappan, 70 (5), 395-401. 
Remmey, N., \& McIlhenny, D. T. (1987). Two year developmental kindergarten program. Warminster, PA: Centennial School District.

Riffel, J. A., \& Switzer, M. (1986) . Student promotion and retention: Towards a model policy. Education Canada, $\underline{26}(3), 4-8$.

Riley, R. W. (1986). Can we reduce the risk of failure? Phi Delta Kappan, 68(4), 214-219.

Rose, J. S., \& Medway, F. J. (1981). Measurement of teachers' beliefs in their control over student outcome. Journal of Educational Research, 74(3),

Rose, J. S., Medway, F. J., Cantrell, V. L., \& Marus, S. H. (1983). A fresh look at the retention-promotion controversy. Journal of School Psychology, 21 (3), 201-211.

Rothman, R. (1989, December 13). NAEP ponders plan to develop national performance goals. Education Week, pp. 1, 21 .

Rothman, R. (1990a, May 2). Abolish grade retention, Massachusetts chief says. Education Week, p. 17.

Rothman, R. (1990b, December 5). Bush panel members express support for a national test. Eduction Week, p. 18 .

Rothman, R. (1990c, August 1). Study of 8 th graders finds $20 \%$ at high risk of failure. Education Week, p. 11.

Safer, D. (1977). Socioeconomic factors influencing the rate of non-promotion in elementary schools. Peabody Journal of Education, 54(4), 275-281.

Safer, D. (1986). Nonpromotion correlates and outcomes at different grade levels. Journal of Learning Disabilities, $19(8), 500-503$.

Sandoval, J. (1982). Light's retention scale does not predict success in first-grade retainees. Psychology in the Schools, 19(3), 310-314.

Sandoval, J. (1984). Repeating the first grade: How the decision is made. Psychology in the schools, 21 (4), 457-476. 
Sandoval, J., \& Fitzgerald, P. (1985). A high school follow-up of children who were nonpromoted or attended a junior first grade. Psychology in the schools, 22(2), 164-170.

Sandoval, J., \& Hughes, G. P. (1981). Success in nonpromoted first grade children. Davis, CA: California University. (ERIC Document Reproduction Service No. ED 212 371)

Schatzman, L., \& Strauss, A. L. (1973). Field research: strategies for a natural sociology. Englewood Cliffs, NJ: Prentice-Hall.

Schultz, T. (1989). Testing and retention of young children: Moving from controversy to reform. Phi Delta Kappan, 71(2), 125-128.

Schuyler, N. B. (1985, April). Does retention help? Perspectives after three years. Austin, TX: Austin Independent School District, Office of Research and Evaluation.

Schweinhart, L. J., Koshel, J. J., \& Bridgman, A. (1987). Policy options for preschool programs. Phi Delta Kappan, 68(7), 524-529.

Schweinhart, L. J., \& Weikart, D. P. (1986). Early childhood development programs: A public investment opportunity. Educational Leadership, 44(3), 4-12.

Scott, B. A., \& Ames, L. B. (1969, May). Improved academic, personal, and social adjustment in selected primary school repeaters. The Elementary School Journal, 69, 431-439.

Seidel, J. V., Kjolseth, R., \& Seymour, E. (1988). The ethnograph: A Program for the computer assisted analysis of text based data [Computer program]. Littleton, CO: Qualis Research Associates.

Shepard, L. A. (1989). A review of research on kindergarten retention. In L. A. Shepard \& M. L. Smith (Eds.), Elunking grades: Research and policies on retention (pp. 64-78). Philadelphia: Falmer.

Shepard, L. A., \& Smith, M. L. (1985). Boulder Valley kindergarten study: Retention practices and retention effects. Boulder, co: Boulder Valley Public Schools. 
Shepard, L. A., \& Smith, M. L. (1986). Synthesis of research on school readiness and kindergarten

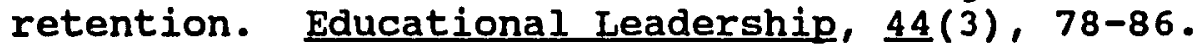

Shepard, L. A., \& Smith, M. L. (1987). Effects of kindergarten retention at the end of first grade. Psychology in the Schools, 24(4), 346-357.

Shepard, L. A., \& Smith, M. I. (1988a). Escalating academic demand in kindergarten: Counterproductive policies. The Elementary School Journal, 89(2), 135-145.

Shepard, L. A., \& Smith, M. L. (1988b). Flunking kindergarten: Escalating curriculum leaves many behind. American Educator: The Professional Journal of the American Federation of Teachers, 12(2), 34-38.

Shepard, L. A., \& Smith, M. L. (Eds.) . (1989). Flunking grades: Research and policies on retention. Philadelphia: Falmer.

Shepard, I. A., \& Smith, M. L. (1990). Synthesis of research on grade retention. Educational Leadership, $\underline{47}(8), 84-88$.

Slavin, R. E. (1987). Ability grouping and student achievement in elementary schools: A best-evidence synthesis. Review of Educational Research, 57(3), 293-336.

Slavin, R. E., Karweit, N. L., \& Madden N. A. (1989). Effective programs for students at risk. Boston: Allyn and Bacon.

Smith, M. L. (1989). Teachers' beliefs about retention. In L. A. Shepard \& M. L. Smith (Eds.), Flunking grades: Research and policies of retention (pp. 132-150). Philadelphia: Falmer.

Smith, M. L., \& Shepard, L. A. (1987). What doesn't work: Explaining policies of retention in the early grades. Phi Delta Kappan, 68(2), 129-134.

Smith, M. L., \& Shepard, L. A. (1988). Kindergarten readiness and retention: A qualitative study of teachers' beliefs and practices. American Educational Research Journal, 25(3), 307-333. 
Smith, M. L., \& Shepard, L. A. (1989). Flunking grades: A recapitulation. In $L$. A. Shepard \& M. L. Smith (Eds.), Flunking grades: Research and policies on retention (pp. 214-236). Philadelphia: Falmer.

Soderman, A. K., \& Phillips, M. (1986). The early education of males: Where are we failing them? Educational Leadership, 44(3) 70-72.

Solem, M. R. (1981). Junior first grade: A year to get ready. Phi Delta Kappan, 63 (4), 283-284.

Solodrzano, L., \& Atkins A. (1990, September 6). Holding a child back a grade? It may be a bad idea, experts say. The oregonian, p. D4.

Spradley, J. P. (1979). The ethnographic interview. New York: Holt, Rinehart and winston.

Staff. (1990, October). Texas won't fail kindergartners. Communicator, $14(2), 11$.

Stainback, W., \& Stainback, S. (Eds.). (1990). Support networks for inclusive schooling: Interdependent integrated education. Baltimore: Brooks.

Stammer, J. D. (1987) . Retaining or promoting a child: Making the best decision. PTA Today, 13(1), 13-14.

stammer, J. D., \& Cooke, G. E. (1986). A decision making model for promotion, retention, and placement at the elementary level. ERS Spectrum, $\underline{4}(3), 43-46$.

Steinberg, A. (1990). Kindergarten: Producing early failure? Principal, 69(5), 6-9.

stennett, R. G., \& Earl, L. M. (1984) . Early identification system: Followup of those students in the kindergarten class of $1978-79$ who did not reach grade 4 in 1982-83 (Report No. 84-070). Ontario: London Board of Education.

Stringer, I. A. (1960, April). Report on a retentions program. Elementary School Journal, 60(7), 370-375.

Stroup, A. L., \& Robbins, L. N. (1972). Elementary school predictors of high school dropout among Black males. Sociology of Education, 45, 212-222.

Stroup, S., \& zirkel, P. A. (1983). A legal look at the retention-promotion controversy. Journal of School Psychology, 21 (3), 213-217. 
SYSTAT, Inc. (1990) - SYSTAT [Computer program] Evanston, IL: Author.

Taylor, B. L. (1978). Effects of minimum competencies on promotion standards. Educational Leadership, $\underline{36}(1)$, 23-26.

Taylor, S. J., \& Bogdan, R. (1984). Introduction to gualitative research methods: The search for meanings (2nd ed.). New York: John Wiley.

Templin, R. S. (1940). A check-up of non-promotions. Journal of Education, 123(8), 259-260.

Terman, L. M., \& Merrill, M. A. (1937). Measuring intelligence. Boston: Houghton Mifflin.

Thompson, M. (1979a). Because schools are burying social promotion, kids must perform to pass. American School Board Journal, 166 (1) 30-32.

Thompson, M. (1979b) . Social promotion: Going, going . . . gone? Education Digest, $44(8), 11-13$.

Thompson, S. (1980). Grade retention and social promotion. School Management Digest, $1(20)$.

Toch, T. (1984). The dark side of the excellence movement. Phi Delta Kappan, 66(3), 173-176.

Towner, D. R. (1988). A review of research literature on the effects of pupil retention. Unpublished master's thesis, Indiana University, South Bend, IN.

Trevino, S. G. (1991). Mission impossible? Success for at-risk students. Principal, 70(3), 31-32.

Tyack, D. B. (1974). The one best system. Cambridge: Harvard University Press.

Uphoff, J., \& Gilmore, J. (1985). Pupil age at school entrance: How many are ready for success? Educational Leadership, 43(1), 86-90.

Vasa, S. (1984). Light's retention scale: Does it have content validity? Psychology in the Schools, 21(4), 447-449.

Vogler, G. P., Defrieds, J. C. \& Decker, S. N. (1985). Family history as an indicator of risk for reading disability. Journal of Learning Disabilities, 18(7), 419-421. 
Walden, J. C., \& Gamble, L. R. (1985). Student promotion and retention policies: Legal considerations. Journal of Law and Education, 14(4), 609-623.

Walker, E., \& Madhere, S. (1987). Multiple retentions: Some consequences for the cognitive and affective maturation of minority elementary students. Urban Education, 22(1), 85-102.

Walker, N. W. (1984). Elementary school grade retention: Avoiding abuses through systematic decision-making. Journal of Research and Development in Education, $18(1), 1-6$.

Walker, R. (1989, December 13). Bush and governors may set goals a month early. Education Week, p. 21.

Walker, W. E. (1973). The slow-progress student in graded and nongraded programs. Peabody Journal of Education, $\underline{50}(3), 191-210$.

Weaver, R. I. (1990) . Separate is not equal. Principal, $\underline{69}(5), 40-42$.

Weinstein, L. (1968-69). School entrance age and adjustment. Journal of School Psychology, I(3), 20-28.

White, K. R. (1985) . Efficacy of early intervention. The Journal of Special Education, 19(4), 401-416.

White, K. , \& Howard, J. L. (1973). Failure to be promoted and self concept among elementary school children. Elementary School Guidance and counseling, I(3), 182-187.

Will, M. C. (1986). Educating children with learning problems: A shared responsibility. Exceptional children, $\underline{52}(5), 411-415$.

Williams, M. (1987). What do we does with "what do it does?" kindergartners? Young Children, 42(5), 28-29.

Yin, R. K. (1989). Case study research: Design and methods (rev. ed.). Newbury Park, CA: Sage.

Zinski, J. P. (1983, summer). A study of the effects of a pre-first grade transitional class as compared with first grade retention on reading achievement. Florida Educational Research and Development Council Research Bulletin, 17(1), 1-50. 
Zirkel, P. A., \& Gluckman, I. B. (1982). A legal brief: Nonpromotion of students. NASSP Bulletin, $66(452)$, 114-116. 
APPENDIX A

DEFINITION OF TERMS 


\section{DEFINITION OF TERMS}

Achievement: A student's progress in mastering the work of the current grade assignment.

Achievement Test: A test used to measure a student's mastery of subject matter presented; usually of the basic skills and given annually.

At Risk: Those students considered in jeopardy of school failure.

Blended Classroom: A classroom where two grades are taught in one room with integrated instruction.

Failure: The inability of the student to master the work of the grade; the denial of promotion, resulting in a student's repeating the same grade.

Free Lunch Program: A federal program based upon financial need to provide qualifying students with a free or reduced price school lunch.

Grade Placement: The level to which a student is assigned.

Non-promotion: The practice of keeping a student in the same grade; the failure to be promoted.

Probationary promotion: The practice of promoting a student the next grade level on a trial basis.

Promotion: The assignment of a student to the next higher grade.

Pupil/Teacher Ratio: The number of students per teacher.

Remediation: Efforts to assist the student with

achievement, other than the usual program.

Repeater: A student who is assigned to repeat the work and subject matter of the grade/year just completed.

Retention: Training or keeping a student in the same grade for a second year. The failure to be promoted.

Retention process: The method by which a decision to retain or promote a student is made.

Self-concept: The image or perception of oneself as an individual. 
Social Promotion: The practice of promoting or advancing a student to the next grade for reasons other than achievement.

Socio-economic status: The classification of students or families based upon their financial means, established by guidelines for the federal free lunch program.

Special Education: Specialized classes to assist students who qualify through identified need.

Stability: A school characteristic determined by the attendance of the student population.

Transition class: A half-step class in the graded school to help students considered unready for the next grade. This is usually a class between kindergarten and first grade.

Ungraded Primary: A reorganization of normally graded classes into an ungraded structure using a continuous progress model for planning curriculum and measuring achievement. 
APPENDIX B

SURVEY LETTER TO RESPONDENTS AND FOLLOW-UP LETTER 
December 1, 199].

Dear Colleague:

If you have returned the survey I sent you in october, Tus ar? you! If you have not yet done so, I am enclosing a second copy with a stamped envelope for your convenience. I realize ho: busy you are but your input is greatly needed to complete this study regarding student non-promotion.

I would appreciate your response as soon as possible. The survey is brjef and should take only a few minutes of your time. ALI RESPONSES WILL BE KEPT STPICTLY CONFIDENTIAL AND TIIL BE REPORTED BY CATEGORY AND NOT BY NAME OR PLACE. Since the results are confidential, all participants will receive this letter. If you have any guestions, please call me at $255-$ 5508. I am grateful for your help and assistance with this project.

sincerely,

Doris Cameron-Minar

Doctoral Cancidate, Dortland State University 
Dear Coll eague

My name is norjs Minard. I am a principal in the David Douglas school nistrict and a doctoral student at port]and state Iniversity.

The tonjc of my dissertation concerns the methods schools use to make non-promotion (retention) decisions in kindergarten and fjrst grade. This is a timejy issue as school accountability for student success is increasingly discussed and as educators try to reduce student drop-out rates.

You are one of the teachers sejected to particinate in this survey. Its nurnose is to (I) identify the the process you and your staff use to make retentjon decisjons and (2) to ohtain your opinions ahout the effectiveness of retention.

kindergarten, first grade teachers, and principals from nine schnols wijl be surveyed. A non-random sample of responcients will also be interviewer in person. since the number of participants is smalj, it is especially important that I have vour assistance. This will. help to clarify current school policies and practices as well as educators' beliefs about retention.

Please take a few minutes to fil] out the enclosed survey and return it in the envelope provined. ALL RESPONSES WILL BE REPT STRICTLY CONFIDENTIAL. No names or other joientifying data are necessary aric all data will be reported as groun clata.

I womld be hanpy to share the results of the study with you. If you wish to have a summary of the report, please indicate on the survey jtself or call me at. 256-6508.

I apprecjate your assistance with this project. Thank you for your time and help.

Rest regaris:

Doris Minard

$9 / 91$ 
APPENDIX C

LIST OF CODE CATEGORIES 
DORIS MILARD is COOEBOOK

VARIABLE MANE

STATUS

CURPOS

TAUGITG

TAUGHT

YEARSSC

GENDER

EDULEVL

STPOP

NCLASSK

NCLASSF

NCLASST

K39091

K38990

K38889

F69091

F68990

F68889
VALUE

1. HIGH

2. MIODLE

3. LOW

1. KINDERGARTEN TEACHER

2. FIRST GRADE TEACHER

3. PRINCIPAL

1. $1-3$ YEARS

2. $4-10$

3. $11-15$

4. OVER 15

1. $1-3$

2. $4-10$

2. $4-10$

4. $16 \cdot 20$

5. $21+$

1. 1-3

2. $4-10$

3. $11 \cdot 15$

4. OVER 15

1. MALE

2. FEMALE

1. $B A / B A$

2. BA/BS PLUS

3. $M A$

4. MA PLUS

5. Ph.D

1. BELOH 300

2. $300-400$

3. $400-500$

4. $500-600$

5. OVER 600

ACTUAL \# OF CLASSROOMS

ACTUAL \# OF CLASSROOMS

ACTUAL \# OF CLASSROOMS

$\#$

\#

$\#$

\#

*
EXPLAMATION

CURRENT POSITION

NUMBER OF YEARS TEACHING AT THIS GRADE LEVEL

TOTAL YEARS A TEACHER OR PRINCIPAL HAS TAUGHT

NUMBER OF YEARS AT THIS SCHOOL

GENDER

EDUCATION LEVEL

STUDENT POPULATION OF BUILDING

CLASSROOMS IN KINDERGARTEN

CLASSROOMS IH FIRST GRADE

TRANSITIONAL CLASSROOMS

NUMBER OF STUDENTS RETAINED

NUMBER OF STUDENTS RETAIMED

NUMBER OF STUOENTS RETAINED

HUMBER OF STUDENTS RETAINED

NUMBER OF STUDENTS RETAINED

NUMBER OF STUDENTS RETAINED 
PAGE THREE AND FOUR QUESTIONS

\begin{tabular}{|c|c|}
\hline HRITPOL & $\begin{array}{l}\text { 1. YES } \\
\text { 0. NO } \\
\text { 2. UNSURE }\end{array}$ \\
\hline DEVPRH & $\begin{array}{l}\text { 1. YES } \\
\text { 0. NO }\end{array}$ \\
\hline DEVCO & $\begin{array}{l}\text { 1. YES } \\
0 . \text { NO }\end{array}$ \\
\hline DEVDC & $\begin{array}{l}\text { 1. YES } \\
0 . \text { NO }\end{array}$ \\
\hline DEVMOT & $\begin{array}{l}\text { 1. YES } \\
\text { 0. HO }\end{array}$ \\
\hline DEVBd & $\begin{array}{l}\text { 1. YES } \\
0 \text {. NO }\end{array}$ \\
\hline DEVSEDD & $\begin{array}{l}\text { 1. YES } \\
\text { 0. HO }\end{array}$ \\
\hline DEWNSUR & $\begin{array}{l}\text { 1. YES } \\
0 . \text { NO }\end{array}$ \\
\hline FOLDPOL & $x$ VALUE \\
\hline PARDCMKG & $\begin{array}{l}\text { 0. UNSURE } \\
\text { 1. NEVER } \\
\text { 2. RARELY } \\
\text { 3. SOMET IMES } \\
\text { 4. USUALLY } \\
\text { 5. ALWAYS }\end{array}$ \\
\hline PARCHDEC & SAME AS ABOVE \\
\hline SPOL & $\begin{array}{l}\text { 1. NO POLICY } \\
\text { 2. AN UNURITIEN POLICY } \\
\text { 3. A WRITTEN POLICY }\end{array}$ \\
\hline SPOLDEV & $\begin{array}{l}\text { 1. PRINCIPAL } \\
\text { 2. TEACHERS } \\
\text { 3. BUILDING COHMIITEE/INCLUDING } \\
\text { SPECIALISTS } \\
\text { 4. BOARD } \\
\text { 5. DISTRICT/OISTRICT COMM. } \\
\text { 6. UHSURE } \\
\text { 7. FROH ANOTHER SCHOOL }\end{array}$ \\
\hline FOLSPOL & $x \#$ \\
\hline PARCONS & $\begin{array}{l}\text { 0. UNSURE } \\
\text { 1. NEVER } \\
\text { 2. RARELY } \\
\text { 3. SOMETIMES } \\
\text { 4. USUALLY } \\
\text { 5. ALWAYS }\end{array}$ \\
\hline FINDEC & $\begin{array}{l}\text { 1. PRINCIPAL } \\
\text { 2. TEACHER } \\
\text { 3. PARENT } \\
\text { 4. PRINCIPAL/TEACHER/PAREHT } \\
\text { 5. TEAH }\end{array}$ \\
\hline
\end{tabular}

DOES THE SCHOOL DISTRICT HAVE A URITTEN RETENTION POLICY

POLICY DEVELOPED BY PRINCIPALS

POLICY DEVELOPED BY CEN. OFFICE

POLICY DEVELOPED BY DISTRICT COMMITTEE

POLICY DEVELOPED BY MULTI.DISC. TEAM

BOARD

SPECIAL ED/OIST

UNSURE HHO POLICY WAS DEVELOPED BY

PROPORTION IN PERCENTAGE OF STAFF IN THE SCHOOL THAT FOLLOWS THE DISTRICT RETENTION POLICY

HON OFTEN THE POLICY ALLOWS PARENTS TO PARTICIPATE IN RETENTIOH DEC. MKG.

HOW OFTEN THE POLICY ALLOWS PARENTS TO CHALLENGE THE RETENTION DECISION

WHETHER THE SCHOOL HAS NO POLICY ON RETENTION, AH UNURITTEN ONE OR A WRITTEN ONE

RETENTION POLICY AT THIS SCHDOL DEVELOPED BY WHOM

PERCENTAGE OF THE STAFF THAT FOLLONS THE SCHOOL'S RETENTION POLICY

HOW OFTEN PARENTAL CONSENT IS REOUIRED BEFORE A CHILO CAN BE RETAINEO AT THIS SCHOOL

WHO HAS THE FINAL DECISION TO RETAIN A CHILD 
DECISION MUKING PROCESS OUESTIONS

\begin{tabular}{|c|c|c|}
\hline DMP1 & $\begin{array}{l}\text { 0. UNSURE } \\
\text { 1. HEVER } \\
\text { 2. RARELY } \\
\text { 3. SOMET IHES } \\
\text { 4. USUALLY } \\
\text { 5. ALHAYS }\end{array}$ & $\begin{array}{l}\text { DECISION-MAKING PROCESS IF } \\
\text { PARENT OPPOSES RETENTIOH THE } \\
\text { STUDENT IS ALHAYS PROHOTED... }\end{array}$ \\
\hline DMP2 & SAME AS ABOVE & $\begin{array}{l}\text { TEACHER MUST CONSULT WITH THE } \\
\text { PRIHCIPAL BEFORE A RETENTION } \\
\text { DECISION IS MADE... }\end{array}$ \\
\hline DMP3 & SAME AS ABOVE & $\begin{array}{l}\text { THE TEACHER MUST COHSULT HITH } \\
\text { OTHER BUILDIHG PERSOHNEL BEFORE } \\
\text { A RETENTION DECISIOH IS MADE... }\end{array}$ \\
\hline DMP4 & SAHE AS ABOVE & $\begin{array}{l}\text { DATA ARE REQUIRED TO SUPPORT A } \\
\text { RETENTION RECOMMENDATION }\end{array}$ \\
\hline TABLE PAGE & nat & 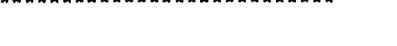 \\
\hline 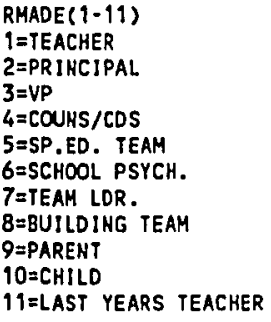 & $\begin{array}{l}\text { 0. NO } \\
\text { i. YES }\end{array}$ & RETENTION RECOMMEDATION MADE BY \\
\hline $\begin{array}{l}\text { RRECD }(1-11) \\
\text { NUMBERS SAME AS ABOVE }\end{array}$ & $\begin{array}{l}\text { 0. NO } \\
\text { 1. YES }\end{array}$ & $\begin{array}{l}\text { REIENTION RECOMMENDATION } \\
\text { RECEIVED BY }\end{array}$ \\
\hline $\begin{array}{l}\text { RDIS }(1-11) \\
\text { NUMBERS SAME AS ABOVE }\end{array}$ & $\begin{array}{l}\text { 0. NO } \\
\text { 1. YES }\end{array}$ & $\begin{array}{l}\text { RETETION RECOMMENDATION } \\
\text { DISCUSSED WITH }\end{array}$ \\
\hline $\begin{array}{l}\text { DATGAT }(1-11) \\
\text { RUMBERS SAME AS ABOVE }\end{array}$ & $\begin{array}{l}\text { O. NO } \\
\text { i. YES }\end{array}$ & SUPPORTING DATA GATHERED BY \\
\hline $\begin{array}{l}\text { RDISPAR }(1-11) \\
\text { NUMBERS SAME AS ABOVE }\end{array}$ & $\begin{array}{l}\text { 0. NO } \\
\text { 1. YES }\end{array}$ & $\begin{array}{l}\text { RETENTION RECOMMENDATIN } \\
\text { DISCUSSED WITH PARENT }\end{array}$ \\
\hline $\begin{array}{l}\text { DECMADE }(1-11) \\
\text { NUMBERS SAME AS ABOVE }\end{array}$ & $\begin{array}{l}\text { 0. NO } \\
\text { 1. YES }\end{array}$ & RETENTION DECISION MADE BY \\
\hline FORMCOH $(1-11)$ & $\begin{array}{l}\text { 0. NO } \\
\text { 1. YES }\end{array}$ & RETENTION FORM COMPLETED BY \\
\hline
\end{tabular}


RETENTION BELIEFS QUESTIONS

RB?

RB2

RB3

RB4

R85

RB6

RB7

RBB

RB9

RB10

RB11

RB12

RB13

RB14

RB15

RB16

RB17
1. STRONGLY DISAGREE

2. DISAGREE

0 . UHDECIDED

3. AGREE

4. STRONGLY AGREE

SAME AS ABOVE

SAME AS ABOVE

SAME AS AVOVE

SAME AS ABOVE

SAME AS ABOVE

SAME AS ABOVE

SAME AS ABOVE

SAME AS ABOVE

SAME AS ABOVE

SAME AS ABOVE

SAME AS ABOVE

SAME AS ABOVE

SAME AS ABOVE

SAME AS ABOVE

SAME AS ABOVE

SAME AS ABOBE
IS IT IMPORTANT TO HAVE A WRITTEN POLICY ON RETENTION

THE DECISION TO RECOMMEND RETENTIOH SHOULD BE MADE ONLY BY THE TEACHER

THE DECISION TO RECOMMEND RETEHTION SHOULO BE MADE ONLY BE THE PRINCIPAL

THE DECISION TO RECOMMEND RETENTIOH SHOULD BE MADE ONLY BE A BUILDING TEAM

THE PARENTS SHOULD BE INVOLVED IH THE DECISIOH TO RETAIN A CHILD

IT IS IMPORTANT FOR THE TEACHER TO INCLUDE OTHER SCHOOL PERSONHEL IN RETENTION DEC.MKG.

AHY DECISION TO RETAIN A CHILD SHOULD BE SUPPORTED BY ACHIEVEMENT DATA

BEFORE RECOMMENDING RETENTIOH THE TEACHER SHOULD DISCUSS THE RETENTION WITH THE BUILOING PRINCIPAL

BEFORE RECONMENDING RETENTION THE TEACHER SHOULD OISCUSS THE RETENTIOH WITH THE COUNSELOR/CHILD OEV. SPECIALIST IF AVAILABLE

BEFORE RECONMENDING RETEHTION THE TEACHER SHOULD DISCUSS THE RETENTION WITH $A$ BUILDING TEAM OF SCHOOL PERSONHEL

BEFORE RECOMMENDING RETENTION THE TEACHER SHOULD GATHER DATA ON ACHIEVEMENT

RETENTION IS EFFECTIVE IN HELPING CHILDREN BE SUCCESSFUL IH SCHOOL

CHILDREN SHOULO BE RETAINED IF THEY ARE BELOW GRADE LEVEL EXPECTATIONS

IF A CHILD IS STRUGGLING WITH ACADEMICS RETENTION IS USUALLY IH HIS OR HER BEST INTEREST

RETENTION IS BENEFICIAL IF A CHILD IS YOUNG ANO IMMATURE

RETENTION SHOULO ONLY BE DONE IN THE PRIMARY GRADES, $\mathrm{K}=3$

CHILDREN SHOULD NEVER BE RETAINED FOR AHY REASON 
RB18

RB19

RB20

RB21

RB22

RB23

RB24

RB25
SAME AS ABOVE

SAME AS ABOVE

SAME AS ABOVE

SAME AS ABOVE

SAME AS ABOVE

SAME AS ABOVE

SAME AS ABOVE

SAME AS ABOVE
COHSIDERATION FOR A CHILD'S SELF-ESTEEM SHOULD NOT PREVENT RETENTION

RETENTION INCREASES THE CHANCE $A$ CHILD WILL DROP OUT OF SCHOOL

RETENTION ALLONS A CHILD TIME TO GRON AND DEVELOP

It IS IMPORTANT TO HAVE Th: INPUT OF SPECIALIST SUCH AS THE COUNS.. SP.ED. TEACHER OR TEAM

LEADERS IN MAKING RETENTION DECISIONS

CHILOREN WHO ARE RETAINED GENERALLY DO BETTER ACADEMICALLY THE SECOHO YEAR

STUDENTS WHO FALL IN SPECIAL NEED CATEGORIES ARE SOMETIMES RETAINED INAPPROPRIATELY

SOCIAL PROMOTION IS IN THE BEST IHTEREST OF THE CHILD

KEEPING STUDENTS HITH THEIR PEER GROUP IS MORE IMPORTANT THAN CONCERN WITH LOW ACADEMIC SKILLS 
SECOND TO LAST QUESTION

REASONS(A-0)

$A=L A C K S$ BASIC SKILLS

g=EXCESSIVE ABSENCE

$C=0$ ISCIPLINE PROBLEMS

$D=$ SOCIALLY IMMATURE

E=LON LEARHING ABILITY

$F=$ SMALL FOR AGE

G=OHE OF THE YOUNGEST IN CLASS

$H=$ IMMATURE, ACTS YOUNG FOR AGE

I=DOING BELOW GRADE LEVEL HORK

$J=S H O R T$ ATTENTION SPAN

$K=F R E Q U E N T L Y$ NEEDS HELP

L=NON-EHGLISH.SPEAKIHG

$M=P O O R$ WORK HABITS

$N=P S Y C H O L O G I S T$ RECOMMEHDS

$O=L O W$ SELF-ESTEEM
0. DION'T PUT AT ALL

1. LEAST

2. MORE IMPORTANT

ON UP TO...

5. MOST IMPORTANT
FIVE MOST IMPORTANT REASONS FOR TEACHERS' DECISIOHS RECONHEND RETENTION

LAST OUESTION

REDUCE (A-L)

$A=$ REMEDIAL PROGRAMS

$B=H I G H E R$ AGE REQUIREMENTS FOR

SCHOOL ENTRY

$C=$ FULL DAY KIND.

$D=S C H O O L$ ENTRANCE SCREENING

$E=L O N E R$ CLASS SIZES

$q=$ SUMMER SCHOOL
$G=$ GREATER PARENT COOPERATION

$H=$ PRESCHOOL PROGRAMS

I =DEVELOPMENTALLY APPROPRIATE

PRACTICES

$J=U N G R A D E S$

$K=$ TUTORING/COUNSELING

L=TRANSITIONAL
0. OLDN'T PUT AT ALL

1. MOST TO....

7. LEAST SIGNIFICANT

\author{
HHICH OF THE FOLLONING HOULD \\ REDUCE THE USE OF \\ RETENTION....PRIORITIZE HITH (1) \\ AS THE LEAST AND (7) OR (8) AS \\ MOST SIGNIFICANT
}

